\title{
Riding the Wave of Crypto-Exuberance: The Potential Misusage of Corporate Blockchain Announcements
}

\author{
Erdinc Akyildirim ${ }^{a, b}$, Shaen Corbet ${ }^{c, d *}$, Douglas J. Cumming ${ }^{e}$, \\ Brian Lucey $^{f, g, h}$, Ahmet Sensoy ${ }^{i}$ \\ ${ }^{a}$ Department of Banking and Finance, University of Zurich, Zurich, Switzerland \\ ${ }^{b}$ Department of Mathematics, ETH, Zurich, Switzerland \\ ${ }^{c}$ DCU Business School, Dublin City University, Dublin 9, Ireland \\ ${ }^{d}$ School of Accounting, Finance and Economics, University of Waikato, New Zealand \\ ${ }^{e}$ FAU College of Business, Florida Atlantic University, Boca Raton, FL 33431, United States \\ ${ }^{f}$ Trinity Business School, Trinity College Dublin, Dublin 2, Ireland \\ ${ }^{g}$ University of Sydney Business School, University of Sydney, Sydney, New South Wales, Australia \\ ${ }^{h}$ Institute of Business Research, University of Economics Ho Chi Minh City, Vietnam \\ ${ }^{i}$ Bilkent University, Faculty of Business Administration, Ankara 06800, Turkey \\ *Corresponding Author: shaen.corbet@dcu.ie
}

\begin{abstract}
Cryptocurrencies have been broadly scrutinised in recent times for a host of concerning regulatory and cybercriminality issues. Although steps have been taken to promote regulatory sufficiency in the near future, we examine the avenues through which this extremely high-risk industry can derive potentially devastating contagion channels, influencing both unwilling and unsuspecting investors. We focus this research on the expressions of interest by publicly traded companies across the world to utilise cryptocurrency and blockchain projects. We find evidence that there exists a substantial stock price premium and sustained increase in volatility in the aftermath of blockchain announcements, with emphasis on highly-speculative motives such as coin creation and corporate name changes. Changes in price discovery and information flows are found to be largely determined from cryptocurrency-based pricing sources in the aftermath of speculative announcements. We discuss the inherent ethical and legal issues, considering as to whether such announcements are simply an attempt to artificially manipulate share prices and take part in the current phase of crypto-exuberance.
\end{abstract}

Keywords: Cryptocurrencies; Market Manipulation; ICO; Volatility; Price Discovery. 


\section{Introduction}

An asset price bubble is defined as 'a market phenomenon characterised by surges in asset prices to levels significantly above the fair value of that asset'. In the case of cryptocurrencies, such a situation is exceptionally difficult to identify due to the debate that surrounds what exactly constitutes the 'fair value' of them. Cheah and Fry (2015) were among the first to categorically state that the fundamental price of Bitcoin was zero, and that the market was prone to speculative bubbles. Corbet et al. (2018b) echoed this sentiment, identifying evidence of clear bubble behaviour, even after controlling for the information contained within the hashrate, block size and number of transactions for both Bitcoin and Ethereum. While much evidence points to the existence of a pricing bubble within the cryptocurrency market, opposition to such statement are entrenched in their defensive stance to what exactly constitutes the fundamental value of one particular coin? It is with certainty that whether in a bubble phase or not, cryptocurrencies have been at the centre of attention throughout financial markets in recent years. This has resulted in a substantial increase in not only the amount of media coverage, but also related academic research across a number of disciplines and geographic regions. ${ }^{1}$

One of the largest signals that there exists the presence of irrational exuberance in cryptocurrency markets is denoted within not only the number of Initial Coin Offerings (ICOs) in recent years, but indeed the source of these coin offerings. A substantial number of corporate entities have made announcements with regards to their intentions to enter the cryptocurrency sphere, for a host of differing reasons. This has raised alarm due to the inherent dangers associated with asymmetric information and moral hazard (Corbet et al., 2020b). Further, (Jain and Jain, 2019) generated a list of companies that changed their names to add the terms 'blockchain' or 'bitcoin' to their names, to find that those who used this strategy experience significant abnormal positive return that lasts for two months, suggesting that these firms changed took this decision in order to take advantage of the price hysteria surround Bitcoin. As with any new financial product, we must be aware of the potential for illicit and ethically-challenging decision-making as the boundaries of regulation are designed. The very creation of cryptocurrencies has somewhat challenged regulators. Cryptocurrencies have provided an exceptionally easy platform that can be used for cross-border trade and generally illicit activity. Companies and governments alike can utilise these products for 'questionable' practices. Two key concerns have been identified: 1) the use of cryptocurren-

\footnotetext{
${ }^{1}$ While only three cryptocurrency-related research papers were published in the period between 2011 and 2013, this number has increased dramatically to 135 and 467 publications throughout 2017 and 2018 respectively.
} 
cies by governments to circumvent internationally-binding sanctions and controls; and 2) the announcement of companies of their broad intentions to enter the cryptocurrency market, however, with little or no intention of following through on their commitments. Both of these situations necessitate broad consideration by regulators and policy-makers.

Our research focuses specifically on the role that corporate ICOs have played since the creation of cryptocurrencies. This is an exceptionally important question. While much research has identified that there exists a relative isolation of cryptocurrency markets from traditional financial markets (Corbet et al., 2018c), one must consider the side-effects of both the announcement and investment practices of well-known publicly traded companies within this new asset-market. This, of course, opens a direct avenue through with these exceptionally risky products can generate substantial volatility transmission effects. Further, we must consider the ethical and legal construction of such announcements. While it is of course completely legal to announce that a company is considering a venture into the area of cryptocurrencies, we must consider the side-effects of such association with what is largely considered a market containing a substantial pricing bubble due to a lack of credible fundamental value observation. Therefore, we must investigate the financial market effects of such announcements along with the ethical association of announcement and then subsequent non-delivery. This latter scenario very much indicates that such companies are attempting to benefit and profit from 'crypto-exuberance'.

As cryptocurrency markets continue to evolve, it is imperative that policy-makers and regulators continue to monitor the potential development of sophisticated manipulation and cybercriminality techniques that appear to have developed throughout the markets for cryptocurrencies. There have been a number of ethically-challenged issues that have arisen since the theoretical establishment of Bitcoin (Nakamoto, 2008). Regulatory bodies and policymakers alike have observed the growth of cryptocurrencies with a certain amount of scepticism based on the growing potential for illegality and malpractice through the use of cryptocurrencies. Some regulatory authorities, including the International Monetary Fund, have expressed their satisfaction with the product's development and the benefits that are contained within its continued growth, however, the Securities and Exchange Commission have backtracked on earlier positivity to warn of the potential market manipulation techniques such as spoofing (US Securities and Exchange Commission, Public Statement, Statement on Potentially Unlawful Online Platforms for Trading Digital Assets).

Further, cryptocurrencies have been under suspicion of facilitating pump-and-dump schemes that are found to operate when traders manipulate prices by purchasing assets in groups. One particular example of an infamous cryptocurrency pump-and-dump was based on the price of CloakCoin traded on the Binance exchange. While anticipated through the usage of 
messaging networks, the price proceeded to increase by over $50 \%$ to US $\$ 5.77$ before dropping substantially within two minutes to almost US $\$ 1$ with a total of 6,700 trades worth around US $\$ 1.7$ million. In the hour preceding the pump-and-dump, CloakCoin had zero volume traded. ${ }^{2}$

Another example of potential misusage of cryptocurrencies has been identified in Venezuela and the announcement of the Petro. While we focus on the use of ICOs from a corporate perspective, the Petro presents an example of the misuse of an ICO in a sovereign setting. In mid-December 2018, the Venezuelan economy is estimated by the IMF to have exceeded $1,000,000 \%$ price inflation combined with a premium of approximately $2,500 \%$ between its official currency, the bolivar, and a black-market exchange rate. Throughout 2018, the Venezuelan government established a number of routes through which they could reduce the burden of economic collapse. One of the proposed mechanisms for the struggling population was to switch from the bolivar to a new cryptocurrency called the Petro which is defined as a cryptocurrency that would be supported 'by oil assets and issued by the Venezuelan State as a spearhead for the development of an independent, transparent and open digital economy open to direct participation of citizens'. The base price of the Petro was denoted at one barrel of oil and the Venezuelan government stated that US $\$ 3.3$ billion was raised through the sale. However, a year after its announcement it has yet to present any physical evidence of commodity-support. Instead, it is simply backed by a government's guarantee that it is backed by oil. The very creation, advertisement and distribution of such a currency during a period of exceptional economic strife generated substantial concern about the credibility of this ground-breaking sovereign asset. White et al. (2020) identified that as a currency, Bitcoin as a representation of broad cryptocurrencies, fails as a unit of account despite its transactional value and diffuses like a technology-based product rather than like a currency. Moreover, one major concern identified in this new cryptocurrency's ability was to circumvent US sanctions that had been implemented on the Venezuelan economy and their ability to access international financing.

While considering such specific issues, it is also important to observe the broader suspi-

\footnotetext{
${ }^{2}$ In July 2018, the Wall Street Journal analysed trading data and online communications among traders between January and the end of July 2018 to identify 175 'pump and dump' schemes involving 121 different digital coins. It is estimated that these schemes resulted in approximately US $\$ 825$ million in trading activity and hundreds of losses by legitimate investors. The pump-groups are online chatrooms, similar to boiler rooms, where the Big Pump Signal was denoted as the largest of these with more than 74,000 followers on the messaging app Telegram. There was evidence of a large number of private pump groups, accessible only by invitation.
} 
cious trading activities and structural problems within the cryptocurrency markets. Griffins and Shams (2018) examined whether Tether influenced Bitcoin and other cryptocurrency prices to find that purchases with Tether were timed following market downturns and resulted in significant increases in the price of Bitcoin. Further, less than $1 \%$ of the hours in which Tether experienced significant transactions were found to be associated with $50 \%$ of the increase of Bitcoin prices and $64 \%$ of other top cryptocurrencies, drawing the damning conclusion that Tether was used to provide price support and manipulate cryptocurrency prices. Furthermore, Gandal et al. (2018) identified the impact of suspicious trading activity on the Mt.Gox Bitcoin exchange theft when approximately 600,000 Bitcoins were attained. The authors demonstrated that the suspicious trading likely caused the spike in price in late 2013 from $\$ 150$ to $\$ 1,000$, most likely driven by one single actor. These two significant pieces of research have fine-tuned the focus of regulators, policy-makers and academics alike, as the future growth of cryptocurrencies cannot be sustained at pace with such significant questions of abnormality remaining unanswered.

In our study, we contribute to research surrounding cryptocurrencies across multiple fronts. First, we find evidence that there exists a stock price premium based on the type of cryptocurrency announcement that companies have made. Secondly, there exists a substantial and sustained increase in share price volatility where announcements denoted as speculative, with emphasis on companies that have created cryptocurrencies or changed their name to incorporate blockchain terminology, exhibit substantially more pronounced share price growth and volatility. Third, we find evidence that there exist both significant and substantial changes in dynamic correlations between cryptocurrency markets and companies that have partaken in such speculative announcements. A fourth finding indicates that there exists a dramatic change in the determination of price discovery and information flow between cryptocurrency markets and the companies making these announcements. Finally, we have found evidence of a decoupling of companies with domestic peers in the aftermath of speculative blockchain and cryptocurrency announcements with evidence provided of increased levels of information flow from cryptocurrency markets. These results indicate the potential presence of a number of ethical and regulatory concerns with regards to the interactions of companies with blockchain and cryptocurrency development. The evolution of crypto-euphoria is confirmed in the changing dynamics of information flow and price discovery. Our results indicate that companies that have no interconnection with cryptocurrency markets begin to share informational correlations with these new high-risk products. These interconnections present channels through which contagion effects can influence both unwilling and unsuspecting investors.

Remainder of this paper is organised as follows. In Section 2, we provide a concise 
overview of the development of research relating to the valuation of cryptocurrencies and the speculative behaviour of their prices. Section 3 introduces the data and then offers a thorough description of the methodologies used to investigate our hypotheses relating to market manipulation. The results are described in Section 4. Further, in Section 5 we discuss the methodological limitations, the practical implications of our work and a number of directions for future research that we observed. Concluding remarks are offered in Section 6.

\section{Previous Literature and Hypotheses Development}

A thorough overview of research on cryptocurrency markets is provided by Corbet et al. (2019), who focus much attention on the broad number of regulatory issues inherent in the markets that had developed in such a short time period. Two particular arguments to date take precedent. First, is the approximate valuation of Bitcoin. Second, is the behaviour of pricing efficiency and dynamics, with particular emphasis on the speculative behaviour and potential presence of a bubble.

With respect to the first argument above, Cheah and Fry (2015) are among the first to state that the fundamental price of Bitcoin is zero. However, Dwyer (2015) finds that the use of cryptocurrency technologies and the limitation of the quantity produced can create an equilibrium in which a digital currency has a positive value. Later, Van Vliet (2018) investigates the role that Metcalfe's Law (which can provide insight into the longterm value of Bitcoin, but not short term price movements) played in the valuation of Bitcoin and argue that Bitcoin might have long-term positive value. Recently, Hayes (2019) finds that the marginal cost of production plays an important role in explaining Bitcoin prices, challenging the allegations that Bitcoin is essentially worthless. Yet, Fry and Cheah (2016) argue that the extent to which law enforcement and government measures can affect Bitcoin markets appears mixed, which naturally would impact the value of this asset. Whether these assets have an intrinsic value or not, they still provide opportunities in the market to create monetary value. For example, Makarov and Schoar (2020) investigate the cross-market arbitrage opportunities in the cryptocurrency world. They find that countries with higher Bitcoin premia over the US bitcoin price see widening arbitrage deviations when Bitcoin appreciates. All these studies above bring out an interesting discussion on the potential impacts of involving in blockchain and cryptocurrency related operations on companies' stock prices. If indeed cryptocurrencies have fundamental value, this might be reflected positively on a company's stock price once the company announces its interest in such business, yet the type of business would also be expected to have a significant effect. Therefore, our first research question is presented as the following: 
- $H_{1}$ : Does there exist a stock-price premium based on the type of cryptocurrency announcement that corporates have made?

Regarding the second argument, Chaim and Laurini (2018) find that cryptocurrencies have very high unconditional volatility, and are subject to sudden and massive price swings. Indeed, liquidity risks may generate these heavy-tails in Bitcoin and cryptocurrency markets in general (Fry, 2018). Other potential sources could be herding and speculation. For example, Bouri et al. (2019) examine herding behaviour in cryptocurrency markets, taking into account the fact that prices of such assets possess structural breaks and non-linearity. Their dynamic setup helps them reveal that herding tends to occur as uncertainty increases, which might create wild price swings. Bianchi and Dickerson (2019) investigate the information content within the trading volumes in cryptocurrency markets and find results that are consistent with the view that cryptocurrencies are based on 'speculation' defined by private information. Moreover, Corbet et al. (2018b); Holub and Johnson (2019); Guder et al. (2019) and Cretarola and Figà-Talamanca (2019) all investigate the bubble behaviour of cryptocurrencies, in particular Bitcoin, for different periods and clearly identify phases of bubble behaviour. These studies reveal that cryptocurrency prices are very volatile and display speculative patters. In case a company announces its interest in cryptocurrency related operations, it is a plausible assumption that its stock price might be effected in a similar manner since the future price of cryptocurrencies will be an input when evaluating company's value. Therefore, our second research question is the following:

- $H_{2}$ : Does there exist a substantial change in stock price volatility based on the type of cryptocurrency announcement that corporates have made?

Panagiotidis et al. (2018) and Panagiotidis et al. (2019) investigate the influence of factors such as stock market returns, exchange rates, gold and oil returns, the Fed's and ECB's rates and internet trends on Bitcoin returns for alternate time periods. Overall, authors find significant interaction between Bitcoin and traditional stock markets, however, weak interaction with foreign exchange markets and the macro-economy. Corbet et al. (2020a) classify digital assets into three categories and examine their reactions to US Federal Fund interest rate and quantitative easing announcements. Accordingly, authors find different reactions corresponding to different categories, indicating a diverse market within which, not all assets are comparable to Bitcoin. López-Cabarcos et al. (2019) show that during stable periods, S\&P 500 returns, VIX returns, and investor sentiment influence Bitcoin volatility. As evident from these studies, cryptocurrencies are already in interaction with some of the major asset classes. One thing that might be of question is, how far can this interaction go, 
in particular if a company announces that it is interested in cryptocurrencies and blockchain in general? Would it be possible to observe a significantly increased contemporaneous relationship between cryptocurrency prices and stock price of the company that makes such an announcement? From a different perspective, how would the relationship between this company's stock price and stock price of the companies that belong to the same peer group but who have not made such announcements? Is it possible that we observe a decoupling effect? These questions lead us to our third and fourth points to examine, namely,

- $H_{3}$ : Does there exist a substantial change in dynamic correlation between the target company and other peers and geographically similar companies in the periods after such cryptocurrency announcements?

- $H_{4}$ : Does there exist a substantial change in dynamic correlation between the target company and cryptocurrency (crypto indices) in the periods after such cryptocurrency announcements?

Arguably speculative nature of cryptocurrencies brings out the need for in detail volatility analysis of these assets. Shen et al. (2019) study the volatility of Bitcoin through a battery of heterogeneous autoregressive (HAR) models. They show that HAR models with structural breaks outperform models without structural breaks. Their findings reveal the importance of the temporal variation and squared jump components at different time horizons. Corbet et al. (2018a) investigate the introduction of futures trading in Bitcoin to show that spot volatility has increased following the appearance of futures contracts and that price discovery is driven by uninformed investors in the spot market. The authors argue that Bitcoin is a speculative asset rather than a currency. The study by Corbet et al. (2018a) touches an interesting point since it focuses on a subject rather different than the common studies. According to their study, price is formed first in the spot market then it determines the futures price. This is in contrast to those studies on several asset classes such as equities and foreign exchange markets. At this stage, an interesting argument would be that the prices of the companies that make cryptocurrency related announcements are now effected by the value of cryptocurrencies up to some extent. Naturally, the same argument might also be asserted in the reverse direction. In order to reveal whether this effect (if ever exists) is significant in any direction, we consider the following research question:

- $H_{5}$ : Does there exist a substantial change in information flows between the target company and cryptocurrency (crypto indices) in the periods after such cryptocurrency announcements? 
In addition to Bitcoin, various other cryptocurrencies are also prone to speculation due to the complex market structure. For example, Antonakakis et al. (2019) analyse the contagion patterns in cryptocurrency markets and show that these markets have been gradually becoming more complex, which might be attributed to the unique characteristics and possibilities inherent in the technology of each cryptocurrency. Regarding the arguments on speculative behaviour of cryptocurrency prices, the discussion indeed starts with the birth of cryptocurrencies them-self. According to Adhami et al. (2018), startups around the world raised more than $\$ 5.3$ bn through ICOs by the end of 2017 where the success of the offering depends on various reasons (Zhang et al., 2019; Fisch, 2019). However, in any case, it is for sure that abrupt price changes occur for many cryptocurrencies in this non-regulated structure right after the offering process. Perez et al. (2020) produced an empirical study of 537 young cryptocurrencies and ICOs carried out in 2018 to explore the role of digital social capital in ICO performance to find that website social capital is the strongest determinant of ICO performance followed by the social capital management. Domingo et al. (2020) found that while Bitcoin spot and Bitcoin futures returns exert a positive influence on ICO returns, the existence of a pre-sale period exerts a negative influence, and ICO category seems to be non-significant. Sentiment extracted from social networks positively influences ICO returns. While investigating ICOs, Felix and von Eije (2019) find that there exists an average level of underpricing of $123 \%$ for USA ICOs and $97 \%$ for the other countries examined. Due to these dramatic value fluctuations, some experts suggest that ICO processes have to be regarded from the perspective of securities laws (such as the EU's MiFID), rather than from the perspective of payments laws. In this respect, Hendrickson and Luther (2017) go as far as to suggest of banning Bitcoin. The authors state that a government of sufficient size can prevent an alternative currency from being issued and circulating without relying on punishments, where they can ban the cryptocurrency as long as it disseminates sufficiently severe punishments.

The continued evolution of cryptocurrencies and the underlying exchanges on which they are traded have generated tremendous urgency to develop our understanding of a product that has been identified as a potential enhancement and replacement for traditional cash as we know it. As our understanding of FinTech evolves (Goldstein et al., 2019) and the value of blockchain grows (Chen et al., 2019), stronger interactions between cryptocurrencies and other more traditional financial markets are inevitable. It is therefore, of the utmost importance to protect broader markets from any exposure to contagion effects contained within these new financial products, especially until we develop a thorough understanding of the interactions contained within. It is widely accepted that there are substantial ethical issues surrounding the use of cryptocurrencies (Edwards et al., 2019). One must widely 
consider as to why exactly a user of digital currency would explicitly want to mask their identity and develop a break in traceability. Regulatory bodies and policy-makers alike have observed the growth of cryptocurrencies with a certain amount of scepticism, based on this growing potential for illegality and malpractice. Foley et al. (2019) estimate that around $\$ 76$ billion of illegal activity per year involve Bitcoin (46\% of Bitcoin transactions). This is estimated to be in the same region of the U.S. and European markets for illegal drugs, and is identified as 'black e-commerce'.

Overall, our findings will help us uncover the following general question related to the relationship between cryptocurrencies and the companies that announce their interest in the cryptocurrency world:

- $H_{6}$ : Overall, do such companies present evidence of decoupling with peers and geographically similar companies, acting in a more similar manner to traditional cryptocurrency markets?

Based on the provision of evidence either supporting or refuting the above hypotheses, we aim to present overall arguments based on the potential misuse of cryptocurrencies by corporate entities with little or no particular involvement in the area. It is particularly important to clarify to what extent this particular mechanism has been used, while either supporting or eliminating the broad possibility that certain corporate entities are attempting to partake in a period of crypto-exuberance to artificially support share price. The very existence of such a relationship presents a very damaging avenue through which contagion risks from exceptionally volatile cryptocurrency markets can flow, therefore, directly influencing both unwilling and unsuspecting investors.

\section{Data and Methodology}

\subsection{Data}

We primarily develop a concise list of corporate announcement that specifically constitute a news release relating to cryptocurrency development. To complete such a task, we develop a number of strict rules in an attempt to standardise the process across major international financial markets. The first implemented rule is that the specified company must be a publicly traded company with an available stock ticker between the period January 1 , 2014 and April 10, 2019. While the sample period covers from 2014 to 2019, our company announcement period covers from May 2016 to December 2018 due to the fact that we need to perform pre-and post-announcement analysis (announcement data was not available prior to May 2016). Stock price data is taken from Thomson Reuters Eikon. The second news 
selection rule is based on the source of the data. We develop on a combined search of LexisNexis, Bloomberg and Thomson Reuters Eikon, search for the keywords ${ }^{3}$ under traditional corporate announcements. To obtain a viable observation, a single data observation must be present across the three search engines and the source was denoted as an international news agency, a mainstream domestic news agency or the company making the announcement itself. Forums, social media and bespoke news websites were omitted from the search. Finally, the selected observation is based solely on the confirmed news announcements being made on the same day across all of the selected sources. If a confirmed article or news release had a varying date of release, it was omitted due to this associated ambiguity. All observations found to be made on either a Saturday or Sunday (nine announcements in total) are denoted as active on the following Monday morning. The dataset incorporates 153 total announcements made across 23 countries during the selected time period. All times are adjusted to GMT, with the official end of day closing price treated as the listed observation for each comparable company when analysing associated contagion effects. Figure 1 presents a visual description of both the timing and geographical distribution of the selected announcements. We can clearly identify that the United States and Canada represent the countries where companies have most frequently announced their involvement in blockchain and cryptocurrency investment and development, while there is evidence of a substantial growth in company announcements throughout 2017 with a peak in December 2017. Such announcements appear to have fallen somewhat throughout 2018.

The data is further categorised into nine specific groupings based on the type of announcement that has been made. Table 1 lists these groups. While we are specifically interested in the companies that have announced their intention to create a bespoke cryptocurrency, accounting for forty-eight individual occurrences, there are a number of specific blockchain and cryptocurrency-related announcements that are central to developing a thorough analysis of the hypotheses investigated in this research. This scenario would be mostly identified as opportunistic for companies that in some of these cases, had no prior direct business involvement in digital-technological investment. Such cases include announcements by companies such as Kodak (KodakCoin, Jan 2018); Mitsubishi UFJ Financial Group (MUFG Coin, May 2018); Plant Ventures (STRYKZ Tokens, Jan 2018) and Atari (Atari Token, Feb 2018). With regards to investment in digital finance and blockchain technology, sixteen companies announced their intentions to directly invest in blockchain in an attempt to generate corporate

\footnotetext{
${ }^{3}$ The selected keywords used in this search include that of: "cryptocurrency", "digital currency", "blockchain", "distributed ledger", "cryptography", "cryptographic ledger", "digital ledger", "altcoin" and "cryptocurrency exchange".
} 
Figure 1: Frequency and geographic location of companies announcing blockchain and cryptocurrency development

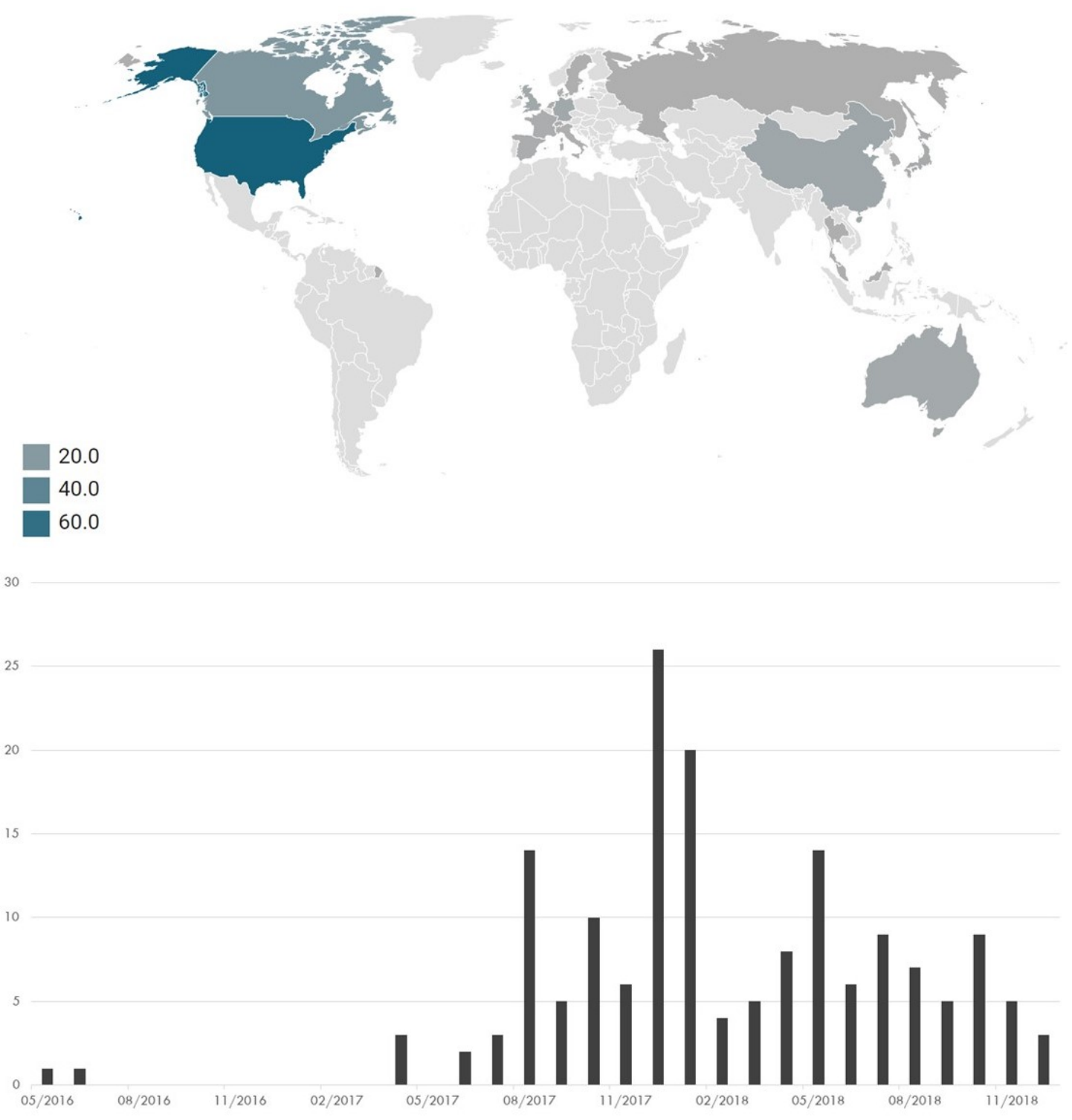

Note: Based on the 153 identified cryptocurrency announcements, we present above both the geographical distribution and the frequency of occurrence of companies denoted their intention to further their involvement in blockchain and cryptocurrency development. 
profits while twelve companies announced their intentions to create investment funds.

Most incredibly, five companies announced their intentions to change their name. Along with the creation of cryptocurrencies, this situation is of particular interest. These companies had little involvement in the sector and suddenly changed their name to develop association with the area of blockchain and digital finance. For example, Stapleton Capital plc, a UK-based telecommunication buyout firm changed their name to Blockchain Worldwide. Incredibly, a company formerly known as Long Island Iced Tea Corp in December 2017, changed its name to Long Blockchain Technology, resulting in a share price increase of almost 300\%. Other examples include Nodechain Inc, formerly known as Vapetek Inc and UBI Blockchain, formerly known as JA Energy whose stock was halted from trading and owners both receiving significant investigation and penalties from the SEC due to the trading of restricted shares. Five further publicly traded companies made announcements relating to forthcoming intentions to go into partnership with industry experts in the field of blockchain. Six companies announced that they were developing technology to specifically improve mining efficiency in an attempt to further profit from the creation of cryptocurrencies. Ten companies announced that they had invested in blockchain-related projects in an attempt to develop and strengthen internal technological security. These companies include Microsoft and their intention to develop the ID2020 Alliance, and companies such as Westpac who announced their intention to digitise the guarantee process. Finally, a total of fifty companies are identified to have directly announced their intentions to both invest and

incorporate blockchain, cryptocurrency and other forms of digital-financial technologies into their day-to-day operations. The broad variety of rationale provided for such investment is central to the following analysis provided. Reasons such as security and efficiency development would perhaps indicate decision-making by prudent, defensive-minded companies that are focused mostly on the structural improvements that such investment could provide.

The availability of such a strong dataset enables the specific investigation of a number of key areas. Overall, we focus on three specific methodologies that can be used to investigate six hypotheses that analyse differing dimensions of the changing dynamics of financial market behaviour after a corporate announcement of intention to invest in cryptocurrency technology.

\subsection{Methodology}

\subsubsection{Investigating the crypto-exuberance premium}

We begin our analysis with $H_{1}$ via a thorough investigation of the cumulative abnormal returns for each company and the average cumulative abnormal returns in the aftermath of an announcement relating to either blockchain or cryptocurrency. Abnormal returns 
Table 1: Announcement types

\begin{tabular}{clcc}
\hline Group & Announcement types & Count & Nature of Announcement \\
\hline 1 & Advertising Ban & 1 & Strategic \\
2 & Blockchain Investment & 16 & Speculative \\
3 & Blockchain Partnership & 5 & Speculative \\
4 & Coin Creation & 48 & Speculative \\
5 & Investment Fund & 12 & Speculative \\
6 & Mining Efficiency & 6 & Strategic \\
7 & Name Change & 5 & Speculative \\
8 & Security Improvements & 10 & Strategic \\
9 & Technological Improvement & 50 & Strategic \\
\hline \hline
\end{tabular}

Note: The above table presents the summary statistics based on the corporate announcements that specifically relate to stated plans for the use of blockchain and cryptocurrency announcements. These announcements are covered in a sample period from May 2016 to December 2018 (announcements prior to May 2016 are unavailable). To complete such a task, we develop a number of strict rules in an attempt to standardise the process across major international financial markets. The first implemented rule is that the specified company must be a publicly traded company with an available stock ticker between the period January 2014 and April 2019 (stock data covers a larger period than the announcement data since we need to perform pre- and post-announcement analysis). Stock price data is taken from Thomson Reuters Eikon. The second news selection rule is based on the source of the data. We develop on a combined search of LexisNexis, Bloomberg and Thomson Reuters Eikon, search for the keywords under traditional corporate announcements. To obtain a viable observation, a single data observation must be present across the three search engines and the source was denoted as an international news agency, a mainstream domestic news agency or the company making the announcement itself. Forums, social media and bespoke news websites were omitted from the search. Finally, the selected observation is based solely on the confirmed news announcements being made on the same day across all of the selected sources. If a confirmed article or news release had a varying date of release, it was omitted due to this associated ambiguity. All observations found to be made on either a Saturday or Sunday (nine announcements in total) are denoted as active on the following Monday morning. The dataset incorporates 153 total announcements made across 23 countries during the selected time period. All times are adjusted to GMT, with the official end of day closing price treated as the listed observation for each comparable company when analysing associated contagion effects. 
are calculated as the companies' returns less that of the exchange on which the company trades. We have subdivided such an analysis into two distinct groups. The first group is composed of those companies that have identified their use of blockchain and cryptocurrency for strategic reasons, or those announcements denoted as improving mining efficiency, or the use of blockchain for internal security and technological improvements. The second group is denoted as speculative, comprising companies that have identified their use of blockchain and cryptocurrencies for reasons relating to blockchain partnerships, coin creation, investment fund establishment, the change of the company's name or indeed the establishment of a significant blockchain investment pool.

We then extend this premium analysis to include not only the stock market effect but also the cryptocurrency markets' overall movements through a regression design with various dummy variable specifications for alternative post-announcement periods.

\subsubsection{The volatility effects of corporate cryptocurrency announcements}

Hypothesis $H_{2}$ specifically investigates as to whether there exists a substantial change in stock price volatility based on the type of cryptocurrency announcement that corporates have made? While a number of other recent works focus on the presence of dynamic relationships between traditional financial markets and cryptocurrencies (Corbet et al., 2018c), we set out to analyse as to whether the structure of associated volatility in the periods both before and after the designated announcement presents evidence of substantial change.

We start investigating $H_{2}$ first by statistically testing whether there is an increase in unconditional variance of the company stocks' daily returns (and the corresponding excess returns over the market they are traded in) after announcements for various time periods by utilising a common variance inequality test. We then dig deeper by building upon the GARCH family to understand the volatility dynamics of crypto-exuberance in the conditional variances. At this stage, a number of goodness-of-fit testing procedures identified the $\operatorname{EGARCH}(1,1)$ model as the best selected to identify specific volatility changes in the companies' returns, thus we exercise our analysis using this model. ${ }^{4}$ We express the variance

\footnotetext{
${ }^{4} \mathrm{EGARCH}$ exploits information contained in realised measures of volatility while providing a flexible leverage function that accounts for return-volatility dependence. While remaining in a GARCH-like modelling framework and estimation convenience, the model allows independent return and volatility shock and this dual shock nature leaves a room for the establishment of a variance risk premium. In our selection, other competitive models included EGARCH, TGARCH, Asymmetric Power ARCH (APARCH), Component GARCH (CGARCH) and the Asymmetric Component GARCH (ACGARCH). The optimal model is chosen according to three information criteria, namely the Akaike (AIC), Bayesian (BIC) and Hannan-Quinn (HQ).
} 
equation of our EGARCH model as follows:

$$
\ln \left(h_{t}^{2}\right)=\omega+\alpha \varepsilon_{t-1}+\gamma\left(\left|\varepsilon_{t-1}\right|-E\left(\left|\varepsilon_{t-1}\right|\right)\right)+\beta \ln \left(h_{t-1}^{2}\right)+D_{t}
$$

Here, we include an additional $D_{t}$ term in equation (1) in our analysis to provide a coefficient relating to the observed volatility in the subsequent days following each event for each of our investigated companies.

Before we proceed with the EGARCH analysis, we mitigate exogenous effects which can be completed through the inclusion of the returns of traditional financial products in the mean equation of the $\mathrm{EGARCH}(1,1)$ methodology as displayed in equation (2).

$$
R_{t}=a_{0}+b_{1} R_{t-1}+b_{2} \text { Dom.Ind } d_{t}+b_{3} \text { Cryp.Fund } d_{t}+\varepsilon_{t}
$$

The volatility sourced in shocks that are incorporated in the returns of traditional financial markets are therefore considered in the volatility estimation of the selected structure.

In equation (2), $R_{t-1}$ represents the lagged value of the observed company returns. Dom.Ind $d_{t}$ is the returns of the benchmark index where the stock is traded, and represents the interaction between the selected company returns and the corresponding domestic market

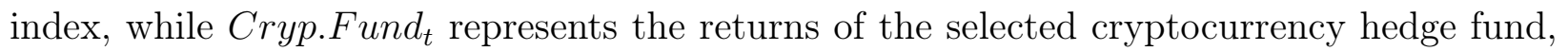
and is included in the mean equation to control for the cryptocurrency markets' aggregate movements. ${ }^{5}$

\subsubsection{Analysing contagion effects: DCC methodology}

The next stage consists of investigating $H_{3}$ and $H_{4}$. Our analysis develops on the channels through which cryptocurrency volatility could influence other more traditional financial markets, and indeed, potentially unwilling and unsuspecting traders of such financial product. However, we are also concerned with changes in such contagion pathways between corporate entities. Changing correlation dynamics could also indicate that the company is being treated differently by investors in the aftermath of involvement in blockchain or cryptocurrency. For example, we must specifically analyse as to whether investors, who perceive these

\footnotetext{
${ }^{5}$ The selected cryptocurrency hedge fund in the analysis is Pantera Capital which is the oldest and biggest crypto fund in the world, and mostly preferred by institutional investors and retail investors with very high net worth. The reason we select this fund index instead of various available cryptocurrency indices is because the latter is strictly dominated by the movements of Bitcoin due to its excessive market cap relative to other coins. However, in the case of the selected crypto hedge fund, the investment in Bitcoin is limited by a certain value, therefore it is a better representative of the whole coin market.
} 
new financial products to be exceptionally high-risk, also observe their corporate utilisation as a similar high-risk strategy.

To consider the contagion effects, we use the popular dynamic conditional correlation (DCC) model of Engle (2002). We first let $r_{t}=\left[r_{1, t}, \ldots, r_{n, t}\right]^{\prime}$ be the vector of financial time series returns and $\varepsilon_{t}=\left[\varepsilon_{1, t}, \ldots, \varepsilon_{n, t}\right]^{\prime}$ be the vector of return residuals obtained after some filtration. Let $h_{i, t}$ be the corresponding conditional volatilities obtained from a univariate EGARCH process.

Assume that $E_{t-1}\left[\varepsilon_{t}\right]=0$ and $E_{t-1}\left[\varepsilon_{t} \varepsilon_{t}^{\prime}\right]=H_{t}$, where $E_{t}[\cdot]$ is the conditional expectation on $\varepsilon_{t}, \varepsilon_{t-1}, \ldots$. The asset conditional covariance matrix $H_{t}$ can be written as

$$
H_{t}=D_{t}^{1 / 2} R_{t} D_{t}^{1 / 2}
$$

where $R_{t}=\left[\rho_{i j, t}\right]$ is the asset conditional correlation matrix and the diagonal matrix of the asset conditional variances is given by $D_{t}=\operatorname{diag}\left(h_{1, t}, \ldots, h_{n, t}\right)$. Engle (2002) models the right hand side of Eq.(3) rather than $H_{t}$ directly and proposes the dynamic correlation structure

$$
\begin{array}{r}
R_{t}=\left\{Q_{t}^{*}\right\}^{-1 / 2} Q_{t}\left\{Q_{t}^{*}\right\}^{-1 / 2}, \\
Q_{t}=(1-a-b) S+a u_{t-1} u_{t-1}^{\prime}+b Q_{t-1}
\end{array}
$$

where $Q_{t} \equiv\left[q_{i j, t}\right], u_{t}=\left[u_{1, t}, \ldots, u_{n, t}\right]^{\prime}$ and $u_{i, t}$ is the transformed residuals, that is, $u_{i, t}=$ $\varepsilon_{i, t} / h_{i, t}, S \equiv\left[s_{i j}\right]=E\left[u_{t} u_{t}^{\prime}\right]$ is the $n \times n$ unconditional covariance matrix of $u_{t}, Q_{t}^{*}=\operatorname{diag}\left\{Q_{t}\right\}$ and $a, b$ are non-negative scalars satisfying $a+b<1$. The parameters of the DCC model are estimated by using the quasi-maximum likelihood method with respect to the log-likelihood function, and according to the state two-step procedure.

\subsubsection{The information flows and price discovery following cryptocurrency-related announce-} ments

In the final stage of our analysis, after developing on arguments surrounding pricing premiums, changing volatility dynamics and behavioural differences in the contagion effects between the observed companies and cryptocurrency markets, we finally test $H_{5} \& H_{6}$, and analyse as to whether there has been a substantial change in both the information flow and structures underlying price discovery relationships between the announcement company and cryptocurrency markets. There are two standard measures of price discovery commonly employed in the literature: the Hasbrouck (1995) Information Share (IS) and the Gonzalo and Granger (1995) Component Share (CS) measure. Hasbrouck (1995) demonstrates that the contribution of a price series to price discovery (the 'information share') can be measured 
by the proportion of the variance in the common efficient price innovations that is explained by innovations in that price series. Gonzalo and Granger (1995) decompose a cointegrated price series into a permanent component and a temporary component using error correction coefficients. The permanent component is interpreted as the common efficient price, the temporary component reflects deviations from the efficient price caused by trading fractions. We estimate IS and CS, as developed by Hauptfleisch et al. (2016) using the error correction parameters and variance-covariance of the error terms from the Vector Error Correction Model (VECM):

$$
\begin{gathered}
\Delta_{p 1, t}=\alpha_{1}\left(p_{1, t-1}-p_{2, t-1}\right)+\sum_{i=1}^{200} \gamma_{i} \Delta p_{1, t-i}+\sum_{j=1}^{200} \delta_{j} \Delta p_{2, t-j}+\varepsilon_{1, t} \\
\Delta_{p 2, t}=\alpha_{2}\left(p_{1, t-1}-p_{2, t-1}\right)+\sum_{k=1}^{200} \varphi_{k} \Delta p_{1, t-k}+\sum_{m=1}^{200} \phi_{m} \Delta p_{2, t-m}+\varepsilon_{2, t}
\end{gathered}
$$

where $\Delta p_{i, t}$ is the change in the $\log$ price $\left(p_{i, t}\right)$ of the asset traded in market $i$ at time $t$. The next stage is to obtain the component shares from the normalised orthogonal coefficients to the vector of error correction, or:

$$
C S_{1}=\gamma_{1}=\frac{\alpha_{2}}{\alpha_{2}-\alpha_{1}} ; C S_{2}=\gamma_{2}=\frac{\alpha_{1}}{\alpha_{1}-\alpha_{2}}
$$

Given the covariance matrix of the reduced form VECM error terms ${ }^{6}$ where:

$$
M=\left(\begin{array}{cc}
m_{11} & 0 \\
m_{12} & m_{22}
\end{array}\right)=\left(\begin{array}{cc}
\sigma_{1} & 0 \\
\rho \sigma_{2} & \sigma_{2}\left(1-\rho^{2}\right)^{\frac{1}{2}}
\end{array}\right)
$$

we calculate the IS using:

$$
\begin{aligned}
I S_{1} & =\frac{\left(\gamma_{1} m_{11}+\gamma_{2} m_{12}\right)^{2}}{\left(\gamma_{1} m_{11}+\gamma_{2} m_{12}\right)^{2}+\left(\gamma_{2} m_{22}\right)^{2}} \\
I S_{2} & =\frac{\left(\gamma_{2} m_{22}\right)^{2}}{\left(\gamma_{1} m_{11}+\gamma_{2} m_{12}\right)^{2}+\left(\gamma_{2} m_{22}\right)^{2}}
\end{aligned}
$$

Recent studies show that IS and CS are sensitive to the relative level of noise in each market, they measure a combination of leadership in impounding new information and the relative level of noise in the price series from each market. The measures tend to overstate the price discovery contribution of the less noisy market. An appropriate combination of

$$
{ }^{6} \Omega=\left(\begin{array}{cc}
\sigma_{1}^{2} & \rho \sigma_{1} \sigma_{2} \\
\rho \sigma_{1} \sigma_{2} & \sigma_{2}^{2}
\end{array}\right) \text { and its Cholesky factorisation, } \Omega=M M^{\prime}
$$


IS and CS cancels out dependence on noise (Yan and Zivot, 2010; Putniňš, 2013). The combined measure is known as the Information Leadership Share (ILS) which is calculated as:

$$
I L S_{1}=\frac{\left|\frac{I S_{1}}{I S_{2}} \frac{C S_{2}}{C S_{1}}\right|}{\left|\frac{I S_{1}}{I S_{2}} \frac{C S_{2}}{C S_{1}}\right|+\left|\frac{I S_{2}}{I S_{1}} \frac{C S_{1}}{C S_{2}}\right|} \text { and } I L S_{2}=\frac{\left|\frac{I S_{2}}{I S_{1}} \frac{C S_{1}}{C S_{2}}\right|}{\left|\frac{I S_{1}}{I S_{2}} \frac{C S_{2}}{C S_{1}}\right|+\left|\frac{I S_{2}}{I S_{1}} \frac{C S_{1}}{C S_{2}}\right|}
$$

We estimate all three price discovery metrics, noting that they measure different aspects of price discovery.

\section{Results}

\subsection{Does there exist a crypto-exuberance premium?}

The separation of our observations into eight categories allows for the analysis of varying share price behaviour in the aftermath of the stated company announcements relating to blockchain and cryptocurrency development. We therefore investigate as to whether there exists a premium, or immediate and sustained elevation in share prices in the aftermath of the grouped announcements as set out in $H_{1}$. The first grouping represents announcements that are designated as an attempt to profit from crypto-exuberance, where companies exhibited no prior involvement with blockchain, cryptocurrency or indeed digital finance prior to the stated announcement. This group therefore contains the groupings for the announcement of blockchain partnerships, intentions to create a coin, announcements relating to the establishment of investment funds in cryptocurrency, intentions to invest directly in blockchain development, and indeed, changing the company name to establish a new company direction in the growing area. The results of this analysis are displayed in both Table 2 and Figure 2. While announcements relating to both blockchain partnership and the creation of cryptocurrency investment funds lead to initial gains in the day after related announcements $(2.37 \%$ and $3.22 \%$ respectively), both result in reduced abnormal returns twenty days thereafter $(-1.02 \%$ and $-3.89 \%$ respectively). Investments in blockchain result in a sharp increase of $12.92 \%$ in the day after such announcements, with momentum supporting and price growth remaining positive throughout the period resulting in a short-term, twenty-day premium of approximately $39 \%$.

The two most controversial and speculative announcement mechanisms involve that of the creation of coins, where the company has had no prior relationship with digital currencies, and indeed the changing of the name of the company altogether. With regards to coin creation, results show a premium of between $4-7 \%$ for the twenty-day period after such an 
Table 2: Share price behaviour in the aftermath of cryptocurrency announcements

\begin{tabular}{|c|c|c|c|c|c|c|}
\hline \multicolumn{7}{|c|}{ Mechanism to directly profit from crypto-exubeance } \\
\hline Type & & 1 day & 5 days & 10 days & 15 days & 20 days \\
\hline \multirow[t]{3}{*}{ Blockchain Partnership } & AAR & 2.37 & 4.38 & -0.48 & 1.45 & 0.26 \\
\hline & CAR & - & 0.90 & 0.15 & 2.56 & -1.02 \\
\hline & Largest Changes & Marat & Ion Patel & it Group ( & $9.41 \%)$ & \\
\hline \multirow[t]{3}{*}{ Coin Creation } & AAR & 3.17 & 2.39 & 1.43 & 2.84 & 2.03 \\
\hline & CAR & - & 4.08 & 6.03 & 7.83 & 7.16 \\
\hline & Largest Changes & Kodak & $(57.31 \%$ & & & \\
\hline \multirow[t]{3}{*}{ Investment Fund } & AAR & 3.22 & 0.55 & -1.40 & -1.88 & -3.07 \\
\hline & CAR & - & 2.87 & -0.28 & -0.46 & -3.89 \\
\hline & Largest Changes & Neptu & e Dash & $27.27 \%)$ & & \\
\hline \multirow[t]{3}{*}{ Name Change } & AAR & 60.28 & -4.86 & -0.52 & -1.15 & -1.97 \\
\hline & CAR & - & 88.18 & 80.96 & 77.49 & 82.13 \\
\hline & Largest Changes & On-lin & Blockch & ain $\mathrm{Plc}(17$ & $3.52)$ & \\
\hline \multirow[t]{3}{*}{ Blockchain Investment } & AAR & 12.92 & 2.30 & 1.99 & 0.63 & 1.01 \\
\hline & CAR & - & 9.93 & 27.85 & 42.10 & 39.29 \\
\hline & Largest Changes & Riot $\mathrm{B}$ & lockchain & $(18.10 \%)$ & & \\
\hline \multicolumn{7}{|c|}{ Mechanism to develop blockchain internally for corporate strategic reasons } \\
\hline Type & & 1 day & 5 days & 10 days & 15 days & 20 days \\
\hline \multirow[t]{3}{*}{ Mining Efficiency } & AAR & 1.64 & 0.02 & 0.17 & -0.24 & 0.12 \\
\hline & CAR & - & -2.32 & -0.71 & -3.96 & -2.44 \\
\hline & Largest Changes & Squire & $(11.25 \%)$ & & & \\
\hline \multirow[t]{3}{*}{ Security Improvements } & AAR & 0.53 & 0.48 & 0.59 & -0.15 & 0.51 \\
\hline & CAR & - & 1.05 & 2.00 & 0.34 & 0.12 \\
\hline & Largest Changes & Optun & $(1.87 \%)$ & & & \\
\hline \multirow[t]{3}{*}{ Technological Improvements } & AAR & 1.85 & -0.49 & -0.99 & 0.82 & 0.03 \\
\hline & CAR & - & 0.59 & -0.77 & -2.00 & -4.06 \\
\hline & Largest Changes & Blok 1 & echnolog & es $(8.25 \%)$ & & \\
\hline \multicolumn{7}{|l|}{ CAR Changes Comparison } \\
\hline & & 1 day & 5 days & 10 days & 15 days & 20 days \\
\hline \multirow{2}{*}{\multicolumn{2}{|c|}{$\begin{array}{l}\text { Speculative Announcement } \\
\text { Strategic Announcement }\end{array}$}} & 16.40 & 21.19 & 22.94 & 25.91 & 24.73 \\
\hline & & 1.34 & -0.22 & 0.17 & -1.87 & -2.13 \\
\hline
\end{tabular}

Note: AAR represents the Average Abnormal Return, while CAR represents cumulative abnormal return. The denoted largest change is within that of the sub-grouping on the first date after the stated announcement. All of the above results are found to be significant at the $1 \%$ level. 
announcement. One of the most extreme cases involved that of Kodak and their announcement of KodakCoin, which resulted in a one-day abnormal return of over $57 \%$, in a company who 'produces camera-related products' with its historic basis on photography. Changing the name of the company to incorporate terminology relating to blockchain, cryptocurrency and digital finance is found to result in a one-day premium in excess of $60 \%$. Evidence suggests that this mechanism is found to boost share prices in excess of $80 \%$ in the four week period after such an announcement, indicating that it is one of the most aggressive forms of behaviour relative to company positioning, supporting the work of Jain and Jain (2019). In one of the most discerning examples of such behaviour, 'On-line Plc', a company that traditional business practice was based upon investment in internet and information businesses, changed its name in October 2017 to 'On-line Blockchain Plc'. Since the company's original listing in 1996, the daily elevation in share price was at one point almost $400 \%$ following the news, further associated with sixteen times the previous year's trading volume on the day of the announcement. The company calls itself an 'incubator and investor in internet and information businesses' where the only distinctive change in business approach is the inclusion of the word 'blockchain' when compared to the day before the announcement. In a statement, the board announced that 'The Board of On-line PLC (AIM: ONL), notes the significant share price movement today'.

The second comparison group includes those companies that have made explicit blockchain and cryptocurrency announcements with the intention of taking a new internal strategy direction. This sub-group includes announcements relating to mining efficiency and both internal security and technological improvements through the use of blockchain. A number of contrasting results are clear. While there is evidence of some sharp increase in share price in the day of the announcements, such as that of Blok Technology (8.25\%) and Squire $(11.25 \%)$, there is much evidence to suggest that this premium diminishes very quickly, with cumulative abnormal returns returning to levels incorporating negligible differences within five days. In fact, twenty days after the stated announcements, the results show that announcements relating to both mining efficiency and technological improvements result in share price devaluation of $2.44 \%$ and $4.06 \%$ respectively. Contrasting these two scenarios in Table 2 presents strong evidence that there exists a strong positive and sustained premium for the consideration of blockchain and cryptocurrency announcements. Just one day after the event, announcements denoted as speculative are found to have resulted in a $16.40 \%$ increase in share price compared to a $1.34 \%$ increase for announcements denoted as strategic. Furthermore, speculative cumulative abnormal returns are found to result in a sustained share price premium of $24.73 \%$ after twenty days. Announcements denoted as strategic reverse to a cumulative abnormal reduction in share price within five days and lead to an 
Figure 2: Average cumulative abnormal returns in the period after an announcement relating to blockchain and cryptocurrencies
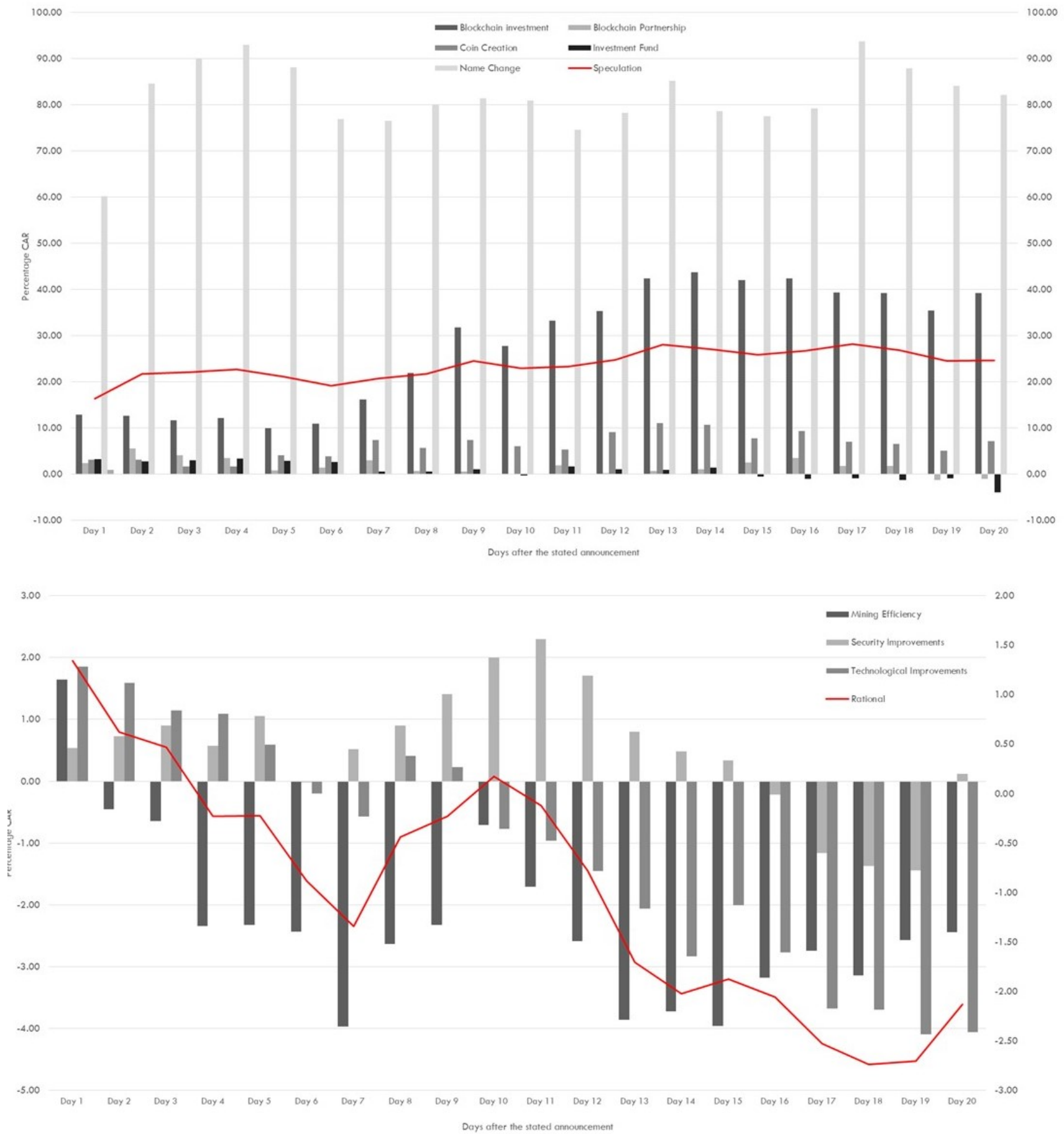

Note: The above figure represents the cumulative abnormal returns (CARs) for announcements denoted to be of a speculative nature and most likely to be an attempt to take advantage of crypto-exuberance. The lower figure represents the CARs of companies who have made blockchain and cryptocurrency announcements indicating their intentions to use the product for security improvements, internal technological improvements and the improved efficiency of the mining process. 
average fall of approximately $2 \%$ almost four weeks later.

The above mentioned AAR and CAR approaches account for the market returns however, in our analysis, we also would like to control for the aggregate cryptocurrency markets' behaviour as well. Accordingly, we estimate the following equation for each company.

$$
R_{t}=a_{0}+b_{1} R_{t-1}+b_{2} \text { Dom.Ind } d_{t}+b_{3} \text { Cryp.Fund } t+D_{t}+\varepsilon_{t}
$$

As explained earlier, in equation (12), $R_{t-1}$ represents the lagged value of the observed company returns. Dom.Ind $d_{t}$ is the returns of the benchmark index where the stock is traded

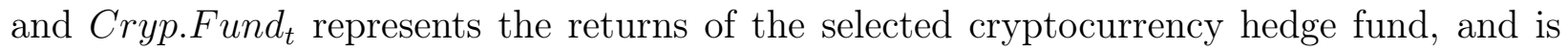
included in the mean equation to control for the cryptocurrency markets' overall movements. Finally, $D_{t}$ is a dummy term to provide a coefficient relating to the observed return changes in the subsequent days following each event for each of our investigated companies and it is the main variable of interest in this part of our analysis. We select various periods for the dummy variable, including 1-10-20-40-60-all days, after announcements to analyse the crypto-premium effect on stock returns. The results are provided in Tables 3 and 4 for the short ( 5 business days) and long-run (60 business days) respectively.

The results in Table 3 support the findings in Table 2, and shows that even after controlling for the aggregate cryptocurrency market, which is found to be significant in various cases, there are a considerable number of companies that experience a return premium 5 days after a crypto-related announcement. Analysis on the estimated dummy coefficients shows us that among the sample companies, the highest impacts were observed in UBI Blockchain, Longfin Corp, On-line Blockchain Plc, Nodechain Inc and Kodak. It is no surprising to see that the highest impacts belong to the announcement categories of name change, blockchain investment and coin creation; which are all with a speculative nature. However, according to Table 4, the same analysis over an extended period of 60 business days shows us that the premium tends to disappear for most of the companies in the long-run. The only companies that still experience a return premium related to the announcements are Riot Blockchain, Victory Square Technologies, Kodak, On-line Blockchain Plc and Pfizer. On the other hand, according to the dummy coefficients, the premiums have diminished and statistically weakened over this period. Furthermore, after 60 days, four out of the five companies with significant premium belong to the speculative announcement group.

Table 5 provides a summary of the number of companies experiencing a positive and significantly positive return premiums due to announcements for various periods in Panel A and Panel B respectively. In essence, we see that there are a considerable number of companies that benefit an abnormally increased share price in 1 to 20 days following announcements, even after controlling for the stock market and the whole cryptocurrency market. Yet, these 
Table 3: Significant positive impact of cryptocurrency and blockchain related announcements on stock return's premium in the short-run

\begin{tabular}{|c|c|c|c|c|c|}
\hline Company & const $a_{0}$ & $R_{t-1}$ & Dom.Ind $_{t}$ & Cryp.Fund $_{t}$ & $D_{t}^{5 d}$ \\
\hline \multicolumn{6}{|l|}{ Blockchain Investment } \\
\hline BTCS & $\begin{array}{l}-0.0027^{*} \\
(-1.8929)\end{array}$ & $\begin{array}{l}0.0277 \\
(1.0292)\end{array}$ & $\begin{array}{c}-0.2036 \\
(-0.359)\end{array}$ & $\begin{array}{l}0.9527^{* *} \\
(2.3034)\end{array}$ & $\begin{array}{l}0.0409^{*} \\
(1.713)\end{array}$ \\
\hline Longfin Corp & $\begin{array}{l}-0.0036 \\
(-0.8756)\end{array}$ & $\begin{array}{l}0.1541^{* * *} \\
(2.7766)\end{array}$ & $\begin{array}{l}0.1667 \\
(0.1244)\end{array}$ & $\begin{array}{l}-0.3794 \\
(-0.3713)\end{array}$ & $\begin{array}{l}0.1556^{* * *} \\
(4.3257)\end{array}$ \\
\hline Net Element & $\begin{array}{l}-0.0021^{*} \\
(-1.8898)\end{array}$ & $\begin{array}{l}-0.0689^{* *} \\
(-2.5704)\end{array}$ & $\begin{array}{l}0.1918 \\
(0.4453)\end{array}$ & $\begin{array}{l}1.0326^{* * *} \\
(3.2859)\end{array}$ & $\begin{array}{l}0.0954^{* * *} \\
(5.2148)\end{array}$ \\
\hline TD Ameritrade & $\begin{array}{l}-0.0001 \\
(-0.3429)\end{array}$ & $\begin{array}{l}0.0033 \\
(0.1559)\end{array}$ & $\begin{array}{l}0.9966^{* * *} \\
(16.4776)\end{array}$ & $\begin{array}{l}0.2953^{* * *} \\
(6.6676)\end{array}$ & $\begin{array}{l}0.0046^{*} \\
(1.8289)\end{array}$ \\
\hline Victory Square Technologies & $\begin{array}{l}-0.0012 \\
(-1.1028)\end{array}$ & $\begin{array}{l}-0.0893^{* *} \\
(-2.4987)\end{array}$ & $\begin{array}{l}0.8718 \\
(1.6428)\end{array}$ & $\begin{array}{l}0.4587 \\
(1.6464)\end{array}$ & $\begin{array}{l}0.0398^{* * *} \\
(3.0253)\end{array}$ \\
\hline Marathon Patent Group & $\begin{array}{l}-0.0015^{*} \\
(-1.741)\end{array}$ & $\begin{array}{l}-0.1157^{* * *} \\
(-4.3499)\end{array}$ & $\begin{array}{l}-0.3271 \\
(-0.9755)\end{array}$ & $\begin{array}{l}1.2745^{* * *} \\
(5.2049)\end{array}$ & $\begin{array}{l}0.0673^{* * *} \\
(4.7467)\end{array}$ \\
\hline \multicolumn{6}{|l|}{ Coin Creation } \\
\hline Blue Financial & $\begin{array}{l}-0.0004 \\
(-1.0326)\end{array}$ & $\begin{array}{l}0.0876^{* * *} \\
(2.592)\end{array}$ & $\begin{array}{l}0.1713^{* *} \\
(2.3321)\end{array}$ & $\begin{array}{l}0.1136 \\
(1.2655)\end{array}$ & $\begin{array}{l}0.0083^{*} \\
(1.6572)\end{array}$ \\
\hline Cannabis Science & $\begin{array}{l}-0.0004 \\
(-0.5321)\end{array}$ & $\begin{array}{l}0.0634^{* *} \\
(2.379)\end{array}$ & $\begin{array}{l}0.1943 \\
(0.6033)\end{array}$ & $\begin{array}{l}0.4176^{*} \\
(1.7767)\end{array}$ & $\begin{array}{l}0.0452^{\text {*** }} \\
(3.335)\end{array}$ \\
\hline Future Fintech Group & $\begin{array}{l}-0.0014^{*} \\
(-1.7742)\end{array}$ & $\begin{array}{l}-0.0849^{* * * *} \\
(-3.146)\end{array}$ & $\begin{array}{l}1.0563^{* * *} \\
(3.3099)\end{array}$ & $\begin{array}{l}-0.0866 \\
(-0.3714)\end{array}$ & $\begin{array}{l}0.0846^{* * *} \\
(6.1974)\end{array}$ \\
\hline Geopulse Explorations & $\begin{array}{l}0.0020 \\
(0.7342)\end{array}$ & $\begin{array}{l}-0.0635^{* *} \\
(-2.3487)\end{array}$ & $\begin{array}{l}-0.2862 \\
(-0.267)\end{array}$ & $\begin{array}{l}-1.5345^{* *} \\
(-1.962)\end{array}$ & $\begin{array}{l}0.0843^{*} \\
(1.8748)\end{array}$ \\
\hline Gozo Travel & $\begin{array}{l}0.0000 \\
(-0.1184)\end{array}$ & $\begin{array}{l}-0.0081 \\
(-0.3717)\end{array}$ & $\begin{array}{l}1.2284^{* * *} \\
(17.8157)\end{array}$ & $\begin{array}{l}0.1766^{* * *} \\
(3.5047)\end{array}$ & $\begin{array}{l}0.0072^{* *} \\
(2.5)\end{array}$ \\
\hline Home Meal Replacement & $\begin{array}{l}0.0000 \\
(-0.3335)\end{array}$ & $\begin{array}{l}0.0875^{* * *} \\
(2.9364)\end{array}$ & $\begin{array}{l}0.0113 \\
(0.5102)\end{array}$ & $\begin{array}{l}-0.038 \\
(-1.5939)\end{array}$ & $\begin{array}{l}0.0057^{* * *} \\
(3.7299)\end{array}$ \\
\hline Kodak & $\begin{array}{l}-0.0013 * * * \\
(-2.9124)\end{array}$ & $\begin{array}{l}0.0044 \\
(0.1685)\end{array}$ & $\begin{array}{l}0.7774^{* * *} \\
(4.281)\end{array}$ & $\begin{array}{l}0.598^{* * *} \\
(4.5149)\end{array}$ & $\begin{array}{l}0.0947 * * * \\
(11.8121)\end{array}$ \\
\hline Macau Capital & $\begin{array}{l}-0.0009 \\
(-0.7776)\end{array}$ & $\begin{array}{l}-0.3726^{* * *} \\
(-13.8399)\end{array}$ & $\begin{array}{l}-0.0726 \\
(-0.1684)\end{array}$ & $\begin{array}{l}0.6269^{* *} \\
(1.983)\end{array}$ & $\begin{array}{l}0.0443^{* *} \\
(2.5401)\end{array}$ \\
\hline \multicolumn{6}{|l|}{ Investment Fund } \\
\hline Berkshire Hathaway Inc. & $\begin{array}{l}0.0000 \\
(0.4383)\end{array}$ & $\begin{array}{l}-0.0044 \\
(-0.2581)\end{array}$ & $\begin{array}{l}1.0116^{* * *} \\
(35.05)\end{array}$ & $\begin{array}{c}-0.0512^{* *} \\
(-2.4253)\end{array}$ & $\begin{array}{l}0.004^{* * *} \\
(3.2782)\end{array}$ \\
\hline Plus500 & $\begin{array}{l}0.0002 \\
(0.4355)\end{array}$ & $\begin{array}{l}0.0942^{* * *} \\
(3.5143)\end{array}$ & $\begin{array}{l}0.438^{* * *} \\
(3.2137)\end{array}$ & $\begin{array}{l}0.0062 \\
(0.0575)\end{array}$ & $\begin{array}{l}0.0193^{* * *} \\
(2.6505)\end{array}$ \\
\hline \multicolumn{6}{|l|}{ Name Change } \\
\hline Blockchain Worldwide & $\begin{array}{l}-0.0013 \\
(-0.9035)\end{array}$ & $\begin{array}{l}-0.0281 \\
(-0.557)\end{array}$ & $\begin{array}{l}0.0779 \\
(0.1613)\end{array}$ & $\begin{array}{l}0.2018 \\
(0.67)\end{array}$ & $\begin{array}{l}0.0455^{* * *} \\
(3.5278)\end{array}$ \\
\hline Long Blockchain Technology & $\begin{array}{l}0.0004 \\
(0.3121)\end{array}$ & $\begin{array}{l}0.0836^{* * *} \\
(3.0689)\end{array}$ & $\begin{array}{l}0.4752 \\
(0.9208)\end{array}$ & $\begin{array}{l}-0.5634 \\
(-1.5017)\end{array}$ & $\begin{array}{l}0.0368^{*} \\
(1.7028)\end{array}$ \\
\hline Nodechain Inc & $\begin{array}{l}-0.0050 \\
(-1.6076)\end{array}$ & $\begin{array}{l}-0.0205 \\
(-0.4462)\end{array}$ & $\begin{array}{l}-0.5853 \\
(-0.5395)\end{array}$ & $\begin{array}{l}0.2715 \\
(0.3436)\end{array}$ & $\begin{array}{l}0.0993^{* * *} \\
(3.2663)\end{array}$ \\
\hline On-line Blockchain Plc & $\begin{array}{l}-0.0004 \\
(-0.604)\end{array}$ & $\begin{array}{l}-0.1307 * * * \\
(-4.8579)\end{array}$ & $\begin{array}{l}0.1015 \\
(0.5109)\end{array}$ & $\begin{array}{l}0.2116 \\
(1.3493)\end{array}$ & $\begin{array}{l}0.1227^{* * *} \\
(11.1152)\end{array}$ \\
\hline UBI Blockchain & $\begin{array}{l}-0.0023 \\
(-0.7904)\end{array}$ & $\begin{array}{l}-0.0137 \\
(-0.5061)\end{array}$ & $\begin{array}{l}-1.1112 \\
(-0.9602)\end{array}$ & $\begin{array}{l}0.1556 \\
(0.1843)\end{array}$ & $\begin{array}{l}0.2027^{* * *} \\
(4.1458)\end{array}$ \\
\hline \multicolumn{6}{|l|}{ Technological Improvement } \\
\hline BNP Paribas SA & $\begin{array}{l}-0.0002 \\
(-1.5808)\end{array}$ & $\begin{array}{l}0.046^{* * *} \\
(2.7615)\end{array}$ & $\begin{array}{l}1.2517^{* * *} \\
(40.4253)\end{array}$ & $\begin{array}{l}0.002 \\
(0.0636)\end{array}$ & $\begin{array}{l}0.0071^{* * *} \\
(3.4325)\end{array}$ \\
\hline NXT-ID & $\begin{array}{l}-0.0017^{*} \\
(-1.9552)\end{array}$ & $\begin{array}{l}-0.0192 \\
(-0.708)\end{array}$ & $\begin{array}{l}0.5166 \\
(1.5555)\end{array}$ & $\begin{array}{l}0.2274 \\
(0.9378)\end{array}$ & $\begin{array}{l}0.0875^{* * *} \\
(6.1403)\end{array}$ \\
\hline Pfizer & $\begin{array}{l}0.0000 \\
(-0.2193)\end{array}$ & $\begin{array}{l}0.0408^{*} \\
(1.8266)\end{array}$ & $\begin{array}{l}0.7716^{* * *} \\
(18.4105)\end{array}$ & $\begin{array}{l}0.0193 \\
(0.6315)\end{array}$ & $\begin{array}{l}0.0038^{* *} \\
(2.1626)\end{array}$ \\
\hline Social Reality Inc & $\begin{array}{l}-0.0007 \\
(-0.8797)\end{array}$ & $\begin{array}{l}-0.1882^{* * *} \\
(-7.1644)\end{array}$ & $\begin{array}{l}0.4495 \\
(1.4792)\end{array}$ & $\begin{array}{l}0.6969^{* * *} \\
(3.1443)\end{array}$ & $\begin{array}{l}0.0356^{* * *} \\
(2.785)\end{array}$ \\
\hline
\end{tabular}

Note: This table presents the estimation results of the equation $R_{t}=a_{0}+b_{1} R_{t-1}+b_{2}$ Dom.Ind $_{t}+b_{3}$ Cryp.Fund $d_{t}+D_{t}+\varepsilon_{t}$. $R_{t-1}$ represents the lagged value of the observed company returns. Dom.Ind $d_{t}$ is the returns of the benchmark index where

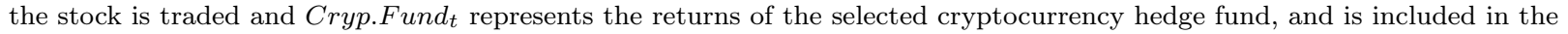
mean equation to control for the cryptocurrency markets' overall movements. $D_{t}$ is a dummy term to provide a coefficient relating to the observed return changes in the subsequent 5 days ( 1 week) following each event for each of our investigated companies. Only the results for the companies with a significant positive $D_{t}$ term is presented. The values in the parentheses are t-statistics. $* * *, * *$ and $*$ denote significant at the $1 \%, 5 \%$ and $10 \%$ level respectively. 
Table 4: Significant positive impact of cryptocurrency and blockchain related announcements on stock return's premium in the long-run

\begin{tabular}{llllll}
\hline Company & const $a_{0}$ & $R_{t-1}$ & Dom.Ind $_{t}$ & Cryp.Fund & $D_{t}^{\text {60d }}$ \\
\hline Blockchain Investment & & & & & \\
\hline Riot Blockchain & -0.0012 & -0.0416 & -0.2671 & $1.3456^{* * *}$ & $0.012^{* * *}$ \\
& $(-1.4364)$ & $(-1.5562)$ & $(-0.826)$ & $(5.6817)$ & $(2.9852)$ \\
Victory Square Technologies & -0.0015 & $-0.0832^{* *}$ & $0.9276^{*}$ & $0.4677^{*}$ & $0.0078^{* *}$ \\
& $(-1.3808)$ & $(-2.3262)$ & $(1.7422)$ & $(1.6731)$ & $(1.9762)$ \\
Coin Creation & & & & & \\
\hline Kodak & $-0.0012^{* *}$ & $0.0951^{* * *}$ & $0.8855^{* * *}$ & $0.533^{* * *}$ & $0.0051^{* *}$ \\
& $(-2.3329)$ & $(3.672)$ & $(4.6586)$ & $(3.8426)$ & $(2.1501)$ \\
\hline Name Change & & & & \\
\hline On-line Blockchain Plc & -0.0006 & $-0.0639^{* *}$ & 0.0858 & 0.2557 & $0.0151^{* * *}$ \\
& $(-0.9111)$ & $(-2.3649)$ & $(0.4165)$ & $(1.5741)$ & $(4.6407)$ \\
\hline Technological Improvement & & & & & \\
\hline Pfizer & -0.0001 & $0.0405^{*}$ & $0.7697^{* * *}$ & 0.0231 & $0.001^{* *}$ \\
& $(-0.5144)$ & $(1.8109)$ & $(18.3327)$ & $(0.7502)$ & $(2.0128)$ \\
\hline
\end{tabular}

Note: This table presents the estimation results of the equation $R_{t}=a_{0}+b_{1} R_{t-1}+b_{2}$ Dom.Ind $_{t}+b_{3}$ Cryp.Fund $d_{t}+D_{t}+\varepsilon_{t}$. $R_{t-1}$ represents the lagged value of the observed company returns. Dom.Ind $d_{t}$ is the returns of the benchmark index where

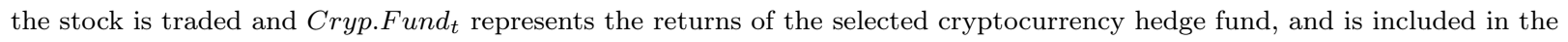
mean equation to control for the cryptocurrency markets' overall movements. $D_{t}$ is a dummy term to provide a coefficient relating to the observed return changes in the subsequent 60 days ( 1 quarter) following each event for each of our investigated companies. Only the results for the companies with a significant positive $D_{t}$ term is presented. The values in the parentheses are standard errors. $* * *, * *$ and $*$ denote significant at the $1 \%, 5 \%$ and $10 \%$ level respectively.

gains are not long lived and completely disappear once the investment horizon extends over 60 business days (a quarter). Such a situation suggests an artificial gain (even a hype-anddump type price behaviour) that would allow companies and their investors to ride the wave of crypto-exuberance, especially in the case of announcements with a speculative nature.

\subsection{Has crypto-exuberance influenced share price volatility dynamics?}

We next analyse $\mathrm{H}_{2}$ which focuses on structural changes in related stock price volatility and as to whether there is evidence of substantial differences based on the type of blockchain and cryptocurrency announcement that has been made.

We first start by applying an F-test to statistically conclude whether there has been a significant increase in unconditional variance of the daily log-returns after announcements. We use several time frames including 10-20-40-60-all days before and after announcements to see the changes in variance both in the short and long-run. Moreover, the control for the market effect, we proceed with the same analysis on not only the raw log-returns but also excess returns (where the daily corresponding market returns are subtracted from individual stock returns). The results are provided in Table 6 .

According to the Panel A (Panel B) of Table 6, around 60\% (33\%) of the announcing companies have experienced a (significant) rise in their stock returns' unconditional volatility after a month. This rise is mostly preserved even after a quarter following the announce- 
Table 5: Number of companies experiencing an increase in their stock returns' premium in the short and long-run after their announcements

\begin{tabular}{|c|c|c|c|c|c|c|c|}
\hline \multicolumn{8}{|c|}{ Panel A: Positive dummy coefficient } \\
\hline News type & $D^{1 d}$ & $D_{t}^{5 d}$ & $D_{t}^{10 d}$ & $D_{t}^{20 d}$ & $D_{t}^{40 d}$ & $D_{t}^{60 d}$ & $D_{t}^{\text {All }}$ \\
\hline Advertising Ban & $0(0)$ & $1(100)$ & $0(0)$ & $1(100)$ & $0(0)$ & $0(0)$ & $0(0)$ \\
\hline Blockchain Investment & $11(68.75)$ & $9(56.25)$ & $9(56.25)$ & $13(81.25)$ & $12(75)$ & $14(87.5)$ & $8(50)$ \\
\hline Blockchain Partnership & $4(80)$ & $4(80)$ & $4(80)$ & $4(80)$ & $5(100)$ & $3(60)$ & $1(20)$ \\
\hline Coin Creation & $26(54.17)$ & $24(50)$ & $29(60.42)$ & $25(52.08)$ & $25(52.08)$ & $19(39.58)$ & $14(29.17)$ \\
\hline Investment Fund & $9(75)$ & $9(75)$ & $8(66.67)$ & $6(50)$ & $7(58.33)$ & $8(66.67)$ & $3(25)$ \\
\hline Mining Efficiency & $0(0)$ & $0(0)$ & $0(0)$ & $0(0)$ & $2(33.33)$ & $1(16.67)$ & $1(16.67)$ \\
\hline Name Change & $5(100)$ & $5(100)$ & $5(100)$ & $5(100)$ & $3(60)$ & $3(60)$ & $1(20)$ \\
\hline Security Improvments & $6(60)$ & $5(50)$ & $8(80)$ & $7(70)$ & $6(60)$ & $6(60)$ & $2(20)$ \\
\hline Technological Improvement & $26(52)$ & $25(50)$ & $20(40)$ & $19(38)$ & $16(32)$ & $14(28)$ & $16(32)$ \\
\hline ALL & $87(56.86)$ & $82(53.59)$ & $83(54.25)$ & $80(52.29)$ & $76(49.67)$ & $68(44.44)$ & $46(30.07)$ \\
\hline \multicolumn{8}{|c|}{ Panel B: Significant positive dummy coefficient } \\
\hline News type & $D^{1 d}$ & $D_{t}^{5 d}$ & $D_{t}^{10 d}$ & $D_{t}^{20 d}$ & $D_{t}^{40 d}$ & $D_{t}^{60 d}$ & $D_{t}^{A l l}$ \\
\hline Advertising Ban & $0(0)$ & $0(0)$ & $0(0)$ & $0(0)$ & $0(0)$ & $0(0)$ & $0(0)$ \\
\hline Blockchain Investment & $3(18.75)$ & $5(31.25)$ & $4(25)$ & $5(31.25)$ & $5(31.25)$ & $2(12.5)$ & $0(0)$ \\
\hline Blockchain Partnership & $1(20)$ & $1(20)$ & $1(20)$ & $1(20)$ & $0(0)$ & $0(0)$ & $0(0)$ \\
\hline Coin Creation & $9(18.75)$ & $8(16.67)$ & $7(14.58)$ & $8(16.67)$ & $2(4.17)$ & $1(2.08)$ & $0(0)$ \\
\hline Investment Fund & $2(16.67)$ & $2(16.67)$ & $1(8.33)$ & $1(8.33)$ & $0(0)$ & $0(0)$ & $0(0)$ \\
\hline Mining Efficiency & $0(0)$ & $0(0)$ & $0(0)$ & $0(0)$ & $0(0)$ & $0(0)$ & $0(0)$ \\
\hline Name Change & $5(100)$ & $5(100)$ & $4(80)$ & $3(60)$ & $1(20)$ & $1(20)$ & $0(0)$ \\
\hline Security Improvments & $1(10)$ & $0(0)$ & $2(20)$ & $0(0)$ & $0(0)$ & $0(0)$ & $0(0)$ \\
\hline Technological Improvement & $2(4)$ & $4(8)$ & $4(8)$ & $3(6)$ & $1(2)$ & $1(2)$ & $0(0)$ \\
\hline ALL & $23(15.03)$ & $25(16.34)$ & $23(15.03)$ & $21(13.73)$ & $9(5.88)$ & $5(3.27)$ & $0(0)$ \\
\hline
\end{tabular}

Note: This table shows the number of companies that experience an increase in their stock returns' premium after their announcements. The column headers show the number of days that we calculate the return premium after the announcements. In the table, the values in the parentheses are the percentage of companies within the sub-groups experiencing an increase in their stock returns' premium. Panel A (Panel B) reports the number of companies that experience a (significantly) higher return premium in their stocks. 
Table 6: Number of companies experiencing an increase in their stock returns' unconditional volatility in the short and long-run after their announcements

\begin{tabular}{|c|c|c|c|c|c|}
\hline \multicolumn{6}{|c|}{ Panel A: Log-returns with higher variance } \\
\hline News type & {$[-10,+10]$} & {$[-20,+20]$} & {$[-40,+40]$} & {$[-60,+60]$} & $\begin{array}{l}\text { [all pre-, all } \\
\text { post-ann] }\end{array}$ \\
\hline Advertising Ban & $1(100)$ & $1(100)$ & $1(100)$ & $1(100)$ & $1(100)$ \\
\hline Blockchain Investment & $6(37.5)$ & $9(56.25)$ & $8(50)$ & $8(50)$ & $9(56.25)$ \\
\hline Blockchain Partnership & $3(60)$ & $2(40)$ & $3(60)$ & $3(60)$ & $3(60)$ \\
\hline Coin Creation & $35(72.92)$ & $31(64.58)$ & $23(47.92)$ & $20(41.67)$ & $20(41.67)$ \\
\hline Investment Fund & $8(66.67)$ & $7(58.33)$ & $7(58.33)$ & $8(66.67)$ & $8(66.67)$ \\
\hline Mining Efficiency & $3(50)$ & $2(33.33)$ & $3(50)$ & $3(50)$ & $3(50)$ \\
\hline Name Change & $5(100)$ & $5(100)$ & $5(100)$ & $5(100)$ & $4(80)$ \\
\hline Security Improvments & $6(60)$ & $6(60)$ & $1(10)$ & $3(30)$ & $6(60)$ \\
\hline Technological Improvement & $23(46)$ & $29(58)$ & $29(58)$ & $30(60)$ & $27(54)$ \\
\hline ALL & $90(58.82)$ & $92(60.13)$ & $80(52.29)$ & $81(52.94)$ & $81(52.94)$ \\
\hline \multicolumn{6}{|c|}{ Panel B: Log-returns with significantly higher variance } \\
\hline News type & {$[-10,+10]$} & {$[-20,+20]$} & {$[-40,+40]$} & {$[-60,+60]$} & $\begin{array}{l}\text { [all pre-, } \\
\text { post-ann] }\end{array}$ \\
\hline Advertising Ban & $1(100)$ & $1(100)$ & $1(100)$ & $1(100)$ & $1(100)$ \\
\hline Blockchain Investment & $5(31.25)$ & $6(37.5)$ & $5(31.25)$ & $5(31.25)$ & $5(31.25)$ \\
\hline Blockchain Partnership & $2(40)$ & $1(20)$ & $3(60)$ & $2(40)$ & $2(40)$ \\
\hline Coin Creation & $16(33.33)$ & $17(35.42)$ & $18(37.5)$ & $16(33.33)$ & $17(35.42)$ \\
\hline Investment Fund & $5(41.67)$ & $4(33.33)$ & $2(16.67)$ & $6(50)$ & $6(50)$ \\
\hline Mining Efficiency & $0(0)$ & $0(0)$ & $1(16.67)$ & $2(33.33)$ & $3(50)$ \\
\hline Name Change & $5(100)$ & $5(100)$ & $5(100)$ & $5(100)$ & $4(80)$ \\
\hline Security Impr & 0( & $1(10)$ & $0(0)$ & $0(0)$ & $5(50)$ \\
\hline Technological Improvement & $12(24)$ & $17(34)$ & $22(44)$ & $25(50)$ & $23(46)$ \\
\hline ALL & $46(30.07)$ & $52(33.99)$ & $57(37.25)$ & $62(40.52)$ & $66(43.14)$ \\
\hline \multicolumn{6}{|c|}{ Panel C: Excess returns with higher variance } \\
\hline News type & {$[-10,+10]$} & {$[-20,+20]$} & {$[-40,+40]$} & {$[-60,+60]$} & $\begin{array}{l}\text { [all pre-, } \\
\text { post-ann] }\end{array}$ \\
\hline Advertising Ban & $1(100)$ & $0(0)$ & $1(100)$ & $1(100)$ & $1(100)$ \\
\hline Blockchain Investment & $5(31.25)$ & $7(43.75)$ & $6(37.5)$ & $6(37.5)$ & $9(56.25)$ \\
\hline Blockchain Partnership & $3(60)$ & $2(40)$ & $3(60)$ & $3(60)$ & $3(60)$ \\
\hline Coin Creation & $34(70.83)$ & $33(68.75)$ & $22(45.83)$ & $21(43.75)$ & $19(39.58)$ \\
\hline Investment Fund & $8(66.67)$ & $8(66.67)$ & $6(50)$ & $8(66.67)$ & $8(66.67)$ \\
\hline Mining Efficiency & $3(50)$ & $2(33.33)$ & $2(33.33)$ & $3(50)$ & $2(33.33)$ \\
\hline Name Change & $5(100)$ & $5(100)$ & $5(100)$ & $5(100)$ & $4(80)$ \\
\hline 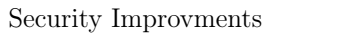 & & $6(60)$ & 5( & $2(20)$ & $4(40)$ \\
\hline Technological Improvement & $26(52)$ & $27(54)$ & $31(62)$ & $27(54)$ & $26(52)$ \\
\hline ALL & $89(58.17)$ & $90(58.82)$ & $81(52.94)$ & $76(49.67)$ & $76(49.67)$ \\
\hline \multicolumn{6}{|c|}{ Panel D: Excess returns with significantly higher variance } \\
\hline News type & {$[-10,+10]$} & {$[-20,+20]$} & {$[-40,+40]$} & {$[-60,+60]$} & $\begin{array}{l}\text { [all pre-, } \\
\text { post-ann] }\end{array}$ \\
\hline Advertising Ban & 0( & $0(0)$ & $1(100)$ & $1(100)$ & $1(100)$ \\
\hline Blockchain Inves & $3(18.7 \mathrm{~s}$ & $6(37.5)$ & $4(25)$ & $4(25)$ & $6(37.5)$ \\
\hline Blockchain Partnership & $2(40)$ & $2(40)$ & $3(60)$ & $3(60)$ & $3(60)$ \\
\hline Coin Creation & $16(33.33)$ & $19(39.58)$ & $16(33.33)$ & $15(31.25)$ & $17(35.42)$ \\
\hline Investment Fund & $5(41.67)$ & $3(25)$ & $1(8.33)$ & $3(25)$ & $7(58.33)$ \\
\hline Mining Efficiency & $0(0)$ & $0(0)$ & $1(16.67)$ & $2(33.33)$ & $2(33.33)$ \\
\hline Name Change & $5(100)$ & $5(100)$ & $5(100)$ & $5(100)$ & $4(80)$ \\
\hline Security Improvments & $4(40)$ & $3(30)$ & $2(20)$ & $1(10)$ & $1(10)$ \\
\hline Technological Improvement & $13(26)$ & $18(36)$ & $21(42)$ & $25(50)$ & $23(46)$ \\
\hline ALL & $48(31.37)$ & $56(36.6)$ & $54(35.29)$ & $59(38.56)$ & $64(41.83)$ \\
\hline
\end{tabular}

Note: This table shows the number of companies that experience a higher unconditional volatility in their stock prices after announcements. The column headers show the unconditional volatility calculation periods in days before and after the announcements. In the table, the values in the parentheses are the percentage of companies within the sub-groups experiencing an increase in their stock returns' unconditional variances. Panel A (Panel B) reports the number of companies that experience a (significantly) higher variance in their stocks' daily returns. Panel C (Panel D) reports the number of companies that experience a (significantly) higher variance in their stocks' daily excess returns over the corresponding market returns. 
ments. Indeed, in the case of a significant rise in unconditional volatility, the number of such companies even increases. Table 6 also shows that, in the case of increased unconditional variances, there is no strict distinction between the companies that make a strategic or speculative type of announcement; that is, cryptocurrency and blockchain related announcements tend to have a positive impact on the unconditional stock price volatilities of the majority of the announcing companies.

One might argue that the increase in the unconditional volatilities may not be due to the announcements but coming from a market effect. In order to deal with this, we also focus on the (significant) increases in the unconditional volatilites of the excess returns over the market and results are provided in Panel C (Panel D) of Table 6. In this case, results are almost indistinguishable from the previous analysis. Accordingly, 59\% (37\%) of the companies experience a (significant) increase in the unconditional volatility of their stocks' excess returns and this increase is preserved even after a quarter following the announcements. Overall, analysis suggests that cryptocurrency and blockchain related announcements create significant increases in the unconditional volatility of the announcement making companies' stock prices.

The analysis above focuses on the unconditional volatility, however, a deeper investigation is needed as this approach is not capable of eliminating the effects of volatility clustering which is common for many financial time series. Therefore, in the next step, we utilise the EGARCH model in equation (1) after filtering the returns by equation (2) as mentioned earlier. In order to account for the volatility changes after announcements, we use various dummy lengths in equation (1) in our analysis, including 1-10-20-40-60-all days, after announcements.

The extensive results of this analysis are presented in Tables 7 and 8 for the short (10 business days) and long (all days)-run after announcements respectively. In Table 7, we observe that even we control for the volatility clustering through EGARCH modelling, there are still 77 (29) companies with (significant) increase in their stock price volatility in the short term after their announcements. According to the dummy term in the volatility model, within these companies, largest significant increase in the conditional volatility is observed for Kodak, Longfin Corp, Long Blockchain Technology, Applied Advance Mobile Tech and Net Element which are companies that either change their names related to blockchain concepts, announce a coin creation or blockchain investment. For these three companies, the increase in conditional volatility is well ahead of other significant increases. In total, 23 (7) out of 48 coin creation cases, there is an (significant) increase in conditional volatility. While companies, such as Kodak for example, have provided evidence as to the type and purpose supporting the cryptocurrency that they would like to generate, almost all of these companies have failed to 
follow up on their announcements. However, in an important number of cases, the volatility that followed is both substantial and significant. In some cases, these companies through the announcement of new directions and aspirations appear to become more high-volatile and risky corporations, with pricing behaviour that is more similar to cryptocurrency markets than that of their own domestic stock market indices (which will be more evident in the next sub-sections). Such variation in behaviours and dynamics relationships presents substantial opportunity for both astute and more risk-loving investors. 
Table 7: Significant increases in conditional volatility in the short-run after cryptocurrency and blockchain related announcements

\begin{tabular}{|c|c|c|c|c|c|c|c|c|}
\hline Company & $a_{0}$ & Dom.Ind $_{t}$ & Cryp.Fund t $_{\text {. }}$ & $\omega$ & $\alpha$ & $\beta$ & $\gamma$ & $D_{t}$ \\
\hline \multicolumn{9}{|l|}{ Blockchain Investment } \\
\hline BTCS & $\begin{array}{c}-0.0021^{* * *} \\
(0.0007)\end{array}$ & $\begin{array}{c}-0.3820^{* * *} \\
(0.1188)\end{array}$ & $\begin{array}{c}0.7093^{* * *} \\
(0.1685)\end{array}$ & $\begin{array}{l}-0.2481 \\
(0.1834)\end{array}$ & $\begin{array}{l}-0.0188 \\
(0.0336)\end{array}$ & $\begin{array}{c}0.9545^{* * *} \\
(0.0300)\end{array}$ & $\begin{array}{c}0.2936^{* * *} \\
(0.0801)\end{array}$ & $\begin{array}{c}0.3379 * * * \\
(0.0897)\end{array}$ \\
\hline Longfin Corp & $\begin{array}{c}-0.0069^{* * *} \\
(0.0005)\end{array}$ & $\begin{array}{c}-0.7806^{* * *} \\
(0.0347)\end{array}$ & $\begin{array}{c}-1.1577^{* * *} \\
(0.0527)\end{array}$ & $\begin{array}{c}-10.0000^{* * *} \\
(0.5073)\end{array}$ & $\begin{array}{c}0.2083^{* * *} \\
(0.0509)\end{array}$ & $\begin{array}{c}-0.8256^{* * *} \\
(0.0520)\end{array}$ & $\begin{array}{c}0.3519 * * * \\
(0.0663)\end{array}$ & $\begin{array}{c}2.8997^{* * *} \\
(0.6416)\end{array}$ \\
\hline NetCents Technology Inc & $\begin{array}{c}-0.0016^{*} \\
(0.0008)\end{array}$ & $\begin{array}{c}0.1002 \\
(0.1327)\end{array}$ & $\begin{array}{c}0.6890^{* * *} \\
(0.2161)\end{array}$ & $\begin{array}{c}-0.5595^{* * *} \\
(0.0148)\end{array}$ & $\begin{array}{l}-0.0282 \\
(0.0419)\end{array}$ & $\begin{array}{c}0.9097^{* * *} \\
(0.0031)\end{array}$ & $\begin{array}{c}0.3392^{* * *} \\
(0.0857)\end{array}$ & $\begin{array}{c}0.5244^{* * *} \\
(0.1749)\end{array}$ \\
\hline Net Element & $\begin{array}{l}-0.0027 \\
(0.0083)\end{array}$ & $\begin{array}{c}0.9009 \\
(8.6693)\end{array}$ & $\begin{array}{c}0.3449 \\
(7.1671)\end{array}$ & $\begin{array}{l}-1.9591 \\
(1.6722)\end{array}$ & $\begin{array}{c}0.0597 \\
(0.2546)\end{array}$ & $\begin{array}{c}0.6997^{* * * *} \\
(0.2384)\end{array}$ & $\begin{array}{c}0.6906^{* * *} \\
(0.1641)\end{array}$ & $\begin{array}{c}2.2456^{* *} \\
(0.9799)\end{array}$ \\
\hline World Poker Fund Holdings & $\begin{array}{c}-0.0025^{* * *} \\
(0.0003)\end{array}$ & $\begin{array}{l}-0.2903 \\
(1.6198)\end{array}$ & $\begin{array}{c}0.6367 \\
(0.8068)\end{array}$ & $\begin{array}{c}-0.0322^{* * *} \\
(0.0003)\end{array}$ & $\begin{array}{c}-0.1211^{* * *} \\
(0.0252)\end{array}$ & $\begin{array}{c}0.9956^{* * *} \\
(0.0001)\end{array}$ & $\begin{array}{c}-0.0202^{* * *} \\
(0.0025)\end{array}$ & $\begin{array}{c}0.1089^{* * *} \\
(0.0367)\end{array}$ \\
\hline \multicolumn{9}{|l|}{ Coin Creation } \\
\hline Apply Advanced Mobile Tech & $\begin{array}{c}-0.0007^{* *} \\
(0.0003)\end{array}$ & $\begin{array}{c}0.7011^{* * *} \\
(0.2132)\end{array}$ & $\begin{array}{c}0.0123 \\
(0.0363)\end{array}$ & $\begin{array}{l}-2.7178 \\
(1.9291)\end{array}$ & $\begin{array}{l}0.1640^{*} \\
(0.0913)\end{array}$ & $\begin{array}{c}0.6620^{* *} \\
(0.2388)\end{array}$ & $\begin{array}{c}0.2132^{* *} \\
(0.0893)\end{array}$ & $\begin{array}{c}2.4353^{* * *} \\
(1.1235)\end{array}$ \\
\hline Arias Intel Corp & $\begin{array}{c}-0.0012^{* * *} \\
(0.0004)\end{array}$ & $\begin{array}{c}0.6986 \\
(0.6033)\end{array}$ & $\begin{array}{l}-1.3782 \\
(1.2772)\end{array}$ & $\begin{array}{c}-0.8200^{*} \\
(0.4133)\end{array}$ & $\begin{array}{c}0.0319 \\
(0.0549)\end{array}$ & $\begin{array}{c}0.8332^{* * *} \\
(0.0775)\end{array}$ & $\begin{array}{c}0.3917^{* * * *} \\
(0.0709)\end{array}$ & $\begin{array}{l}0.2888^{*} \\
(0.1629)\end{array}$ \\
\hline Bitcoin Group SE & $\begin{array}{l}-0.0004 \\
(0.0006)\end{array}$ & $\begin{array}{c}0.3871 \\
(0.2571)\end{array}$ & $\begin{array}{c}0.2032 \\
(0.1929)\end{array}$ & $\begin{array}{c}-0.8722^{* *} \\
(0.3222)\end{array}$ & $\begin{array}{c}0.0358 \\
(0.0572)\end{array}$ & $\begin{array}{c}0.8827^{* * * *} \\
(0.0409)\end{array}$ & $\begin{array}{c}0.4541^{* * *} \\
(0.0818)\end{array}$ & $\begin{array}{l}0.1949^{*} \\
(0.1003)\end{array}$ \\
\hline Cannabis Science & $\begin{array}{l}-0.0022 \\
(0.0149)\end{array}$ & $\begin{array}{c}0.2429 \\
(3.0345)\end{array}$ & $\begin{array}{c}0.2548 \\
(2.1341)\end{array}$ & $\begin{array}{c}-1.0908^{* * *} \\
(0.3416)\end{array}$ & $\begin{array}{l}-0.0013 \\
(0.4056)\end{array}$ & $\begin{array}{c}0.8465^{* * *} \\
(0.0560)\end{array}$ & $\begin{array}{c}0.6837 \\
(0.4615)\end{array}$ & $\begin{array}{c}0.6455^{* * *} \\
(0.1441)\end{array}$ \\
\hline Jay Mart & $\begin{array}{c}0.0000 \\
(0.0000)\end{array}$ & $\begin{array}{c}0.7903^{* * *} \\
(0.0747)\end{array}$ & $\begin{array}{c}0.0682^{* * *} \\
(0.0121)\end{array}$ & $\begin{array}{c}-1.5241^{* * *} \\
(0.4904)\end{array}$ & $\begin{array}{l}-0.0606 \\
(0.0455)\end{array}$ & $\begin{array}{c}0.8280^{* * *} \\
(0.0551)\end{array}$ & $\begin{array}{c}0.2996^{* * *} \\
(0.0734)\end{array}$ & $\begin{array}{c}0.1222^{* *} \\
(0.0529)\end{array}$ \\
\hline KinerjaPay & $\begin{array}{c}-0.0035^{* * *} \\
(0.0010)\end{array}$ & $\begin{array}{c}0.1457 \\
(0.1362)\end{array}$ & $\begin{array}{c}0.3301^{* *} \\
(0.1229)\end{array}$ & $\begin{array}{c}-2.5905^{* * *} \\
(0.8107)\end{array}$ & $\begin{array}{l}-0.0506 \\
(0.0796)\end{array}$ & $\begin{array}{c}0.5798^{* * *} \\
(0.1313)\end{array}$ & $\begin{array}{c}0.2848^{* * *} \\
(0.0835)\end{array}$ & $\begin{array}{c}1.1070^{* * *} \\
(0.2497)\end{array}$ \\
\hline Kodak & $\begin{array}{c}-0.0011^{* *} \\
(0.0004)\end{array}$ & $\begin{array}{c}0.7315 \\
(0.6490)\end{array}$ & $\begin{array}{l}0.6827^{*} \\
(0.3492)\end{array}$ & $\begin{array}{l}-5.1226 \\
(8.5842)\end{array}$ & $\begin{array}{l}-0.0562 \\
(0.1687)\end{array}$ & $\begin{array}{c}0.4008 \\
(1.0012)\end{array}$ & $\begin{array}{c}0.3058 \\
(0.2089)\end{array}$ & $\begin{array}{c}3.8497^{* *} \\
(1.7130)\end{array}$ \\
\hline \multicolumn{9}{|l|}{ Investment Fund } \\
\hline Berkshire Hathaway Inc. & $\begin{array}{c}0.0001^{* *} \\
(0.0000)\end{array}$ & $\begin{array}{c}0.9858^{* * *} \\
(0.0380)\end{array}$ & $\begin{array}{c}-0.0400^{* * *} \\
(0.0135)\end{array}$ & $\begin{array}{c}-0.3205^{* * *} \\
(0.0065)\end{array}$ & $\begin{array}{c}0.0229 * * * \\
(0.0070)\end{array}$ & $\begin{array}{c}0.9728^{* * *} \\
(0.0004)\end{array}$ & $\begin{array}{c}0.0770^{* * *} \\
(0.0259)\end{array}$ & $\begin{array}{l}0.1634^{*} \\
(0.0966)\end{array}$ \\
\hline CME Group & $\begin{array}{c}0.0001 \\
(0.0001)\end{array}$ & $\begin{array}{c}0.8146^{* * *} \\
(0.0535)\end{array}$ & $\begin{array}{l}-0.0360 \\
(0.0438)\end{array}$ & $\begin{array}{c}-10.0000^{* * *} \\
(1.9861)\end{array}$ & $\begin{array}{c}0.0071 \\
(0.0581)\end{array}$ & $\begin{array}{c}0.0797 \\
(0.1824)\end{array}$ & $\begin{array}{c}0.3608^{* * * *} \\
(0.0644)\end{array}$ & $\begin{array}{l}0.4250^{*} \\
(0.2406)\end{array}$ \\
\hline \multicolumn{9}{|l|}{ Name Change } \\
\hline Blockchain Worldwide & $\begin{array}{c}-0.0023^{* * *} \\
(0.0007)\end{array}$ & $\begin{array}{c}0.3078^{* *} \\
(0.1155)\end{array}$ & $\begin{array}{c}0.4007^{* * *} \\
(0.0231)\end{array}$ & $\begin{array}{c}-0.4771^{* * *} \\
(0.0691)\end{array}$ & $\begin{array}{c}-0.2117^{* *} \\
(0.0933)\end{array}$ & $\begin{array}{c}0.9439^{* * *} \\
(0.1943)\end{array}$ & $\begin{array}{c}-0.2303^{* * *} \\
(0.0705)\end{array}$ & $\begin{array}{c}0.1687^{* * *} \\
(0.0324)\end{array}$ \\
\hline Long Blockchain Technology & $\begin{array}{c}0.0011 \\
(0.0031)\end{array}$ & $\begin{array}{l}0.8305^{*} \\
(0.4261)\end{array}$ & $\begin{array}{c}-0.4647^{* *} \\
(0.2033)\end{array}$ & $\begin{array}{c}-10.0000^{* * *} \\
(1.1193)\end{array}$ & $\begin{array}{l}-0.0011 \\
(0.0605)\end{array}$ & $\begin{array}{c}-0.6324^{* * *} \\
(0.1309)\end{array}$ & $\begin{array}{c}0.1719^{* *} \\
(0.0642)\end{array}$ & $\begin{array}{c}3.0164^{* * *} \\
(0.6691)\end{array}$ \\
\hline \multicolumn{9}{|l|}{ Security Improvements } \\
\hline Accenture & $\begin{array}{c}0.0001 \\
(0.0001)\end{array}$ & $\begin{array}{c}0.9417^{* * *} \\
(0.0588)\end{array}$ & $\begin{array}{c}0.1135^{* *} \\
(0.0465)\end{array}$ & $\begin{array}{l}-2.0682 \\
(1.4755)\end{array}$ & $\begin{array}{c}0.0179 \\
(0.0642)\end{array}$ & $\begin{array}{c}0.8138^{* * *} \\
(0.1323)\end{array}$ & $\begin{array}{l}0.1911^{*} \\
(0.1047)\end{array}$ & $\begin{array}{c}0.2406^{* * *} \\
(0.0886)\end{array}$ \\
\hline Alphabet & $\begin{array}{l}0.0001^{*} \\
(0.0001)\end{array}$ & $\begin{array}{c}0.8243^{* * *} \\
(0.0454)\end{array}$ & $\begin{array}{c}0.2737^{* * *} \\
(0.0286)\end{array}$ & $\begin{array}{c}-2.7452^{* *} \\
(1.1539)\end{array}$ & $\begin{array}{c}0.0445 \\
(0.0796)\end{array}$ & $\begin{array}{c}0.7405^{* * *} \\
(0.1097)\end{array}$ & $\begin{array}{c}0.4916^{* * *} \\
(0.1730)\end{array}$ & $\begin{array}{c}0.4899^{* * *} \\
(0.1574)\end{array}$ \\
\hline Westpac & -0.0001 & $1.2289 * * *$ & -0.0004 & $-0.9687^{* * *}$ & -0.0549 & $0.9150^{* * *}$ & $0.2054^{* * *}$ & $0.1674^{* *}$ \\
\hline
\end{tabular}


Table 7: Significant increases in conditional volatility in the short-run after cryptocurrency and blockchain related announcements

\begin{tabular}{|c|c|c|c|c|c|c|c|c|}
\hline Company & $a_{0}$ & Dom.Ind $_{t}$ & Cryp.Fund f $_{\text {. }}$ & $\omega$ & $\alpha$ & $\beta$ & $\gamma$ & $D_{t}$ \\
\hline & $(0.0001)$ & $(0.0430)$ & $(0.0185)$ & $(0.2916)$ & $(0.0359)$ & $(0.0253)$ & $(0.0418)$ & $(0.0799)$ \\
\hline \multicolumn{9}{|c|}{ Technological Improvement } \\
\hline Bank of China & 0.0001 & $0.6353^{* * *}$ & -0.0431 & $-0.8570^{*}$ & $0.1712^{* *}$ & $0.9168^{* * *}$ & $0.4613^{* * *}$ & $0.2632^{*}$ \\
\hline \multirow{2}{*}{ BHP Billiton Limited } & $(0.0004)$ & $\begin{array}{c}(0.0354) \\
0.4780 * * *\end{array}$ & $\begin{array}{c}(0.0828) \\
0.4848 * * *\end{array}$ & $\begin{array}{c}(0.4571) \\
-0.0473 * * *\end{array}$ & $\begin{array}{c}(0.0744) \\
-0.0201\end{array}$ & $\begin{array}{c}(0.0436) \\
0.9949 * * *\end{array}$ & $\begin{array}{c}(0.0870) \\
0.0801 * * *\end{array}$ & $(0.1363)$ \\
\hline & $\begin{array}{l}-0.0001 \\
(0.0002)\end{array}$ & $(0.0897)$ & $(0.0535)$ & $(0.0024)$ & $(0.0127)$ & $(0.0001)$ & $(0.0056)$ & $(0.0368)$ \\
\hline \multirow[t]{2}{*}{ BLOK Technologies } & $-0.0022^{* * *}$ & $-0.3870^{* * *}$ & $0.3887^{* * *}$ & $-0.3026^{* * *}$ & -0.0746 & $0.9425^{* * *}$ & $0.2076^{* * *}$ & $0.3090^{* *}$ \\
\hline & $(0.0003)$ & $(0.0307)$ & $(0.0365)$ & $(0.0356)$ & $(0.0644)$ & $(0.0036)$ & $(0.0510)$ & $(0.1327)$ \\
\hline \multirow[t]{2}{*}{ BMW } & $-0.0002 * * *$ & $1.1134^{* * *}$ & -0.0062 & $-1.1682^{* * *}$ & -0.0153 & $0.8943^{* * *}$ & $0.1250^{* * *}$ & $0.2698 * * *$ \\
\hline & $(0.0001)$ & $(0.0314)$ & $(0.0297)$ & $(0.0601)$ & $(0.0294)$ & $(0.0052)$ & $(0.0365)$ & $(0.0885)$ \\
\hline \multirow[t]{2}{*}{ Fedex } & -0.0001 & $1.2494^{* * *}$ & 0.0155 & $-0.0244^{* * *}$ & -0.0310 & $0.997 * * * 8$ & $-0.0061^{* *}$ & $0.0636^{*}$ \\
\hline & $(0.0001)$ & $(0.0568)$ & $(0.0589)$ & $(0.0001)$ & $(0.0623)$ & $(0.0002)$ & $(0.0027)$ & $(0.0350)$ \\
\hline \multirow[t]{2}{*}{ Glance Technologies } & $-0.0025^{* * *}$ & -0.7993 & $1.0577^{* * *}$ & $-1.5389^{* * *}$ & 0.0432 & $0.7743^{* * *}$ & $0.5780 * * *$ & $0.3052^{* *}$ \\
\hline & $(0.0006)$ & $(0.5218)$ & $(0.1922)$ & $(0.5179)$ & $(0.0623)$ & $(0.0740)$ & $(0.0859)$ & $(0.1333)$ \\
\hline \multirow[t]{2}{*}{ IBM } & $-0.0002 * * *$ & $0.8839^{* * *}$ & $0.1228^{* * *}$ & $-8.6138^{* *}$ & 0.0320 & 0.2077 & $0.3944^{* *}$ & $0.6551^{*}$ \\
\hline & $(0.0001)$ & $(0.0524)$ & $(0.0223)$ & $(3.6382)$ & $(0.1542)$ & $(0.3354)$ & $(0.1847)$ & $(0.3437)$ \\
\hline \multirow[t]{2}{*}{ Kroger } & $0.0001 * * *$ & $0.8420 * * *$ & $-0.1743^{* * *}$ & $-1.4792^{* *}$ & -0.0109 & $0.8479 * * *$ & $0.3137 * * *$ & $0.4191^{* * *}$ \\
\hline & $(0.0000)$ & $(0.0369)$ & $(0.0240)$ & $(0.7164)$ & $(0.0615)$ & $(0.0725)$ & $(0.0910)$ & $(0.1446)$ \\
\hline \multirow[t]{2}{*}{ Pfizer } & 0.0000 & $0.7589^{* * *}$ & 0.0274 & -1.1731 & -0.0378 & $0.8938 * * *$ & $0.2744^{* *}$ & $0.2402^{* *}$ \\
\hline & $(0.0001)$ & $(0.0414)$ & $(0.0231)$ & $(1.5109)$ & $(0.0379)$ & $(0.1354)$ & $(0.1201)$ & $(0.1098)$ \\
\hline \multirow[t]{2}{*}{ Social Reality Inc } & $-0.0015^{* * *}$ & $0.5606^{* * *}$ & $0.5739 * * *$ & $-3.0736^{* * *}$ & 0.0327 & $0.5717 * * *$ & $0.4623^{* * *}$ & $1.4412^{* * *}$ \\
\hline & $(0.0002)$ & $(0.1094)$ & $(0.0655)$ & $(0.9515)$ & $(0.0578)$ & $(0.1297)$ & $(0.0821)$ & $(0.4245)$ \\
\hline
\end{tabular}

Note: This table presents the estimation results of the mean and conditional variance equations; that is, $R_{t}=a_{0}+b_{1} R_{t-1}+b_{2}$ Dom.Indt $+b_{3} C r y p$.Fund $d_{t}+\varepsilon_{t}$; and $\ln \left(h_{t}^{2}\right)=\omega+\alpha \varepsilon_{t-1}+\gamma\left(\left|\varepsilon_{t-1}\right|-E\left(\left|\varepsilon_{t-1}\right|\right)\right)+\beta \ln \left(h_{t-1}^{2}\right)+D_{t}$ respectively. $R_{t-1}$ represents the lagged value of the observed company returns. Dom.Ind is the returns of the benchmark index where the stock is traded and Cryp.Fund $d_{t}$ represents the returns of the selected cryptocurrency hedge fund, and is included in the mean equation to control for the cryptocurrency markets' overall movements. The term $h_{t}$ is the conditional volatility estimated by the EGARCH process and $D_{t}$ is a dummy term to provide a coefficient relating to the observed changes in the conditional volatility in the subsequent 10 days (2 weeks) following each event for each of our investigated companies. Only the results for the companies with a significant positive $D_{t}$ term is presented. The values in the parentheses are standard errors. ${ }^{* * *},{ }^{* *}$ and ${ }^{*}$ denote significant at the $1 \%, 5 \%$ and $10 \%$ level respectively. 
In the class of technology improvement announcements, 24 (10) out of 50 companies experience a (significant) increase in the stock prices' conditional volatility. Additionally, in five (three) of the ten cases relating to security improvements we observe similar (significant) volatility increases. Due to the widespread significant and scale of the interactions of the dummy variable $D_{t}$, it can be stated that the market appears to be responding quite substantially to these types of news. It would appear that even a statement relating to the use of this digital technology, without any further indication of what it is being used for, can be a substantial trigger-event for following financial market behaviour by investors. This could very much be observed as a behavioural observation most likely to be viewed during times of irrational exuberance, or frenzy-like behaviour. In the case of technology improvement announcements, companies with significant increases include industry giants such as BMW, Fedex, IBM and Pfizer. Similarly, security improvement announcements create significant increase in the volatility of blue-chip companies such as Accenture and Alphabet. This finding shows us that whether the announcing company is small or largely capitalised, a significant volatility increase due to announcements is still possible, thus investors of even these companies might be prone to idiosyncratic risks arising from involvement in cryptocurrency and blockchain related businesses.

Other noteworthy companies with significant increases in their stock price volatility include Berkshire Hathaway and the CME Group from the news categories of investment fund and Bank of China, a central bank with a strict government control, within the technology improvement group.

While the analysis above discusses the findings on announcements effects on the shortterm conditional volatilities, Table 8 provides evidence on the long-term (more than a quarter) effects and Table 9 displays a simple comparison between the two cases. 
Table 8: Significant increases in conditional volatility in the long-run after cryptocurrency and blockchain related announcements

\begin{tabular}{|c|c|c|c|c|c|c|c|c|}
\hline Company & $a_{0}$ & Dom.Ind $_{t}$ & Cryp.Fund $_{t}$ & $\omega$ & $\alpha$ & $\beta$ & $\gamma$ & $D_{t}$ \\
\hline \multicolumn{9}{|l|}{ Coin Creation } \\
\hline eXeBlock Tech & $\begin{array}{c}-0.0047^{* * *} \\
(0.0007)\end{array}$ & $\begin{array}{c}0.9909^{* * *} \\
(0.2337)\end{array}$ & $\begin{array}{c}-0.3650^{* *} \\
(0.1746)\end{array}$ & $\begin{array}{c}-0.6452^{* *} \\
(0.3026)\end{array}$ & $\begin{array}{c}0.0482 \\
(0.0740)\end{array}$ & $\begin{array}{c}0.9125^{* * *} \\
(0.0422)\end{array}$ & $\begin{array}{c}0.2356^{* * *} \\
(0.0640)\end{array}$ & $\begin{array}{c}0.1095^{* *} \\
(0.0652)\end{array}$ \\
\hline Jay Mart & $\begin{array}{c}0.0001 \\
(0.0003)\end{array}$ & $\begin{array}{c}0.7782^{* * *} \\
(0.0992)\end{array}$ & $\begin{array}{c}0.0599 \\
(0.0788)\end{array}$ & $\begin{array}{c}-2.0035^{* * *} \\
(0.4784)\end{array}$ & $\begin{array}{c}-0.0328 \\
(0.0386)\end{array}$ & $\begin{array}{c}0.7798^{* * *} \\
(0.0524)\end{array}$ & $\begin{array}{c}0.2698^{* * *} \\
(0.0644)\end{array}$ & $\begin{array}{c}0.1583^{* *} \\
(0.0770)\end{array}$ \\
\hline Macau Capital & $\begin{array}{c}0.0000 \\
(0.0000)\end{array}$ & $\begin{array}{c}0.0000 \\
(0.0000)\end{array}$ & $\begin{array}{c}0.0000 \\
(0.0000)\end{array}$ & $\begin{array}{c}-1.2499^{* * * *} \\
(0.1822)\end{array}$ & $\begin{array}{c}0.0927 \\
(0.2046)\end{array}$ & $\begin{array}{c}0.9663^{* * *} \\
(0.0041)\end{array}$ & $\begin{array}{c}0.0906 \\
(0.1921)\end{array}$ & $\begin{array}{c}1.0819 * * * \\
(0.3413)\end{array}$ \\
\hline Y Ventures Group & $\begin{array}{c}0.0009^{* * *} \\
(0.0002)\end{array}$ & $\begin{array}{c}0.0482^{* * *} \\
(0.0123)\end{array}$ & $\begin{array}{l}-0.1204 \\
(0.0840)\end{array}$ & $\begin{array}{c}-0.3816^{* * *} \\
(0.0170)\end{array}$ & $\begin{array}{c}0.0150 \\
(0.0102)\end{array}$ & $\begin{array}{c}0.9518^{* * *} \\
(0.0002)\end{array}$ & $\begin{array}{c}0.1282^{* *} \\
(0.0606)\end{array}$ & $\begin{array}{c}0.1116^{* * *} \\
(0.0278)\end{array}$ \\
\hline Name Change & & & & & & & & \\
\hline Blockchain W. & $\begin{array}{l}-0.0001 \\
(0.0001)\end{array}$ & $\begin{array}{c}0.1322 \\
(0.2046)\end{array}$ & $\begin{array}{l}-0.3093 \\
(0.1874)\end{array}$ & $\begin{array}{c}-10.0000^{* *} \\
(3.7680)\end{array}$ & $\begin{array}{c}0.0132 \\
(0.1507)\end{array}$ & $\begin{array}{c}0.0331 \\
(0.3545)\end{array}$ & $\begin{array}{c}0.1714 \\
(0.1924)\end{array}$ & $\begin{array}{c}3.4425^{* *} \\
(1.4171)\end{array}$ \\
\hline Nodechain Inc & $\begin{array}{c}0.0000 \\
(0.0000)\end{array}$ & $\begin{array}{c}0.0000^{* *} \\
(0.0000)\end{array}$ & $\begin{array}{c}0.0000 \\
(0.0000)\end{array}$ & $\begin{array}{c}-3.9880^{* * *} \\
(0.0305)\end{array}$ & $\begin{array}{c}0.0795^{* * *} \\
(0.0001)\end{array}$ & $\begin{array}{c}0.8830^{* * *} \\
(0.0017)\end{array}$ & $\begin{array}{c}-0.0795^{* * *} \\
(0.0001)\end{array}$ & $\begin{array}{c}3.4015^{* * *} \\
(0.0708)\end{array}$ \\
\hline On-line Blockchain Plc & $\begin{array}{c}-0.0001^{* * *} \\
(0.0000)\end{array}$ & $\begin{array}{c}0.0040^{* * *} \\
(0.0009)\end{array}$ & $\begin{array}{c}0.0177^{* * *} \\
(0.0018)\end{array}$ & $\begin{array}{c}-3.0071^{* *} \\
(1.1067)\end{array}$ & $\begin{array}{l}-0.0177 \\
(0.1460)\end{array}$ & $\begin{array}{c}0.6428^{* * *} \\
(0.1071)\end{array}$ & $\begin{array}{c}0.9268^{* * *} \\
(0.1569)\end{array}$ & $\begin{array}{l}0.8798^{*} \\
(0.4435)\end{array}$ \\
\hline Investment Fund & & & & & & & & \\
\hline HIVE Blockchain Investment Fund & $\begin{array}{c}0.0015^{* * *} \\
(0.0002)\end{array}$ & $\begin{array}{c}1.4309^{* * *} \\
(0.1917)\end{array}$ & $\begin{array}{c}0.6610^{* * *} \\
(0.1068)\end{array}$ & $\begin{array}{c}-0.4525^{* * *} \\
(0.0821)\end{array}$ & $\begin{array}{c}0.1262^{* * *} \\
(0.0133)\end{array}$ & $\begin{array}{c}0.9477^{* * *} \\
(0.2982)\end{array}$ & $\begin{array}{c}-0.1526^{* * *} \\
(0.0170)\end{array}$ & $\begin{array}{c}0.0984^{* * * *} \\
(0.0101)\end{array}$ \\
\hline Blockchain Investment & & & & & & & & \\
\hline Riot Blockchain & $\begin{array}{c}-0.0004^{* *} \\
(0.0002)\end{array}$ & $\begin{array}{c}1.6708^{* *} \\
(0.6781)\end{array}$ & $\begin{array}{c}0.2957 \\
(0.2231)\end{array}$ & $\begin{array}{c}-2.1586^{* * *} \\
(0.4602)\end{array}$ & $\begin{array}{c}0.4264^{* * *} \\
(0.1422)\end{array}$ & $\begin{array}{c}0.7072^{* * *} \\
(0.0582)\end{array}$ & $\begin{array}{c}0.5734^{* *} \\
(0.2150)\end{array}$ & $\begin{array}{c}0.4128^{* * *} \\
(0.1007)\end{array}$ \\
\hline Technological Improvement & & & & & & & & \\
\hline Atlas Cloud E. & $\begin{array}{c}-0.0010^{* * *} \\
(0.0000)\end{array}$ & $\begin{array}{c}0.2483^{*} \\
(0.1407)\end{array}$ & $\begin{array}{c}1.3847^{* * *} \\
(0.3004)\end{array}$ & $\begin{array}{c}-0.1549^{* * *} \\
(0.0021)\end{array}$ & $\begin{array}{c}0.0853 \\
(0.0597)\end{array}$ & $\begin{array}{c}0.9841^{* * *} \\
(0.2700)\end{array}$ & $\begin{array}{c}-0.0890^{* * *} \\
(0.0089)\end{array}$ & $\begin{array}{c}0.0513^{* * *} \\
(0.0138)\end{array}$ \\
\hline BBVA & $\begin{array}{c}0.0000 \\
(0.0001)\end{array}$ & $\begin{array}{c}1.2947 * * * \\
(0.0378)\end{array}$ & $\begin{array}{c}-0.0520^{*} \\
(0.0280)\end{array}$ & $\begin{array}{c}-0.2305^{* * *} \\
(0.0625)\end{array}$ & $\begin{array}{c}0.0063 \\
(0.0376)\end{array}$ & $\begin{array}{c}0.9792^{* * *} \\
(0.0051)\end{array}$ & $\begin{array}{c}0.1427^{*} \\
(0.0823)\end{array}$ & $\begin{array}{l}0.0192^{*} \\
(0.0097)\end{array}$ \\
\hline Comcast Corp & $\begin{array}{c}0.0001^{* *} \\
(0.0000)\end{array}$ & $\begin{array}{c}0.9118^{* * *} \\
(0.0250)\end{array}$ & $\begin{array}{c}-0.0168^{* * * *} \\
(0.0034)\end{array}$ & $\begin{array}{c}-0.5550^{* * * *} \\
(0.0203)\end{array}$ & $\begin{array}{c}0.0054 \\
(0.0274)\end{array}$ & $\begin{array}{c}0.9486^{* * *} \\
(0.0017)\end{array}$ & $\begin{array}{c}0.1354^{* * *} \\
(0.0097)\end{array}$ & $\begin{array}{c}0.0440^{* * * *} \\
(0.0155)\end{array}$ \\
\hline MGT Capital Investments Inc & $\begin{array}{c}-0.0019^{* *} \\
(0.0007)\end{array}$ & $\begin{array}{l}-0.1924 \\
(0.2473)\end{array}$ & $\begin{array}{c}0.8871^{* * * *} \\
(0.1811)\end{array}$ & $\begin{array}{c}-0.8032^{* *} \\
(0.3460)\end{array}$ & $\begin{array}{c}0.1011^{* * *} \\
(0.0339)\end{array}$ & $\begin{array}{c}0.8764^{* * *} \\
(0.0511)\end{array}$ & $\begin{array}{c}0.2523^{* * *} \\
(0.0575)\end{array}$ & $\begin{array}{c}0.1412^{* *} \\
(0.0697)\end{array}$ \\
\hline UPS & $\begin{array}{c}0.0000 \\
(0.0001)\end{array}$ & $\begin{array}{c}0.9431^{* * *} \\
(0.0636)\end{array}$ & $\begin{array}{l}-0.0168 \\
(0.0142)\end{array}$ & $\begin{array}{c}-4.8227^{* *} \\
(2.3389)\end{array}$ & $\begin{array}{c}0.2167 \\
(0.1673)\end{array}$ & $\begin{array}{c}0.5843^{* * *} \\
(0.2010)\end{array}$ & $\begin{array}{l}0.4362^{*} \\
(0.2254)\end{array}$ & $\begin{array}{l}0.5106^{*} \\
(0.2827)\end{array}$ \\
\hline Wells Fargo \& Company & $\begin{array}{c}-0.0001 * \\
(0.0001)\end{array}$ & $\begin{array}{c}1.0236^{* * *} \\
(0.0539)\end{array}$ & $\begin{array}{c}0.0747^{* * *} \\
(0.0255)\end{array}$ & $\begin{array}{c}-1.0276^{* * *} \\
(0.0823)\end{array}$ & $\begin{array}{c}0.0150 \\
(0.0319)\end{array}$ & $\begin{array}{c}0.9077^{* * *} \\
(0.0071)\end{array}$ & $\begin{array}{c}0.1754^{* * *} \\
(0.0532)\end{array}$ & $\begin{array}{c}0.0638^{* * * *} \\
(0.0221)\end{array}$ \\
\hline
\end{tabular}

Note: $R_{t-1}$ represents the lagged value of the observed company returns. Dom.Ind $d_{t}$ is the returns of the benchmark index where the stock is traded and Cryp.Fund represents the returns of the selected cryptocurrency hedge fund, and is included in the mean equation to control for the cryptocurrency markets' overall movements. The term $h_{t}$ is the conditional volatility estimated by the EGARCH process and $D_{t}$ is a dummy term to provide a coefficient relating to the observed changes in the conditional volatility in the subsequent all days in the sample period following each event for each of our investigated companies. Only the results for the companies with a significant positive $D_{t}$ term is presented. The values in the parentheses are standard errors. ${ }^{* * *},{ }^{* *}$ and $*$ denote significant at the $1 \%, 5 \%$ and $10 \%$ level respectively. 
Table 9: Number of companies experiencing an increase in their stock returns' conditional variances in the short and long-run after their announcements

\begin{tabular}{lrrrrrrr}
\hline \multicolumn{2}{l}{ Panel A: Positive dummy coefficient } \\
\hline News type & $D^{1 d}$ & $D_{t}^{5 d}$ & $D_{t}^{10 d}$ & $D_{t}^{20 d}$ & $D_{t}^{40 d}$ & \multicolumn{1}{c}{$D_{t}^{60 d}$} & $D_{t}^{\text {All }}$ \\
\hline Advertising Ban & $1(100)$ & $1(100)$ & $1(100)$ & $0(0)$ & $1(100)$ & $1(100)$ & $1(100)$ \\
Blockchain Investment & $9(56.25)$ & $8(50)$ & $8(50)$ & $8(50)$ & $8(50)$ & $10(62.5)$ & $6(37.5)$ \\
Blockchain Partnership & $1(20)$ & $1(20)$ & $2(40)$ & $1(20)$ & $1(20)$ & $1(20)$ & $1(20)$ \\
Coin Creation & $19(39.58)$ & $22(45.83)$ & $23(47.92)$ & $18(37.5)$ & $19(39.58)$ & $18(37.5)$ & $16(33.33)$ \\
Investment Fund & $7(58.33)$ & $7(58.33)$ & $7(58.33)$ & $4(33.33)$ & $2(16.67)$ & $3(25)$ & $11(91.67)$ \\
Mining Efficiency & $2(33.33)$ & $1(16.67)$ & $2(33.33)$ & $2(33.33)$ & $1(16.67)$ & $1(16.67)$ & $3(50)$ \\
Name Change & $5(100)$ & $5(100)$ & $5(100)$ & $5(100)$ & $4(80)$ & $3(60)$ & $4(80)$ \\
Security Improvements & $4(40)$ & $4(40)$ & $5(50)$ & $6(60)$ & $3(30)$ & $2(20)$ & $5(50)$ \\
Technological Improvement & $18(36)$ & $19(38)$ & $24(48)$ & $23(46)$ & $21(42)$ & $19(38)$ & $24(48)$ \\
\hline ALL & $66(43.14)$ & $68(44.44)$ & $77(50.33)$ & $67(43.79)$ & $60(39.22)$ & $58(37.91)$ & $71(46.41)$
\end{tabular}

\begin{tabular}{lrrrrrrr}
\hline \multicolumn{7}{l}{ Panel B: Significant positive dummy coefficient } \\
\hline News type & $D^{1 d}$ & $D_{t}^{5 d}$ & $D_{t}^{10 d}$ & $D_{t}^{20 d}$ & $D_{t}^{40 d}$ & $D_{t}^{60 d}$ & $D_{t}^{\text {All }}$ \\
\hline Advertising Ban & $1(100)$ & $1(100)$ & $0(0)$ & $0(0)$ & $0(0)$ & $1(100)$ & $0(0)$ \\
Blockchain Investment & $3(18.75)$ & $4(25)$ & $5(31.25)$ & $3(18.75)$ & $1(6.25)$ & $2(12.5)$ & $1(6.25)$ \\
Blockchain Partnership & $1(20)$ & $0(0)$ & $0(0)$ & $0(0)$ & $0(0)$ & $0(0)$ & $0(0)$ \\
Coin Creation & $12(25)$ & $7(14.58)$ & $7(14.58)$ & $4(8.33)$ & $2(4.17)$ & $1(2.08)$ & $4(8.33)$ \\
Investment Fund & $2(16.67)$ & $2(16.67)$ & $2(16.67)$ & $0(0)$ & $0(0)$ & $0(0)$ & $1(8.33)$ \\
Mining Efficiency & $0(0)$ & $0(0)$ & $0(0)$ & $0(0)$ & $0(0)$ & $0(0)$ & $0(0)$ \\
Name Change & $4(80)$ & $4(80)$ & $2(40)$ & $2(40)$ & $1(20)$ & $0(0)$ & $3(60)$ \\
Security Improvments & $0(0)$ & $3(30)$ & $3(30)$ & $2(20)$ & $0(0)$ & $0(0)$ & $0(0)$ \\
Technological Improvement & $6(12)$ & $5(10)$ & $10(20)$ & $8(16)$ & $8(16)$ & $2(4)$ & $6(12)$ \\
\hline ALL & $29(18.95)$ & $26(16.99)$ & $29(18.95)$ & $19(12.42)$ & $12(7.84)$ & $6(3.92)$ & $15(9.8)$ \\
\hline
\end{tabular}

Note: This table shows the number (and percentage) of companies that experience a higher conditional volatility in their stock prices after announcements. The column headers show the dummy variables used in the analysis, with superscripts denoting the number of days that dummy variables cover after the announcement period. In the table, the values in the parentheses are the percentage of companies within the sub-groups experiencing an increase in their stock returns' conditional variances. Panel A (Panel B) reports the number of companies that experience a (significantly) higher conditional variance in their stocks' daily returns.

In this case, the general findings do not change. In particular, even after controlling for the volatility clustering, there are still 71 companies with an increase in their stock price volatility in the long-term after their announcements. The significance levels drop as expected, from 29 companies to 15 companies, yet this shows that around $10 \%$ of the sample companies, the announcements created substantial and more importantly sustained volatility effects in their stock prices. Among these 15 companies, three of them belong to the group of name changers. Since there were only five companies that changed their names, the high percentage of significant and sustained increase in volatility within this group is a well indicator of how dangerous the announcements of speculative type can be. The list of significant companies also includes blue-chip organisations such as BBVA, UPS and Wells Fargo. According to these observations, unwilling and may be even unaware investors are forced to carry the risk passed through their companies' involvement in blockchain or cryptocurrency related projects, especially if these involvement have a speculative nature. 
Figure 3: Cryptocurrency related announcements' impact on stock price's volatility compared with the announcing company's size

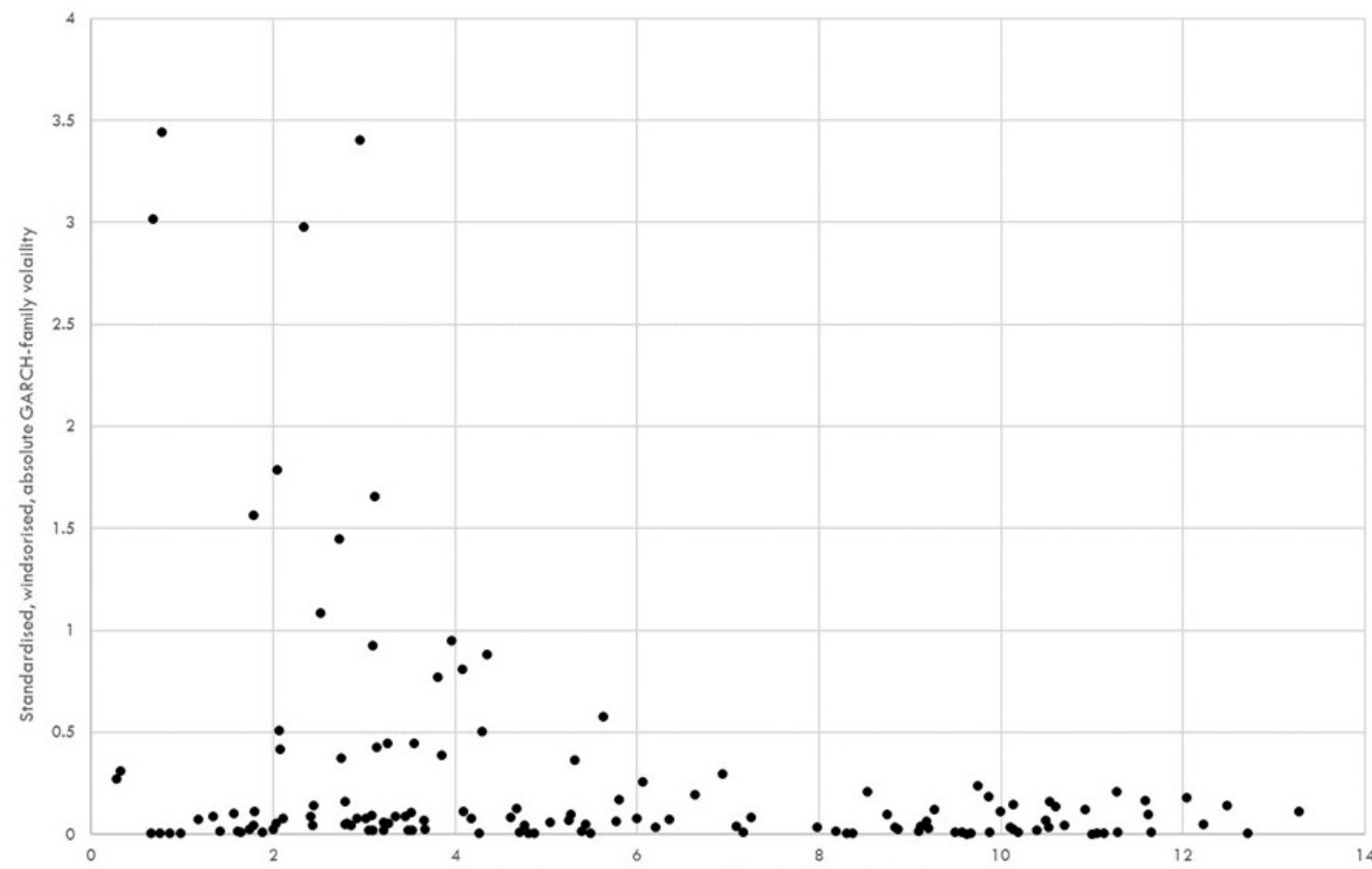

Re-scaled natural logarithm of Market Capitalisation (US\$)

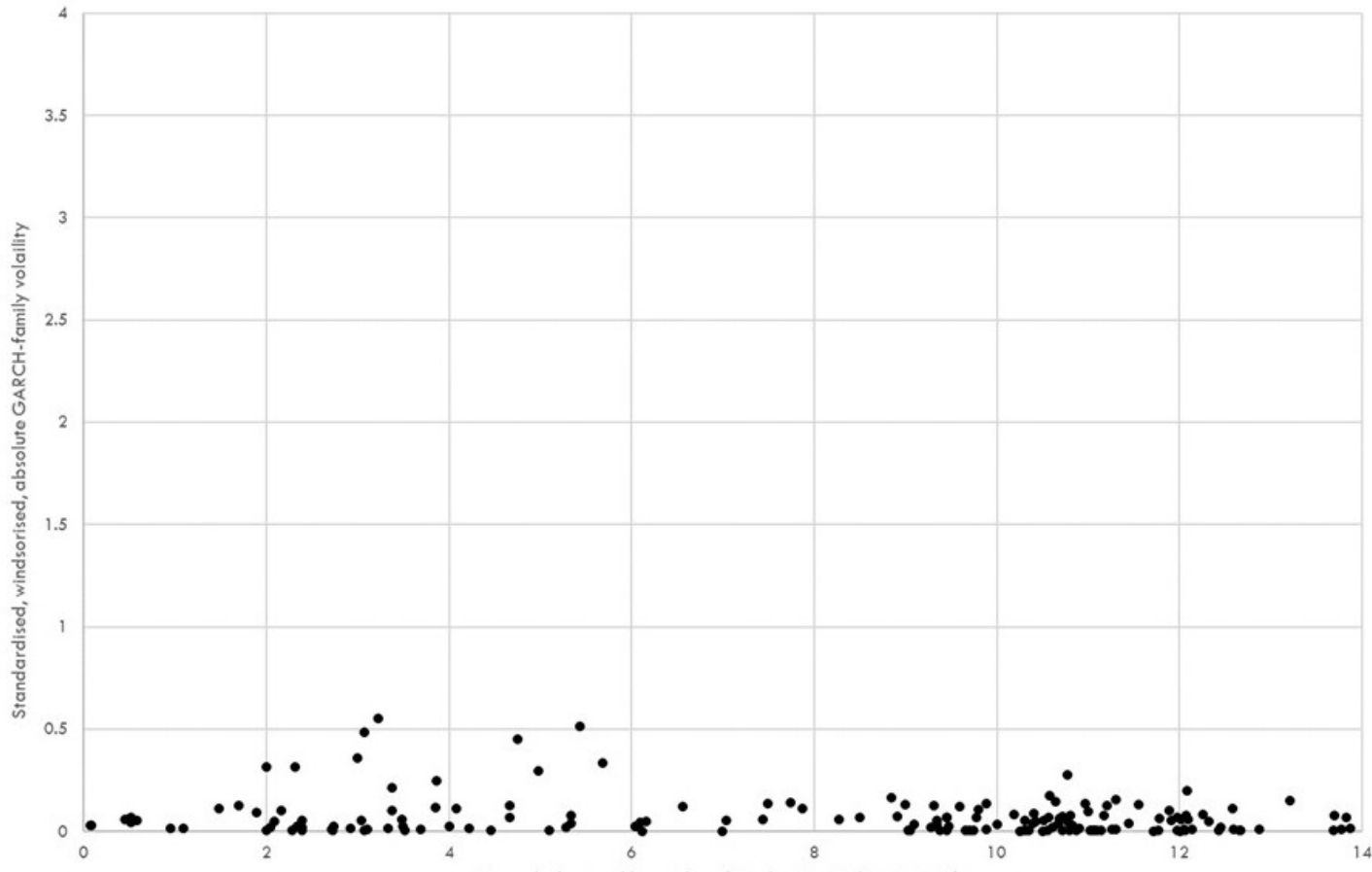

Re-scaled natural logarithm of Market Capitalisation (US\$)

Note: The above figure displays the dummy coefficients (where dummy takes $1(0)$ in all sample days after (before) the announcement) in the EGARCH volatility estimates vs. the announcing company size. In the figure above, the case of announcements denoted to be of a speculative nature is demonstrated and represents most likely to be an attempt to take advantage of crypto-exuberance. The lower figure represents the EGARCH volatility of companies who have made blockchain and cryptocurrency announcements indicating their intentions to use the product for security improvements, internal technological improvements and the improved efficiency of the mining process. The volatility estimates are absolute and winsorized while the natural logarithm of market capitalisation values (in US\$ on the date of the announcement) and re-scaled for presentation. 
To add further evidence of substantial differences in volatility behaviour, in Figure 3, we sub-categorise the companies not only by market capitalisation, but also by the type of announcement as in Section 4.1. Here, we try to visualise the long-term impact of different types of announcements on the conditional volatilites. The first grouping represents announcements that are designated as an attempt to profit from crypto-exuberance, while the second grouping is based on announcements that denote to the market strong intentions to utilise blockchain for internal technological and security development. Two distinct results are evident. Primarily, there appears to be a substantial difference in behaviour between the groups, where more extreme and larger mean absolute volatility deviations are defined for the speculative group compared to that of the strategic-usage group. This supports the results found in Section 4.1, that not only does there exist a premium for company involvement in crypto-exuberance, but there also appears to be a substantial increase in share price volatility in the period thereafter and unlike the premium, this effect sustains more than a quarter. Interestingly, there also appears to be a difference in the volatility behaviour of companies as defined by market capitalisation. For companies over $\$ 100$ million in size, the cryptoexuberance group generate a volatility increase of $0.189 \%$. For companies valued between $\$ 25$ million and $\$ 100$ million, this volatility increases to $0.277 \%$, whereas, for companies below $\$ 25$ million, volatility again increases substantially to $0.599 \%$. These results are not repeated for the strategic usage group, presenting values of $0.037 \%, 0.132 \%$ and $0.155 \%$ respectively. This evidence suggests that companies of a smaller size are substantially more vulnerable to the shocks generated within such announcements, especially in the long-run. As a result of the above analysis, we accept $H_{2}$ and find that there is evidence of differing volatility behaviour dependent on the type of cryptocurrency announcement that has been made. This result also generates substantial ethical and regulatory concerns, as there exist strong evidence that partaking in crypto-exuberance not only presents rewards in terms of share price appreciation, but also generates concerns with regards to the generation of share price volatility, a result that could be exploiting for profit-making opportunities by both leverage and options traders amongst others.

\subsection{Could crypto-exuberance affect unwilling investors?}

We next focus on both hypothesis $H_{3}$ and $H_{4}$ which investigate as to whether there exists a substantial change in dynamic correlations between the target company and both domestic market and cryptocurrency indices respectively in the period of time after an announcement relating to blockchain and cryptocurrency. At this stage, the expected outcome is an overall increase (decrease) in the correlations between the companies' stock prices and cryptocurrency fund performance (domestic index). We start by estimating the following regressions. 


$$
\begin{gathered}
\rho_{i, \text { Cryp.Fund }}^{t}=\alpha+D_{t}+\varepsilon_{t} \\
\rho_{i, \text { Dom.Ind }}^{t}=\alpha+D_{t}+\varepsilon_{t}
\end{gathered}
$$

In equations (13) and (14), $\rho^{t}$ denotes the dynamic conditional correlations, $i$ stands for the selected company's returns, Dom.Ind is the returns of the benchmark index where the stock is traded and Cryp.Fund represents the returns of the selected cryptocurrency hedge fund. Finally, $D_{t}$ is a dummy variable that takes the value one for a certain period of time after company announcements. The detailed results are presented in Table 10 from the shortest (1 business day) to longest (all days) periods after announcements. In Panel A (Panel C) of Table 10, we observe an increase (decrease) in the correlations between stock returns and crypto fund (domestic index) for 71 (82) companies, however, according to Panel B (Panel D), it seems that only 7 (7) of them are significant. So, the announcements do not create instantaneous significant effect on correlations. However, this situation immediately changes once we start to extend the analysis period after announcements. For example, in one month following the corporate announcements, correlations between stock returns and crypto funds (domestic index) significantly increase (decrease) for 48 (36) firms. At some point, this number increases to 65 for the correlations between company stock returns and crypto funds in the case of longest maturity after announcements according to Panel B of Table 10. Similarly, after a quarter following corporate announcements on blockchain related projects, we see a significant decrease in the correlations between announcing companies' stock returns and their corresponding domestic market index (see Panel D).

When it comes to analysing the effects of specific announcement types on the correlation dynamics, Figure 4 provides very striking results. In this figure, we synchronise the correlation series so that the announcement dates overlap for all selected companies and we focus on the time window covering from 60 days before to 60 days after company announcements. Accordingly, we observe substantial differences in the behaviour of dynamic correlations between the identified company and both the domestic index on which the company trades and the selected cryptocurrency fund. Such an analysis provides a significant result that provides quite an interesting outcome for speculative cryptocurrency investment. We can see that in the 60-day period after the company's decision to invest in cryptocurrency, those investments determined to be of a speculative nature rather than that of a strategic decision, we can clearly observe that correlations decline between the company and the domestic index. However, the same correlations increase between the company and cryptocurrency market. This result indicates that there exists an avenue through which unsuspecting investors could be influenced through the elevated risks that such companies have taken through the selection 
Table 10: Number of companies experiencing an increase (decrease) in their stock returns' dynamic conditional correlation between crypto fund index (domestic market index) in the short and long-run after their announcements

Panel A: Positive dummy coefficient

(DCC between company - crypto fund index)

\begin{tabular}{|c|c|c|c|c|c|c|c|}
\hline News type & $D^{1 d}$ & $D_{t}^{5 d}$ & $D_{t}^{10 d}$ & $D_{t}^{20 d}$ & $D_{t}^{40 d}$ & $D_{t}^{60 d}$ & $D_{t}^{\text {All }}$ \\
\hline Advertising Ban & $0(0)$ & $0(0)$ & $0(0)$ & $0(0)$ & $1(100)$ & $1(100)$ & $0(0)$ \\
\hline Blockchain Investment & $8(50)$ & $7(43.75)$ & $8(50)$ & $8(50)$ & $7(43.75)$ & $8(50)$ & $8(50)$ \\
\hline Blockchain Partnership & $2(40)$ & $2(40)$ & $2(40)$ & $2(40)$ & $2(40)$ & $2(40)$ & $4(80)$ \\
\hline Investment Fund & $6(50)$ & $6(50)$ & $5(41.67)$ & $4(33.33)$ & $6(50)$ & $4(33.33)$ & $5(41.67)$ \\
\hline Mining Efficiency & $4(66.67)$ & $3(50)$ & $3(50)$ & $3(50)$ & $4(66.67)$ & $3(50)$ & $5(83.33)$ \\
\hline Name Change & $2(40)$ & $2(40)$ & $3(60)$ & $4(80)$ & $4(80)$ & $5(100)$ & $4(80)$ \\
\hline ALL & $71(46.41)$ & $69(45.1)$ & $69(45.1)$ & $72(47.06)$ & $73(47.71)$ & $81(52.94)$ & $92(60.13)$ \\
\hline
\end{tabular}

\begin{tabular}{|c|c|c|c|c|c|c|c|}
\hline News type & $D^{1 d}$ & $D_{t}^{5 d}$ & $D_{t}^{10 d}$ & $D_{t}^{20 d}$ & $D_{t}^{40 d}$ & $D_{t}^{60 d}$ & $D_{t}^{\text {All }}$ \\
\hline Blockchain Investment & $1(6.25)$ & $5(31.25)$ & $6(37.5)$ & $6(37.5)$ & $6(37.5)$ & $6(37.5)$ & $5(31.25)$ \\
\hline Blockchain Partnership & $0(0)$ & $0(0)$ & $0(0)$ & $1(20)$ & $1(20)$ & $1(20)$ & $2(40)$ \\
\hline Coin Creation & $2(4.17)$ & $11(22.92)$ & $14(29.17)$ & $16(33.33)$ & $17(35.42)$ & $17(35.42)$ & $22(45.83)$ \\
\hline Name Change & $0(0)$ & $2(40)$ & $2(40)$ & $3(60)$ & $2(40)$ & $3(60)$ & $3(60)$ \\
\hline Security Improvments & $1(10)$ & $4(40)$ & $4(40)$ & $3(30)$ & $3(30)$ & $2(20)$ & $3(30)$ \\
\hline Technological Improvement & $2(4)$ & $7(14)$ & $9(18)$ & $14(28)$ & $13(26)$ & $16(32)$ & $23(46)$ \\
\hline ALL & $7(4.58)$ & $32(20.92)$ & $41(26.8)$ & $48(31.37)$ & $50(32.68)$ & $50(32.68)$ & $65(42.48)$ \\
\hline \multicolumn{8}{|c|}{$\begin{array}{l}\text { Panel C: Negative dummy coefficient } \\
\text { (DCC between company - domestic index) }\end{array}$} \\
\hline Blockchain Investment & $8(50)$ & $9(56.25)$ & $11(68.75)$ & $9(56.25)$ & $9(56.25)$ & $10(62.5)$ & $8(50)$ \\
\hline Blockchain Partnership & $3(60)$ & $3(60)$ & $3(60)$ & $3(60)$ & $3(60)$ & $3(60)$ & $3(60)$ \\
\hline Coin Creation & $27(56.25)$ & $23(47.92)$ & $22(45.83)$ & $18(37.5)$ & $21(43.75)$ & $19(39.58)$ & $20(41.67)$ \\
\hline Investment Fund & $6(50)$ & $8(66.67)$ & $8(66.67)$ & $7(58.33)$ & $5(41.67)$ & $7(58.33)$ & $6(50)$ \\
\hline Mining Efficiency & $2(33.33)$ & $2(33.33)$ & $2(33.33)$ & $1(16.67)$ & $0(0)$ & $1(16.67)$ & $0(0)$ \\
\hline Name Change & $2(40)$ & $2(40)$ & $1(20)$ & $0(0)$ & $1(20)$ & $2(40)$ & $4(80)$ \\
\hline Security Improvments & $3(30)$ & $2(20)$ & $2(20)$ & $3(30)$ & $2(20)$ & $3(30)$ & $4(40)$ \\
\hline Technological Improvement & $30(60)$ & $29(58)$ & $31(62)$ & $29(58)$ & $30(60)$ & $31(62)$ & $24(48)$ \\
\hline ALL & $82(53.59)$ & $79(51.63)$ & $80(52.29)$ & $70(45.75)$ & $71(46.41)$ & $76(49.67)$ & $70(45.75)$ \\
\hline
\end{tabular}

Panel D: Significant negative dummy coefficient

(company - domestic index)

\begin{tabular}{|c|c|c|c|c|c|c|c|}
\hline News type & $D^{1 d}$ & $D_{t}^{5 d}$ & $D_{t}^{10 d}$ & $D_{t}^{20 d}$ & $D_{t}^{40 d}$ & $D_{t}^{60 d}$ & $D_{t}^{A l l}$ \\
\hline Advertising Ban & $0(0)$ & $0(0)$ & $0(0)$ & $0(0)$ & $0(0)$ & $0(0)$ & $1(100)$ \\
\hline Blockchain Investment & $1(6.25)$ & $5(31.25)$ & $6(37.5)$ & $6(37.5)$ & $7(43.75)$ & $8(50)$ & $5(31.25)$ \\
\hline Blockchain Partnership & $0(0)$ & $1(20)$ & $3(60)$ & $3(60)$ & $2(40)$ & $2(40)$ & $2(40)$ \\
\hline Investment Fund & $0(0)$ & $2(16.67)$ & $4(33.33)$ & $3(25)$ & $4(33.33)$ & $4(33.33)$ & $5(41.67)$ \\
\hline Mining Efficiency & $0(0)$ & $0(0)$ & $0(0)$ & $0(0)$ & $0(0)$ & $0(0)$ & $0(0)$ \\
\hline Name Change & $0(0)$ & $0(0)$ & $0(0)$ & $0(0)$ & $0(0)$ & $0(0)$ & $0(0)$ \\
\hline Technological Improvement & $2(4)$ & $9(18)$ & $10(20)$ & $16(32)$ & $20(40)$ & $23(46)$ & $17(34)$ \\
\hline ALL & $7(4.58)$ & $25(16.34)$ & $30(19.61)$ & $36(23.53)$ & $47(30.72)$ & $50(32.68)$ & $44(28.76)$ \\
\hline
\end{tabular}

Note: This table shows the number and percentage of companies that experience a higher (lower) correlation between their stock prices and crypto fund index (domestic index) after announcements. The column headers show the dummy variables used in the analysis, with superscripts denoting the number of days that dummy variables cover after the announcement period. In the table, the values in the parentheses are the percentage of companies within the sub-groups experiencing an increase (decrease) in such correlations. Panel A (Panel B) reports the number of companies that experience a (significantly) higher conditional correlation between their stocks' daily returns and the return of the crypto fund index. Panel C (Panel D) reports the number of companies that experience a (significantly) lower conditional correlation between their stocks' daily returns and the return of their domestic index. 
Figure 4: Dynamic conditional correlations (DCC) before and after cryptocurrency related announcements
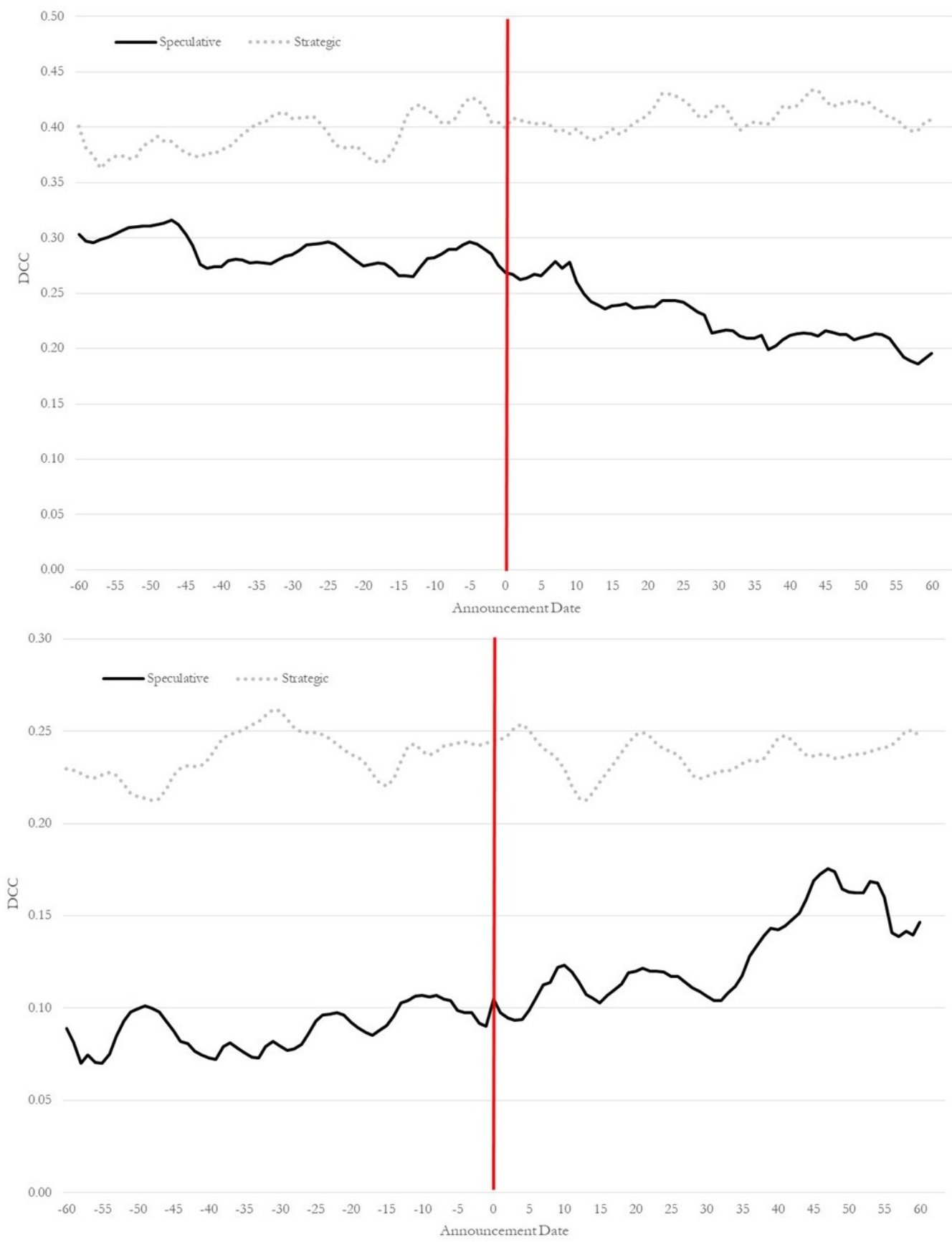

Note: The upper figure presents the average dynamic correlations between companies and the domestic index for the period both 60 days before and after announcements relating to cryptocurrency-based announcements. The lower figure presents the average dynamic correlations between the identified companies and the cryptocurrency index fund for the same period. In both figures, red vertical lines refer to the announcement dates. 
of speculative cryptocurrency-based decisions.

We can therefore accept Hypotheses $H_{3}$ and $H_{4}$ as there is evidence of a significant change in dynamic correlation between the company and both domestic market index and cryptocurrency returns in the period after such announcements have been made.

\subsection{Has crypto-exuberance influenced the process of price discovery and information flow?}

In the final stage of our analysis and developing from the stated increased relationship between the analysed companies and cryptocurrency hedge funds, we next investigate as to whether there exists a substantial change in both information flow and price discovery between the announcement company and cryptocurrency. While both the levels and volatility of the share prices are found to be influenced by speculative blockchain and cryptocurrency announcements, we have also found that such companies have also shared more common characteristics with cryptocurrency markets than that of their domestic indices in the period after such announcements. 
Table 11: Change in price discovery based on corporate announcement-type

\begin{tabular}{|c|c|c|c|c|c|c|c|c|c|c|c|c|}
\hline Breakdown & IS pre & IS post & IS-r pre & IS-r post & CS pre & CS post & ILS pre & ILS post & $\Delta \mathrm{IS}$ & $\Delta \mathrm{IS}-\mathrm{r}$ & $\Delta \mathrm{CS}$ & $\Delta \mathrm{ILS}$ \\
\hline Blockchain Investment & $\begin{array}{l}0.2175 \\
0.7825\end{array}$ & $\begin{array}{l}0.1720 \\
0.8280\end{array}$ & $\begin{array}{l}0.2284 \\
0.7716\end{array}$ & $\begin{array}{l}0.1608 \\
0.8392\end{array}$ & $\begin{array}{l}0.0560 \\
0.9440\end{array}$ & $\begin{array}{l}0.0408 \\
0.9592\end{array}$ & $\begin{array}{l}0.7311 \\
0.2689\end{array}$ & $\begin{array}{l}0.7407 \\
0.2593\end{array}$ & -0.0455 & -0.0676 & -0.0152 & 0.0096 \\
\hline Blockchain Partnership & $\begin{array}{l}0.1419 \\
0.8581\end{array}$ & $\begin{array}{l}0.1339 \\
0.8661\end{array}$ & $\begin{array}{l}0.0750 \\
0.9250\end{array}$ & $\begin{array}{l}0.0811 \\
0.9189\end{array}$ & $\begin{array}{l}0.0967 \\
0.9033\end{array}$ & $\begin{array}{l}0.0925 \\
0.9075\end{array}$ & $\begin{array}{l}0.5481 \\
0.4519\end{array}$ & $\begin{array}{l}0.6257 \\
0.3743\end{array}$ & -0.0079 & 0.0061 & -0.0042 & 0.0776 \\
\hline Coin Creation & $\begin{array}{l}0.1987 \\
0.8013\end{array}$ & $\begin{array}{l}0.3031 \\
0.6969\end{array}$ & $\begin{array}{l}0.2045 \\
0.7955\end{array}$ & $\begin{array}{l}0.2603 \\
0.7397\end{array}$ & $\begin{array}{l}0.1724 \\
0.8276\end{array}$ & $\begin{array}{l}0.1880 \\
0.8120\end{array}$ & $\begin{array}{l}0.5880 \\
0.4120\end{array}$ & $\begin{array}{l}0.6096 \\
0.3904\end{array}$ & 0.1044 & 0.0559 & 0.0156 & 0.0217 \\
\hline Investment Fund & $\begin{array}{l}0.1868 \\
0.8132\end{array}$ & $\begin{array}{l}0.1584 \\
0.8416\end{array}$ & $\begin{array}{l}0.2001 \\
0.7999\end{array}$ & $\begin{array}{l}0.1042 \\
0.8958\end{array}$ & $\begin{array}{l}0.1095 \\
0.8905\end{array}$ & $\begin{array}{l}0.1845 \\
0.8155\end{array}$ & $\begin{array}{l}0.3542 \\
0.6458\end{array}$ & $\begin{array}{l}0.2036 \\
0.7964\end{array}$ & -0.0284 & -0.0959 & 0.0750 & -0.1506 \\
\hline Mining Efficiency & $\begin{array}{l}0.2074 \\
0.7926\end{array}$ & $\begin{array}{l}0.1592 \\
0.8408\end{array}$ & $\begin{array}{l}0.2816 \\
0.7184\end{array}$ & $\begin{array}{l}0.1554 \\
0.8446\end{array}$ & $\begin{array}{l}0.1560 \\
0.8440\end{array}$ & $\begin{array}{l}0.0725 \\
0.9275\end{array}$ & $\begin{array}{l}0.7118 \\
0.2882\end{array}$ & $\begin{array}{l}0.7811 \\
0.2189\end{array}$ & -0.0481 & -0.1262 & -0.0835 & 0.0693 \\
\hline Name Change & $\begin{array}{l}0.9202 \\
0.0798\end{array}$ & $\begin{array}{l}0.6700 \\
0.3300\end{array}$ & $\begin{array}{l}0.7330 \\
0.2670\end{array}$ & $\begin{array}{l}0.7620 \\
0.2380\end{array}$ & $\begin{array}{l}0.9566 \\
0.0434\end{array}$ & $\begin{array}{l}0.9634 \\
0.0366\end{array}$ & $\begin{array}{l}0.2615 \\
0.7385\end{array}$ & $\begin{array}{l}0.0151 \\
0.9849\end{array}$ & -0.2502 & 0.0290 & 0.0068 & -0.2463 \\
\hline Security Improvements & $\begin{array}{l}0.3668 \\
0.6332\end{array}$ & $\begin{array}{l}0.2715 \\
0.7285\end{array}$ & $\begin{array}{l}0.3549 \\
0.6451\end{array}$ & $\begin{array}{l}0.3819 \\
0.6181\end{array}$ & $\begin{array}{l}0.3864 \\
0.6136\end{array}$ & $\begin{array}{l}0.4214 \\
0.5786\end{array}$ & $\begin{array}{l}0.4023 \\
0.5977\end{array}$ & $\begin{array}{l}0.3314 \\
0.6686\end{array}$ & -0.0953 & 0.0270 & 0.0349 & -0.0709 \\
\hline Tech. Improvements & $\begin{array}{l}0.2201 \\
0.7799\end{array}$ & $\begin{array}{l}0.1731 \\
0.8269\end{array}$ & $\begin{array}{l}0.2284 \\
0.7716\end{array}$ & $\begin{array}{l}0.1363 \\
0.8637\end{array}$ & $\begin{array}{l}0.0762 \\
0.9238\end{array}$ & $\begin{array}{l}0.0956 \\
0.9044\end{array}$ & $\begin{array}{l}0.5633 \\
0.4367\end{array}$ & $\begin{array}{l}0.5781 \\
0.4219\end{array}$ & -0.0469 & -0.0921 & 0.0194 & 0.0147 \\
\hline Total Period & $\begin{array}{l}0.2227 \\
0.7773\end{array}$ & $\begin{array}{l}0.2206 \\
0.7794\end{array}$ & $\begin{array}{l}0.2278 \\
0.7722\end{array}$ & $\begin{array}{l}0.1972 \\
0.8028\end{array}$ & $\begin{array}{l}0.1405 \\
0.8595\end{array}$ & $\begin{array}{l}0.1566 \\
0.8434\end{array}$ & $\begin{array}{l}0.5593 \\
0.4407\end{array}$ & $\begin{array}{l}0.5593 \\
0.4407\end{array}$ & -0.0021 & -0.0306 & 0.0162 & 0.0000 \\
\hline
\end{tabular}

Note: The above panel represents the estimated coefficients of price discovery. IS represents the information share, IS-r represents the reverse information share criterion, CS represents the component share of information while ILS represent the information leadership share of information. The four right-hand columns represent the estimated

changes in price discovery in the periods both before and after the announcements of both blockchain and cryptocurrency developments. 
In Table 11, we first investigate the average price discovery relationship between the announcement company and cryptocurrency returns as separated by the type of announcement. There are a number of substantial findings. Prior to the stated announcements, the flow of information and price discovery develops from the company towards cryptocurrency markets with the exception of cases relating the changing of the company's name. Within this group however, the companies are found to be already involved in high-risk strategies and sectors with some involved in blockchain development without the identification of this within the company's name. In the period before the announcement of the company's intention to change their name, the share of price discovery was $92.02 \%$ derived in cryptocurrencies towards the company's share price. In the period thereafter, it had fallen to $67.00 \%$, still quite a substantial share of information sourced from such a high volatility product. In cases where the company had announced their intention to create a cryptocurrency, the share of information sourced from cryptocurrencies was $19.87 \%$, which increases substantially to $30.31 \%$ in the period thereafter. Whereas, in cases denoted as more strategic in nature, such as that of mining efficiency, security improvements and technological improvements, the information share and information leadership share is found to decrease, providing further evidence of differing behaviour that is determined based on whether the type of announcement is denoted as strategic, or indeed, more speculative in nature. These results provide evidence supporting the acceptance of both Hypotheses $H_{5}$ and $H_{6}$ and there is clear evidence of both a change in the information flows between the target companies and cryptocurrency markets, and there is substantial evidence of a decoupling of companies that have partaken in speculative blockchain and cryptocurrency-related announcements with geographically similar companies. 
Table 12: Price Discovery differences due to announcements denoted as crypto-exuberant behaviour

\begin{tabular}{|c|c|c|c|c|c|c|c|c|c|c|c|c|}
\hline Breakdown & IS pre & IS post & IS-r pre & IS-r post & CS pre & CS post & ILS pre & ILS post & $\Delta \mathrm{IS}$ & $\Delta \mathrm{IS}-\mathrm{r}$ & $\Delta \mathrm{CS}$ & $\Delta \mathrm{ILS}$ \\
\hline \multicolumn{13}{|l|}{ Name Change } \\
\hline \multirow[t]{2}{*}{ Blockchain Worldwide } & 0.9454 & 0.3175 & 0.9976 & 0.7854 & 0.9994 & 0.9814 & 0.0505 & 0.0048 & -0.6279 & -0.2121 & -0.0180 & -0.0457 \\
\hline & 0.0546 & 0.6825 & 0.0024 & 0.2146 & 0.0006 & 0.0186 & 0.9495 & 0.9952 & & & & \\
\hline \multirow[t]{2}{*}{ Long Blockchain Technology } & 0.8579 & 0.9571 & 0.8300 & 0.9693 & 0.9915 & 0.9972 & 0.0017 & 0.0076 & 0.0992 & 0.1393 & 0.0057 & 0.0059 \\
\hline & 0.1421 & 0.0429 & 0.1700 & 0.0307 & 0.0085 & 0.0028 & 0.9983 & 0.9924 & & & & \\
\hline \multirow[t]{2}{*}{ On-line Blockchain Plc } & 0.8949 & 0.4062 & 0.1188 & 0.6119 & 0.9880 & 0.8753 & 0.0000 & 0.0481 & -0.4887 & 0.4932 & -0.1127 & 0.0480 \\
\hline & 0.1051 & 0.5938 & 0.8812 & 0.3881 & 0.0120 & 0.1247 & 1.0000 & 0.9519 & & & & \\
\hline \multirow[t]{2}{*}{ UBI Blockchain } & 0.9827 & 0.9992 & 0.9857 & 0.6813 & 0.8472 & 0.9997 & 0.9936 & 0.0000 & 0.0164 & -0.3045 & 0.1525 & -0.9936 \\
\hline & 0.0173 & 0.0008 & 0.0143 & 0.3187 & 0.1528 & 0.0003 & 0.0064 & 1.0000 & & & & \\
\hline \multicolumn{13}{|l|}{ Investment Fund } \\
\hline \multirow[t]{2}{*}{ Berkshire Hathaway Inc. } & 0.1632 & 0.0898 & 0.4082 & 0.1069 & 0.0072 & 0.0026 & 0.9999 & 0.9995 & -0.0734 & -0.3013 & -0.0046 & -0.0003 \\
\hline & 0.8368 & 0.9102 & 0.5918 & 0.8931 & 0.9928 & 0.9974 & 0.0001 & 0.0005 & & & & \\
\hline \multirow[t]{2}{*}{ Cboe Global Markets } & 0.0001 & 0.2049 & 0.0704 & 0.2517 & 0.1626 & 0.0219 & 0.1322 & 0.0000 & 0.2048 & 0.1812 & -0.1407 & -0.1322 \\
\hline & 0.9999 & 0.7951 & 0.9296 & 0.7483 & 0.8374 & 0.9781 & 0.8678 & 1.0000 & & & & \\
\hline \multirow[t]{2}{*}{ CME Group } & 0.1694 & 0.2408 & 0.0173 & 0.3737 & 0.0257 & 0.0542 & 0.0000 & 0.0000 & 0.0714 & 0.3565 & 0.0285 & 0.0000 \\
\hline & 0.8306 & 0.7592 & 0.9827 & 0.6263 & 0.9743 & 0.9458 & 1.0000 & 1.0000 & & & & \\
\hline \multirow[t]{2}{*}{ Coinsilium Group } & 0.0734 & 0.0016 & 0.0576 & 0.0202 & 0.0015 & 0.1107 & 0.9994 & 0.0266 & -0.0718 & -0.0374 & 0.1091 & -0.9728 \\
\hline & 0.9266 & 0.9984 & 0.9424 & 0.9798 & 0.9985 & 0.8893 & 0.0006 & 0.9734 & & & & \\
\hline \multirow[t]{2}{*}{ FastForward Innovations } & 0.1826 & 0.0016 & 0.2229 & 0.0053 & 0.0140 & 0.2309 & 0.0000 & 0.0003 & -0.1810 & -0.2176 & 0.2169 & 0.0003 \\
\hline & 0.8174 & 0.9984 & 0.7771 & 0.9947 & 0.9860 & 0.7691 & 1.0000 & 0.9997 & & & & \\
\hline \multirow[t]{2}{*}{ Goldman Sachs Group Inc. } & 0.4594 & 0.2868 & 0.0783 & 0.0071 & 0.1049 & 0.4623 & 0.3443 & 0.0001 & -0.1727 & -0.0712 & 0.3574 & -0.3443 \\
\hline & 0.5406 & 0.7132 & 0.9217 & 0.9929 & 0.8951 & 0.5377 & 0.6557 & 0.9999 & & & & \\
\hline \multirow[t]{2}{*}{ HIVE Blockchain } & 0.2061 & 0.0821 & 0.2734 & 0.2368 & 0.0018 & 0.0027 & 1.0000 & 0.9999 & -0.1240 & -0.0366 & 0.0009 & -0.0001 \\
\hline & 0.7939 & 0.9179 & 0.7266 & 0.7632 & 0.9982 & 0.9973 & 0.0000 & 0.0001 & & & & \\
\hline \multirow[t]{2}{*}{ Interactive Brokers Group } & 0.2412 & 0.3112 & 0.3566 & 0.0029 & 0.0352 & 0.3170 & 0.0000 & 0.0000 & 0.0699 & -0.3538 & 0.2817 & 0.0000 \\
\hline & 0.7588 & 0.6888 & 0.6434 & 0.9971 & 0.9648 & 0.6830 & 1.0000 & 1.0000 & & & & \\
\hline \multirow[t]{2}{*}{ Morgan Stanley } & 0.0025 & 0.3124 & 0.2229 & 0.0001 & 0.0590 & 0.2736 & 0.0000 & 0.0000 & 0.3099 & -0.2228 & 0.2146 & 0.0000 \\
\hline & 0.9975 & 0.6876 & 0.7771 & 0.9999 & 0.9410 & 0.7264 & 1.0000 & 1.0000 & & & & \\
\hline \multirow[t]{2}{*}{ Plus500 } & 0.2056 & 0.1076 & 0.2477 & 0.0633 & 0.3446 & 0.1186 & 0.2816 & 0.2014 & -0.0980 & -0.1844 & -0.2260 & -0.0802 \\
\hline & 0.7944 & 0.8924 & 0.7523 & 0.9367 & 0.6554 & 0.8814 & 0.7184 & 0.7986 & & & & \\
\hline \multirow[t]{2}{*}{ Prudential } & 0.3510 & 0.1032 & 0.2461 & 0.0783 & 0.4481 & 0.4353 & 0.1392 & 0.0120 & -0.2479 & -0.1679 & -0.0128 & -0.1272 \\
\hline & 0.6490 & 0.8968 & 0.7539 & 0.9217 & 0.5519 & 0.5647 & 0.8608 & 0.9880 & & & & \\
\hline \multicolumn{13}{|l|}{ Coin Creation } \\
\hline \multirow[t]{2}{*}{ Gozo Travel } & 0.0160 & 0.4633 & 0.2664 & 0.1188 & 0.0734 & 0.0247 & 0.9545 & 0.9659 & 0.4473 & -0.1476 & -0.0487 & 0.0114 \\
\hline & 0.9840 & 0.5367 & 0.7336 & 0.8812 & 0.9266 & 0.9753 & 0.0455 & 0.0341 & & & & \\
\hline \multirow[t]{2}{*}{ Helios and Matheson Analytics } & 0.4048 & 0.6590 & 0.6357 & 0.5533 & 0.0723 & 0.0035 & 0.9980 & 1.0000 & 0.2542 & -0.0824 & -0.0688 & 0.0020 \\
\hline & 0.5952 & 0.3410 & 0.3643 & 0.4467 & 0.9277 & 0.9965 & 0.0020 & 0.0000 & & & & \\
\hline \multirow[t]{2}{*}{ Home Meal Replacement } & 0.3782 & 0.0751 & 0.4208 & 0.0353 & 0.0011 & 0.0001 & 1.0000 & 1.0000 & -0.3031 & -0.3856 & -0.0010 & 0.0000 \\
\hline & 0.6218 & 0.9249 & 0.5792 & 0.9647 & 0.9989 & 0.9999 & 0.0000 & 0.0000 & & & & \\
\hline
\end{tabular}


Table 12: Price Discovery differences due to announcements denoted as crypto-exuberant behaviour

\begin{tabular}{|c|c|c|c|c|c|c|c|c|c|c|c|c|}
\hline Breakdown & IS pre & IS post & IS-r pre & IS-r post & CS pre & CS post & ILS pre & ILS post & $\Delta \mathrm{IS}$ & $\Delta$ IS-r & $\Delta \mathrm{CS}$ & $\Delta \mathrm{ILS}$ \\
\hline \multirow[t]{2}{*}{ HSBC } & 0.0175 & 0.0252 & 0.2124 & 0.3030 & 0.4856 & 0.0471 & 0.0755 & 0.0000 & 0.0077 & 0.0906 & -0.4384 & -0.0755 \\
\hline & 0.9825 & 0.9748 & 0.7876 & 0.6970 & 0.5144 & 0.9529 & 0.9245 & 1.0000 & & & & \\
\hline \multirow[t]{2}{*}{ Jay Mart } & 0.2757 & 0.4549 & 0.3318 & 0.4982 & 0.0218 & 0.0073 & 0.9980 & 0.9999 & 0.1793 & 0.1664 & -0.0145 & 0.0019 \\
\hline & 0.7243 & 0.5451 & 0.6682 & 0.5018 & 0.9782 & 0.9927 & 0.0020 & 0.0001 & & & & \\
\hline \multirow[t]{2}{*}{ Kakao } & 0.4982 & 0.4960 & 0.3929 & 0.4956 & 0.0079 & 0.0156 & 0.9998 & 0.9997 & -0.0022 & 0.1028 & 0.0077 & -0.0001 \\
\hline & 0.5018 & 0.5040 & 0.6071 & 0.5044 & 0.9921 & 0.9844 & 0.0002 & 0.0003 & & & & \\
\hline \multirow[t]{2}{*}{ KinerjaPay } & 0.0109 & 0.3591 & 0.0173 & 0.1485 & 0.0009 & 0.0024 & 0.9972 & 0.9998 & 0.3482 & 0.1312 & 0.0015 & 0.0026 \\
\hline & 0.9891 & 0.6409 & 0.9827 & 0.8515 & 0.9991 & 0.9976 & 0.0028 & 0.0002 & & & & \\
\hline \multirow[t]{2}{*}{ Kodak } & 0.4082 & 0.9117 & 0.1647 & 0.9269 & 0.9522 & 0.9852 & 0.0001 & 0.0349 & 0.5035 & 0.7623 & 0.0331 & 0.0348 \\
\hline & 0.5918 & 0.0883 & 0.8353 & 0.0731 & 0.0478 & 0.0148 & 0.9999 & 0.9651 & & & & \\
\hline \multirow[t]{2}{*}{ Leonovus } & 0.1238 & 0.2984 & 0.0959 & 0.4186 & 0.0003 & 0.0005 & 1.0000 & 1.0000 & 0.1746 & 0.3227 & 0.0002 & 0.0000 \\
\hline & 0.8762 & 0.7016 & 0.9041 & 0.5814 & 0.9997 & 0.9995 & 0.0000 & 0.0000 & & & & \\
\hline \multirow[t]{2}{*}{ Macau Capital } & 0.0040 & 0.3374 & 0.0000 & 0.2472 & 0.0064 & 0.0004 & 0.0000 & 1.0000 & 0.3334 & 0.2472 & -0.0060 & 1.0000 \\
\hline & 0.9960 & 0.6626 & 1.0000 & 0.7528 & 0.9936 & 0.9996 & 1.0000 & 0.0000 & & & & \\
\hline \multirow[t]{2}{*}{ Mitsubishi UFJ Financial Group } & 0.3921 & 0.0033 & 0.3026 & 0.0171 & 0.4193 & 0.0822 & 0.2652 & 0.0363 & -0.3888 & -0.2855 & -0.3371 & -0.2290 \\
\hline & 0.6079 & 0.9967 & 0.6974 & 0.9829 & 0.5807 & 0.9178 & 0.7348 & 0.9637 & & & & \\
\hline \multirow[t]{2}{*}{ Mizuho Financial Group } & 0.0075 & 0.0262 & 0.0020 & 0.1679 & 0.0155 & 0.0147 & 0.0157 & 0.9946 & 0.0187 & 0.1659 & -0.0009 & 0.9789 \\
\hline & 0.9925 & 0.9738 & 0.9980 & 0.8321 & 0.9845 & 0.9853 & 0.9843 & 0.0054 & & & & \\
\hline \multirow[t]{2}{*}{ MUFG } & 0.0041 & 0.2317 & 0.0063 & 0.1332 & 0.0452 & 0.4305 & 0.0176 & 0.0397 & 0.2276 & 0.1269 & 0.3853 & 0.0221 \\
\hline & 0.9959 & 0.7683 & 0.9937 & 0.8668 & 0.9548 & 0.5695 & 0.9824 & 0.9603 & & & & \\
\hline \multirow[t]{2}{*}{ Overstock.com } & 0.0024 & 0.2248 & 0.0716 & 0.0008 & 0.1859 & 0.0165 & 0.1025 & 0.0025 & 0.2224 & -0.0708 & -0.1694 & -0.1000 \\
\hline & 0.9976 & 0.7752 & 0.9284 & 0.9992 & 0.8141 & 0.9835 & 0.8975 & 0.9975 & & & & \\
\hline \multirow[t]{2}{*}{ Petroteq } & 0.0131 & 0.4641 & 0.0177 & 0.4130 & 0.2836 & 0.0010 & 0.0021 & 0.0000 & 0.4510 & 0.3953 & -0.2826 & -0.0021 \\
\hline & 0.9869 & 0.5359 & 0.9823 & 0.5870 & 0.7164 & 0.9990 & 0.9979 & 1.0000 & & & & \\
\hline \multirow[t]{2}{*}{ Plant Ventures } & 0.2703 & 0.0801 & 0.2504 & 0.3165 & 0.0002 & 0.0001 & 1.0000 & 1.0000 & -0.1902 & 0.0661 & -0.0001 & 0.0000 \\
\hline & 0.7297 & 0.9199 & 0.7496 & 0.6835 & 0.9998 & 0.9999 & 0.0000 & 0.0000 & & & & \\
\hline \multirow[t]{2}{*}{ Relevium } & 0.1205 & 0.1914 & 0.1042 & 0.0855 & 0.0002 & 0.0001 & 1.0000 & 1.0000 & 0.0708 & -0.0188 & -0.0001 & 0.0000 \\
\hline & 0.8795 & 0.8086 & 0.8958 & 0.9145 & 0.9998 & 0.9999 & 0.0000 & 0.0000 & & & & \\
\hline \multirow[t]{2}{*}{ State Street } & 0.2293 & 0.4799 & 0.2458 & 0.0517 & 0.0590 & 0.0360 & 0.9643 & 0.6815 & 0.2505 & -0.1940 & -0.0230 & -0.2828 \\
\hline & 0.7707 & 0.5201 & 0.7542 & 0.9483 & 0.9410 & 0.9640 & 0.0357 & 0.3185 & & & & \\
\hline \multirow[t]{2}{*}{ Stockholm IT Ventures } & 0.3179 & 0.0238 & 0.3166 & 0.0002 & 0.0039 & 0.0036 & 0.9999 & 0.0038 & -0.2941 & -0.3164 & -0.0004 & -0.9961 \\
\hline & 0.6821 & 0.9762 & 0.6834 & 0.9998 & 0.9961 & 0.9964 & 0.0001 & 0.9962 & & & & \\
\hline \multirow[t]{2}{*}{ Twin Vee PowerCats } & 0.0270 & 0.1619 & 0.0208 & 0.0338 & 0.0074 & 0.0001 & 0.8896 & 1.0000 & 0.1349 & 0.0130 & -0.0073 & 0.1104 \\
\hline & 0.9730 & 0.8381 & 0.9792 & 0.9662 & 0.9926 & 0.9999 & 0.1104 & 0.0000 & & & & \\
\hline \multirow[t]{2}{*}{ UBS } & 0.0602 & 0.2247 & 0.0129 & 0.2797 & 0.0054 & 0.0061 & 0.8503 & 0.9997 & 0.1645 & 0.2669 & 0.0007 & 0.1494 \\
\hline & 0.9398 & 0.7753 & 0.9871 & 0.7203 & 0.9946 & 0.9939 & 0.1497 & 0.0003 & & & & \\
\hline \multirow[t]{2}{*}{ Walt Disney Company } & 0.2702 & 0.2800 & 0.0124 & 0.0001 & 0.0345 & 0.0071 & 0.1109 & 0.0001 & 0.0098 & -0.0124 & -0.0274 & -0.1108 \\
\hline & 0.7298 & 0.7200 & 0.9876 & 0.9999 & 0.9655 & 0.9929 & 0.8891 & 0.9999 & & & & \\
\hline \multirow[t]{2}{*}{ WISeKey International Holding } & 0.0095 & 0.4831 & 0.0004 & 0.4568 & 0.0008 & 0.0029 & 0.2231 & 1.0000 & 0.4736 & 0.4564 & 0.0021 & 0.7769 \\
\hline & 0.9905 & 0.5169 & 0.9996 & 0.5432 & 0.9992 & 0.9971 & 0.7769 & 0.0000 & & & & \\
\hline \multirow[t]{2}{*}{ Y Ventures Group } & 0.0000 & 0.1936 & 0.1656 & 0.1713 & 0.0000 & 0.0002 & 1.0000 & 1.0000 & 0.1936 & 0.0057 & 0.0002 & 0.0000 \\
\hline & 1.0000 & 0.8064 & 0.8344 & 0.8287 & 1.0000 & 0.9998 & 0.0000 & 0.0000 & & & & \\
\hline
\end{tabular}


Table 12: Price Discovery differences due to announcements denoted as crypto-exuberant behaviour

\begin{tabular}{|c|c|c|c|c|c|c|c|c|c|c|c|c|}
\hline Breakdown & IS pre & IS post & IS-r pre & IS-r post & CS pre & CS post & ILS pre & ILS post & $\Delta \mathrm{IS}$ & $\Delta \mathrm{IS}-\mathrm{r}$ & $\Delta \mathrm{CS}$ & $\Delta \mathrm{ILS}$ \\
\hline \multicolumn{13}{|l|}{ Blockchain Partnership } \\
\hline \multirow[t]{2}{*}{ AIA Group } & 0.1447 & 0.0959 & 0.0288 & 0.0033 & 0.1842 & 0.0109 & 0.0169 & 0.0831 & -0.0489 & -0.0255 & -0.1734 & 0.0662 \\
\hline & 0.8553 & 0.9041 & 0.9712 & 0.9967 & 0.8158 & 0.9891 & 0.9831 & 0.9169 & & & & \\
\hline \multirow[t]{2}{*}{ Marathon Patent Group } & 0.0726 & 0.0000 & 0.1457 & 0.0000 & 0.0388 & 0.0053 & 0.9470 & 1.0000 & -0.0726 & -0.1457 & -0.0335 & 0.0530 \\
\hline & 0.9274 & 1.0000 & 0.8543 & 1.0000 & 0.9612 & 0.9947 & 0.0530 & 0.0000 & & & & \\
\hline \multirow[t]{2}{*}{ SAP } & 0.0372 & 0.0021 & 0.0441 & 0.1840 & 0.0097 & 0.0597 & 0.9571 & 0.9266 & -0.0351 & 0.1399 & 0.0500 & -0.0304 \\
\hline & 0.9628 & 0.9979 & 0.9559 & 0.8160 & 0.9903 & 0.9403 & 0.0429 & 0.0734 & & & & \\
\hline \multirow[t]{2}{*}{ Square } & 0.4533 & 0.2034 & 0.1492 & 0.0335 & 0.0763 & 0.3077 & 0.8184 & 0.9940 & -0.2499 & -0.1157 & 0.2314 & 0.1756 \\
\hline & 0.5467 & 0.7966 & 0.8508 & 0.9665 & 0.9237 & 0.6923 & 0.1816 & 0.0060 & & & & \\
\hline \multirow[t]{2}{*}{ Veltyco } & 0.0014 & 0.3683 & 0.0071 & 0.1848 & 0.1746 & 0.0790 & 0.0011 & 0.1250 & 0.3669 & 0.1777 & -0.0957 & 0.1239 \\
\hline & 0.9986 & 0.6317 & 0.9929 & 0.8152 & 0.8254 & 0.9210 & 0.9989 & 0.8750 & & & & \\
\hline \multicolumn{13}{|l|}{ Blockchain Investment } \\
\hline \multirow[t]{2}{*}{ American Express Company } & 0.1689 & 0.0003 & 0.0009 & 0.1800 & 0.0212 & 0.0875 & 0.0015 & 0.0000 & -0.1687 & 0.1791 & 0.0662 & -0.0015 \\
\hline & 0.8311 & 0.9997 & 0.9991 & 0.8200 & 0.9788 & 0.9125 & 0.9985 & 1.0000 & & & & \\
\hline \multirow[t]{2}{*}{ BTCS } & 0.0382 & 0.3628 & 0.0231 & 0.4942 & 0.0194 & 0.0143 & 0.5882 & 0.9998 & 0.3246 & 0.4711 & -0.0051 & 0.4116 \\
\hline & 0.9618 & 0.6372 & 0.9769 & 0.5058 & 0.9806 & 0.9857 & 0.4118 & 0.0002 & & & & \\
\hline \multirow[t]{2}{*}{ Facebook } & 0.2958 & 0.1833 & 0.2693 & 0.0027 & 0.0899 & 0.0398 & 0.0000 & 0.0042 & -0.1124 & -0.2666 & -0.0501 & 0.0042 \\
\hline & 0.7042 & 0.8167 & 0.7307 & 0.9973 & 0.9101 & 0.9602 & 1.0000 & 0.9958 & & & & \\
\hline \multirow[t]{2}{*}{ Intel Corporation } & 0.3684 & 0.1640 & 0.1097 & 0.0471 & 0.0229 & 0.0128 & 0.9652 & 0.9355 & -0.2045 & -0.0626 & -0.0101 & -0.0297 \\
\hline & 0.6316 & 0.8360 & 0.8903 & 0.9529 & 0.9771 & 0.9872 & 0.0348 & 0.0645 & & & & \\
\hline \multirow[t]{2}{*}{ Intesa Sanpaolo S.p.A. } & 0.2418 & 0.0001 & 0.0043 & 0.0432 & 0.0018 & 0.0000 & 0.8482 & 1.0000 & -0.2417 & 0.0389 & -0.0018 & 0.1518 \\
\hline & 0.7582 & 0.9999 & 0.9957 & 0.9568 & 0.9982 & 1.0000 & 0.1518 & 0.0000 & & & & \\
\hline \multirow[t]{2}{*}{ JPMorgan Chase \& Co. } & 0.0914 & 0.0948 & 0.9607 & 0.0523 & 0.1940 & 0.0141 & 0.9999 & 0.9371 & 0.0034 & -0.9084 & -0.1799 & -0.0628 \\
\hline & 0.9086 & 0.9052 & 0.0393 & 0.9477 & 0.8060 & 0.9859 & 0.0001 & 0.0629 & & & & \\
\hline \multirow[t]{2}{*}{ Net Element } & 0.0920 & 0.4288 & 0.0566 & 0.0006 & 0.2270 & 0.2157 & 0.0401 & 0.0000 & 0.3368 & -0.0561 & -0.0113 & -0.0401 \\
\hline & 0.9080 & 0.5712 & 0.9434 & 0.9994 & 0.7730 & 0.7843 & 0.9599 & 1.0000 & & & & \\
\hline \multirow[t]{2}{*}{ NetCents Technology Inc } & 0.1472 & 0.0460 & 0.2793 & 0.2545 & 0.0031 & 0.0008 & 0.9999 & 1.0000 & -0.1012 & -0.0248 & -0.0023 & 0.0001 \\
\hline & 0.8528 & 0.9540 & 0.7207 & 0.7455 & 0.9969 & 0.9992 & 0.0001 & 0.0000 & & & & \\
\hline \multirow[t]{2}{*}{ Ping An Insurance Company } & 0.4017 & 0.0513 & 0.2618 & 0.1743 & 0.0706 & 0.0099 & 0.9562 & 0.9978 & -0.3504 & -0.0875 & -0.0607 & 0.0416 \\
\hline & 0.5983 & 0.9487 & 0.7382 & 0.8257 & 0.9294 & 0.9901 & 0.0438 & 0.0022 & & & & \\
\hline \multirow[t]{2}{*}{ Riot Blockchain } & 0.1823 & 0.4246 & 0.2279 & 0.1000 & 0.0136 & 0.0065 & 0.9978 & 0.9965 & 0.2423 & -0.1278 & -0.0070 & -0.0013 \\
\hline & 0.8177 & 0.5754 & 0.7721 & 0.9000 & 0.9864 & 0.9935 & 0.0022 & 0.0035 & & & & \\
\hline \multirow[t]{2}{*}{ Sberbank Russia } & 0.2303 & 0.0000 & 0.0699 & 0.0006 & 0.0585 & 0.1609 & 0.5943 & 0.4760 & -0.2303 & -0.0693 & 0.1024 & -0.1183 \\
\hline & 0.7697 & 1.0000 & 0.9301 & 0.9994 & 0.9415 & 0.8391 & 0.4057 & 0.5240 & & & & \\
\hline \multirow[t]{2}{*}{ TD Ameritrade } & 0.0538 & 0.1258 & 0.4064 & 0.3666 & 0.0488 & 0.0153 & 0.9944 & 0.9993 & 0.0719 & -0.0398 & -0.0334 & 0.0049 \\
\hline & 0.9462 & 0.8742 & 0.5936 & 0.6334 & 0.9512 & 0.9847 & 0.0056 & 0.0007 & & & & \\
\hline \multirow[t]{2}{*}{ Victory Square Technologies } & 0.2966 & 0.1228 & 0.2397 & 0.0138 & 0.0020 & 0.0076 & 1.0000 & 0.7707 & -0.1738 & -0.2259 & 0.0056 & -0.2293 \\
\hline & 0.7034 & 0.8772 & 0.7603 & 0.9862 & 0.9980 & 0.9924 & 0.0000 & 0.2293 & & & & \\
\hline \multirow[t]{2}{*}{ Walmart } & 0.4546 & 0.3616 & 0.2992 & 0.2561 & 0.0414 & 0.0262 & 0.9899 & 0.9939 & -0.0931 & -0.0431 & -0.0152 & 0.0041 \\
\hline & 0.5454 & 0.6384 & 0.7008 & 0.7439 & 0.9586 & 0.9738 & 0.0101 & 0.0061 & & & & \\
\hline
\end{tabular}


Table 12: Price Discovery differences due to announcements denoted as crypto-exuberant behaviour

\begin{tabular}{|c|c|c|c|c|c|c|c|c|c|c|c|c|}
\hline \multirow{3}{*}{$\begin{array}{l}\text { Breakdown } \\
\text { World Poker Fund Holdings }\end{array}$} & IS pre & IS post & IS-r pre & IS-r post & CS pre & CS post & ILS pre & ILS post & $\Delta \mathrm{IS}$ & $\Delta \mathrm{IS}-\mathrm{r}$ & $\Delta \mathrm{CS}$ & $\Delta \mathrm{ILS}$ \\
\hline & 0.1995 & 0.2145 & 0.2175 & 0.4261 & 0.0258 & 0.0009 & 0.9910 & 1.0000 & 0.0150 & 0.2086 & -0.0249 & 0.0090 \\
\hline & 0.8005 & 0.7855 & 0.7825 & 0.5739 & 0.9742 & 0.9991 & 0.0090 & 0.0000 & & & & \\
\hline
\end{tabular}

Note: The above panel represents the estimated coefficients of price discovery. IS represents the information share, IS-r represents the reverse information share criterion, CS represents the component share of information while ILS represent the information leadership share of information. The four right-hand columns represent the estimated changes in price discovery in the periods both before and after the announcements of both blockchain and cryptocurrency developments. 
Table 13: Price Discovery differences due to announcements denoted as strategic

\begin{tabular}{|c|c|c|c|c|c|c|c|c|c|c|c|c|}
\hline Breakdown & IS pre & IS post & IS-r pre & IS-r post & CS pre & CS post & ILS pre & ILS post & $\Delta \mathrm{IS}$ & $\Delta \mathrm{IS}-\mathrm{r}$ & $\Delta \mathrm{CS}$ & $\Delta \mathrm{ILS}$ \\
\hline \multicolumn{13}{|l|}{ Mining Efficiency } \\
\hline \multirow[t]{2}{*}{ Alibaba Group Holding Ltd } & 0.0775 & 0.2154 & 0.4667 & 0.3156 & 0.1302 & 0.0888 & 0.9716 & 0.9572 & 0.1379 & -0.1512 & -0.0414 & -0.0144 \\
\hline & 0.9225 & 0.7846 & 0.5333 & 0.6844 & 0.8698 & 0.9112 & 0.0284 & 0.0428 & & & & \\
\hline \multirow[t]{2}{*}{ Apollo Power } & 0.1869 & 0.0595 & 0.1901 & 0.1222 & 0.4745 & 0.1210 & 0.0633 & 0.5055 & -0.1274 & -0.0679 & -0.3535 & 0.4422 \\
\hline & 0.8131 & 0.9405 & 0.8099 & 0.8778 & 0.5255 & 0.8790 & 0.9367 & 0.4945 & & & & \\
\hline \multirow[t]{2}{*}{ Digital Power } & 0.2467 & 0.0400 & 0.1794 & 0.1950 & 0.2423 & 0.2167 & 0.3184 & 0.4340 & -0.2067 & 0.0156 & -0.0256 & 0.1156 \\
\hline & 0.7533 & 0.9600 & 0.8206 & 0.8050 & 0.7577 & 0.7833 & 0.6816 & 0.5660 & & & & \\
\hline \multirow[t]{2}{*}{ DMG Blockchain Solutions } & 0.3387 & 0.0282 & 0.3276 & 0.0049 & 0.0024 & 0.0001 & 1.0000 & 0.9995 & -0.3105 & -0.3227 & -0.0023 & -0.0004 \\
\hline & 0.6613 & 0.9718 & 0.6724 & 0.9951 & 0.9976 & 0.9999 & 0.0000 & 0.0005 & & & & \\
\hline \multirow[t]{2}{*}{ Samsung Electronics Co. } & 0.1092 & 0.3219 & 0.2375 & 0.0134 & 0.0854 & 0.0070 & 0.9176 & 0.7902 & 0.2127 & -0.2241 & -0.0784 & -0.1274 \\
\hline & 0.8908 & 0.6781 & 0.7625 & 0.9866 & 0.9146 & 0.9930 & 0.0824 & 0.2098 & & & & \\
\hline \multirow[t]{2}{*}{ Squire } & 0.2851 & 0.2905 & 0.2880 & 0.2811 & 0.0011 & 0.0014 & 1.0000 & 1.0000 & 0.0055 & -0.0069 & 0.0003 & 0.0000 \\
\hline & 0.7149 & 0.7095 & 0.7120 & 0.7189 & 0.9989 & 0.9986 & 0.0000 & 0.0000 & & & & \\
\hline \multicolumn{13}{|l|}{ Security Improvement } \\
\hline \multirow[t]{2}{*}{ Accenture } & 0.0261 & 0.0858 & 0.3994 & 0.1167 & 0.0967 & 0.1731 & 0.0000 & 0.2848 & 0.0597 & -0.2828 & 0.0764 & 0.2848 \\
\hline & 0.9739 & 0.9142 & 0.6006 & 0.8833 & 0.9033 & 0.8269 & 1.0000 & 0.7152 & & & & \\
\hline \multirow[t]{2}{*}{ Alphabet } & 0.4634 & 0.1596 & 0.0967 & 0.0302 & 0.7016 & 0.2783 & 0.0021 & 0.0065 & -0.3038 & -0.0665 & -0.4234 & 0.0044 \\
\hline & 0.5366 & 0.8404 & 0.9033 & 0.9698 & 0.2984 & 0.7217 & 0.9979 & 0.9935 & & & & \\
\hline \multirow[t]{2}{*}{ ANZ } & 0.0411 & 0.3905 & 0.1404 & 0.2732 & 0.0046 & 0.9852 & 0.0000 & 0.0000 & 0.3494 & 0.1328 & 0.9805 & 0.0000 \\
\hline & 0.9589 & 0.6095 & 0.8596 & 0.7268 & 0.9954 & 0.0148 & 1.0000 & 1.0000 & & & & \\
\hline \multirow[t]{2}{*}{ Bank of America } & 0.0097 & 0.0015 & 0.1430 & 0.7686 & 0.0396 & 0.0288 & 0.9425 & 0.9999 & -0.0081 & 0.6256 & -0.0108 & 0.0575 \\
\hline & 0.9903 & 0.9985 & 0.8570 & 0.2314 & 0.9604 & 0.9712 & 0.0575 & 0.0001 & & & & \\
\hline \multirow[t]{2}{*}{ Humana } & 0.0466 & 0.0375 & 0.1834 & 0.0230 & 0.2602 & 0.0355 & 0.2898 & 0.2895 & -0.0091 & -0.1604 & -0.2246 & -0.0003 \\
\hline & 0.9534 & 0.9625 & 0.8166 & 0.9770 & 0.7398 & 0.9645 & 0.7102 & 0.7105 & & & & \\
\hline \multirow[t]{2}{*}{ Microsoft Corporation } & 0.1489 & 0.0005 & 0.0274 & 0.3472 & 0.1995 & 0.0922 & 0.0126 & 0.0000 & -0.1484 & 0.3199 & -0.1073 & -0.0126 \\
\hline & 0.8511 & 0.9995 & 0.9726 & 0.6528 & 0.8005 & 0.9078 & 0.9874 & 1.0000 & & & & \\
\hline \multirow[t]{2}{*}{ Optum } & 0.0003 & 0.0048 & 0.1529 & 0.0348 & 0.1913 & 0.3880 & 0.3679 & 0.0032 & 0.0045 & -0.1181 & 0.1967 & -0.3647 \\
\hline & 0.9997 & 0.9952 & 0.8471 & 0.9652 & 0.8087 & 0.6120 & 0.6321 & 0.9968 & & & & \\
\hline \multirow[t]{2}{*}{ Quest Diagnostics } & 0.0000 & 0.0743 & 0.1798 & 0.0074 & 0.0003 & 0.0156 & 1.0000 & 1.0000 & 0.0743 & -0.1725 & 0.0153 & 0.0000 \\
\hline & 1.0000 & 0.9257 & 0.8202 & 0.9926 & 0.9997 & 0.9844 & 0.0000 & 0.0000 & & & & \\
\hline \multirow[t]{2}{*}{ Siemens AG } & 0.3116 & 0.1402 & 0.3001 & 0.3851 & 0.0667 & 0.0430 & 0.9729 & 0.9949 & -0.1715 & 0.0850 & -0.0237 & 0.0219 \\
\hline & 0.6884 & 0.8598 & 0.6999 & 0.6149 & 0.9333 & 0.9570 & 0.0271 & 0.0051 & & & & \\
\hline \multirow[t]{2}{*}{ Westpac } & 0.4059 & 0.2263 & 0.4127 & 0.3120 & 0.0234 & 0.0060 & 0.9988 & 0.9998 & -0.1796 & -0.1007 & -0.0174 & 0.0010 \\
\hline & 0.5941 & 0.7737 & 0.5873 & 0.6880 & 0.9766 & 0.9940 & 0.0012 & 0.0002 & & & & \\
\hline \multicolumn{13}{|c|}{ Technological Improvements } \\
\hline \multirow[t]{2}{*}{ Advanced Micro Devices } & 0.0364 & 0.4708 & 0.0551 & 0.0568 & 0.0030 & 0.0192 & 0.9974 & 0.9046 & 0.4344 & 0.0017 & 0.0162 & -0.0928 \\
\hline & 0.9636 & 0.5292 & 0.9449 & 0.9432 & 0.9970 & 0.9808 & 0.0026 & 0.0954 & & & & \\
\hline \multirow[t]{2}{*}{ Agricultural Bank of China } & 0.3955 & 0.4081 & 0.4253 & 0.1230 & 0.0033 & 0.0028 & 1.0000 & 0.9996 & 0.0126 & -0.3023 & -0.0005 & -0.0004 \\
\hline & 0.6045 & 0.5919 & 0.5747 & 0.8770 & 0.9967 & 0.9972 & 0.0000 & 0.0004 & & & & \\
\hline
\end{tabular}


Table 13: Price Discovery differences due to announcements denoted as strategic

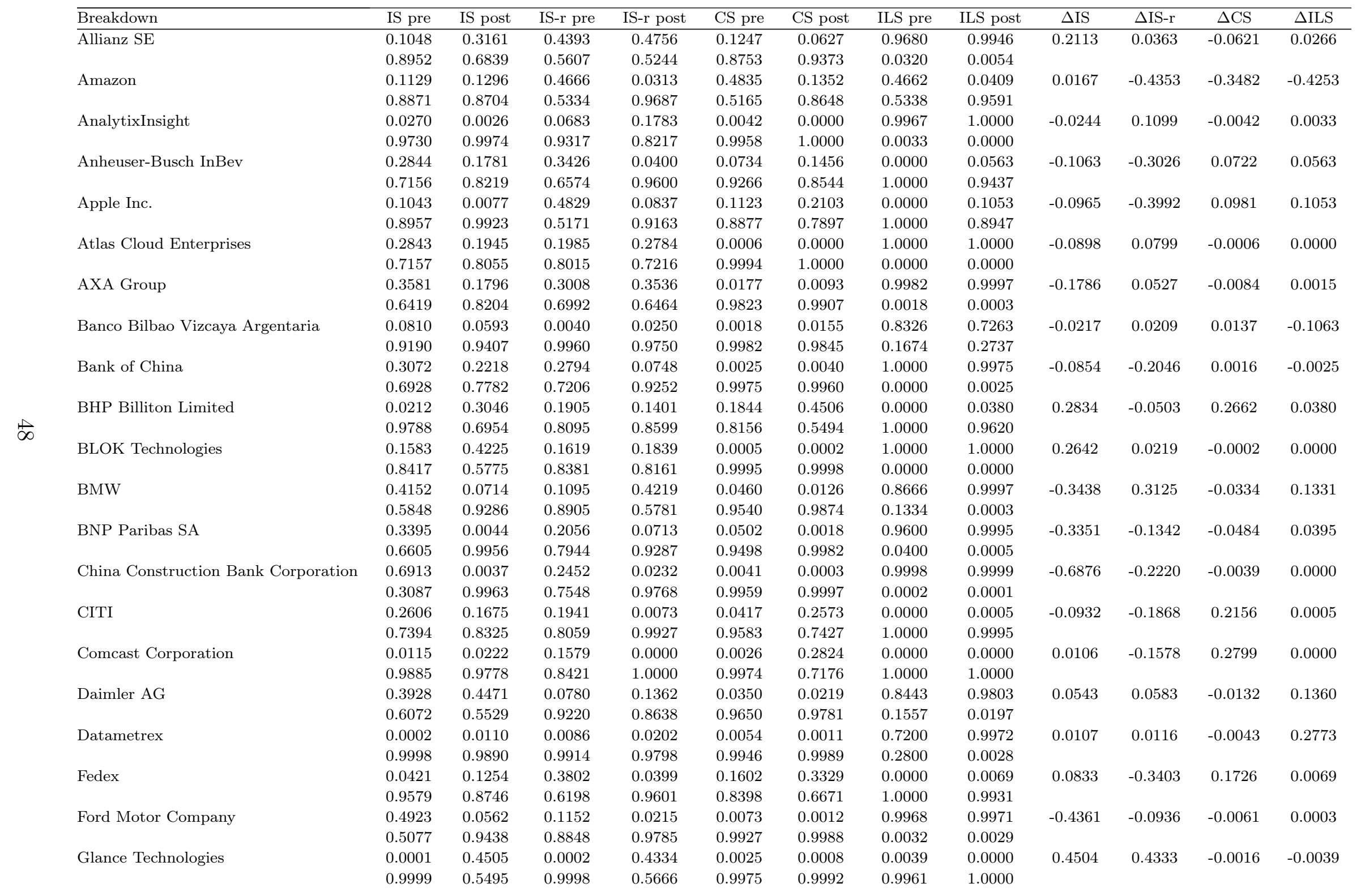


Table 13: Price Discovery differences due to announcements denoted as strategic

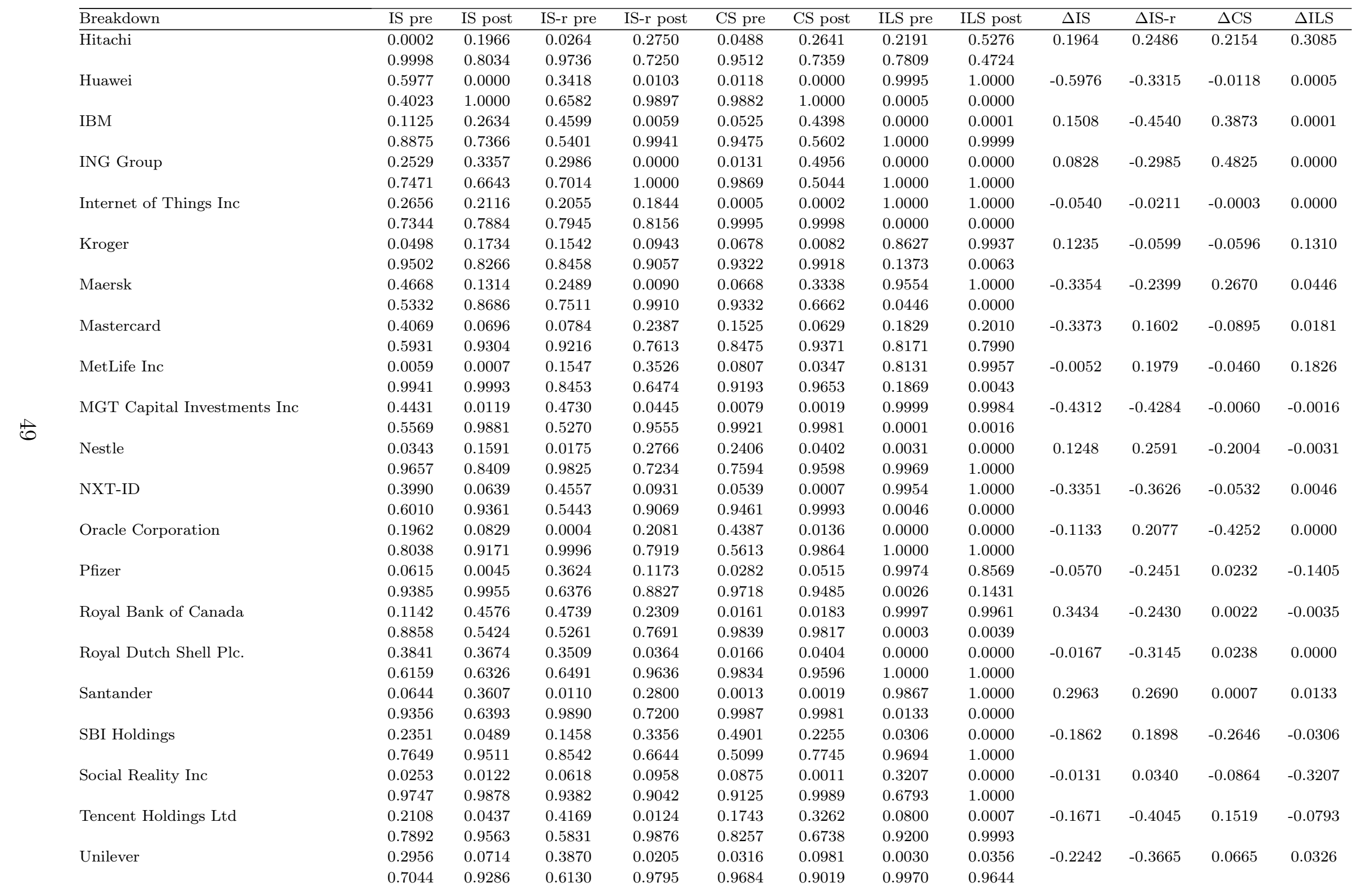


Table 13: Price Discovery differences due to announcements denoted as strategic

\begin{tabular}{|c|c|c|c|c|c|c|c|c|c|c|c|c|}
\hline Breakdown & IS pre & IS post & IS-r pre & IS-r post & CS pre & CS post & ILS pre & ILS post & $\Delta \mathrm{IS}$ & $\Delta \mathrm{IS}-\mathrm{r}$ & $\Delta \mathrm{CS}$ & $\Delta \mathrm{ILS}$ \\
\hline \multirow{2}{*}{ United Healthcare } & 0.3154 & 0.3403 & 0.3108 & 0.0422 & 0.0814 & 0.0642 & 0.0370 & 0.2926 & 0.0248 & -0.2686 & -0.0173 & 0.2556 \\
\hline & 0.6846 & 0.6597 & 0.6892 & 0.9578 & 0.9186 & 0.9358 & 0.9630 & 0.7074 & & & & \\
\hline \multirow[t]{2}{*}{ Wells Fargo \& Company } & 0.3681 & 0.2733 & 0.2025 & 0.0118 & 0.0311 & 0.0762 & 0.0160 & 0.0205 & -0.0948 & -0.1907 & 0.0451 & 0.0045 \\
\hline & 0.6319 & 0.7267 & 0.7975 & 0.9882 & 0.9689 & 0.9238 & 0.9840 & 0.9795 & & & & \\
\hline
\end{tabular}

Note: The above panel represents the estimated coefficients of price discovery. IS represents the information share, IS-r represents the reverse information share criterion, CS represents the component share of information while ILS represent the information leadership share of information. The four right-hand columns represent the estimated changes in price discovery in the periods both before and after the announcements of both blockchain and cryptocurrency developments. 
Tables 12 and 13 provide a more granular analysis by company, echoing the above hypotheses acceptance. Again, companies that have partaken in the creation of coins and the changing of the company's name present evidence of outlier behaviour, with Blockchain Worldwide, Online Blockchain plc, Gozo Travel and Kodak each warranting further investigation for the substantial responses found across all four metrics analysed within this research.

\section{Discussion}

While such results provide valuable insight into the recent speculative behaviour of a number of companies, it instigates a particular debate surrounding the ethical and moral consequences of both the monitoring and regulation of such corporate decision-making relating to blockchain development. At the forefront of such strategic thought should be the investor and the employees of such corporate entities. While some individuals would rather that their respective employers, or corporate investments would act in a manner that conduces both structural and technological advancement, through particular risk-taking, it would also be envisaged that such strategies that seek to profit from short-term trends, or indeed, the announcement of product development without any particular intention of following up on such would be considered in a particularly dim light. Not alone is such behaviour highly unethical, in some jurisdictions it is deemed to be misleading and illicit. Further, when proven not to have taken place, it therefore completely diminishes public trust. That being said, it is very important to state that such results do not indicate that we are assuming that each company has involved itself in an illegal practice. It would be fair that we are asking the question, as should those in a regulatory or governance capacity, why has a company with no previous technological experience decided to create blockchain projects or develop cryptocurrency? Further, as to what benefits can they explicitly provide the corporate structure? More importantly, as to when can employees and investors plan to observe the actual implementation of such projects? The latter question is possibly the most important as most of the projects that we observed were expected to be released in the future, that is, without an estimated timeline or expected release data. It would not be assumed to be unusual should regulators take a dim view of such behaviour, assuming that such companies are attempting to profit from short-term trends in cryptocurrency pricing along with the marketing benefits that such announcements provide.

\subsection{Practical implications of this work}

The primary implications of this research are threefold. First, from a regulatory standpoint, there is both a substantial and sustained share price premium that stems from the 
announcement of corporate intention to initiate blockchain development. There is implicit asymmetric information and morale hazard issues present within the corporate decision, as primarily, the decision-makers within the company are the sole participants that can validate as to whether the intention is in fact true, or indeed, as to whether there is a minute probability of a successful project. Further, investors, knowing that there exists a share price premia can target such announcements, or indeed, utilise news and wire-service searching algorithms with a particular pre-selected lexicon of search terms that can instigate share and options trades based on such news release. Further, such behaviour adds substantial value to the use of insider-trading and trades based on 'rumours' that could exist through social media. While this behaviour is exceptionally difficult to monitor in real-time, it adds a further layer of pricing complexity for investors through added risk sourced in the use of quite an easy tactic by more ethically-opaque managers in less regulated jurisdictions. This could present substantial pressures for companies in highly competitive industries.

A second substantial side-effect of such behaviour can be observed through an unexpected market volatility influence on investors, both directly and indirectly to the company that has partaken in such speculative behaviour. Evidence suggests not only protracted periods of elevated share price volatility, but further, influencing other sectoral companies through dynamic correlations and network effects. This effect is also found to be significant when considering the flow of information within sectors and geographical regions. This result indicates a change for these companies with regards to the way in which investment perceptions manifest. For corporations that rely on financial markets for investment flows, some companies could find themselves vulnerable to elevated levels of pricing volatility through no fault of their own.

Finally, for companies and those in governance that have made such speculative decisions without delivering on the blockchain projects that have been released to investors for consideration, there exists a complete breakdown in trust with an expectation that such reputational damage would be considerable. Those that participate in such news releases without final delivery or a valid purpose for such usage would be reasonably assumed to have not acted in good faith and to have misled investors. For this reason, market participants should proceed with caution, and only trust those companies that have a regulated, validated proof of concept, or indeed, a track record in the development of similar technology. Otherwise, a degree of scepticism should be best maintained.

\subsection{Methodological Limitations}

The primary methodological limitation surrounds data availability, market liquidity and market closure times. To briefly explain, it would be very much preferable if each company presented evidence of thorough market liquidity across a broad number of financial assets, 
providing a concise signal that could be supported across both the company's share price and associated derivatives markets. This would provide substantial robustness to our presented results. However, on close investigation, many of the selected companies did not possess a set of standardised derivatives products, such as forward contracts, options or credit default swaps. Therefore, an analysis of this depth for all companies was not possible. There were further issues surrounding the liquidity of some companies at a high-frequency level. While we had considered the usage of data at a level of 1-, 5-, 10-, 15-, 30- and 60-minutes to add robustness to our results, a number of companies in our sample possessed share prices with relatively segmented trading patterns for specific periods during the day. Therefore, daily data was presented as the most appropriate to best represent this analysis. Finally, to produce estimates of changing international dynamic correlations and information flows, we were quite restrained by market opening hours. That is, to compare the transfer of news across borders, in some cases, the development was announced outside of market hours, including the weekend, in some jurisdictions. This made the measurement of comparable dates quite difficult, and due to the substantial ambiguity associated with such analysis, we felt that it was more appropriate to concentrate on each jurisdiction in isolation.

\subsection{Directions for future research}

The are a number of very interesting directions for future research stemming from this work. Primarily, through the passage of time, it would be very interesting to observe as to whether the identified projects were completed within the designated time-frame, or indeed, as planned. It would also be very much on interest to observe as to how long the associated share price premia, the dynamic correlations and the shifting information flow patterns persisted, and further, as to whether these changes remained dependent on the type of blockchain project announced. We would also envisage a substantial amount of legal-based research based on the cross-border and cross-jurisdictional behavioural differentials with regards to the release of such information and as to how such intention to mislead investors could breach regulations relating to price manipulation and the release of false information. Over time, the number of companies who partake in such behaviour would also be expected to increase, giving rise to a larger sample which would not only increase confidence even further in the associated results, but perhaps provide a wider pool of financial derivatives through which further, related hypotheses could be addressed surrounding the transfer of information.

It would also be very useful to specifically investigate for the presence of two particular types of behaviour: 1) as to whether any board members or managers in the company bought or sold shares or options in the days either before, during or after the public release of corporate information to the market in anticipation of a forthcoming share price premia; and 2) 
using social media data such as that provided by Twitter or Facebook, to analyse as to when the first 'rumours' of such forthcoming blockchain development first manifested. It would be of particular interest to analyse as to whether market conditions, as measured through share price premia, dynamic correlations, or indeed, information flows changed during this time. Evidence of such preemptive purchasing, or indeed, advanced behavioural changes could present quite damning information of the behaviour of those involved.

\section{Conclusion}

Cryptocurrencies have been broadly scrutinised in recent times for a host of concerning regulatory and cybercriminality issues. This new financial product has generated substantial concern as a potential conduit for illicit behaviour, with much evidence presented to support its use for the purchase of drugs, cross-border regulatory avoidance and tax evasion among other black market purposes. Our research, while concerned primarily with the price dynamics of companies who have partaken in blockchain and cryptocurrency development, is also concerned with the potential channels through which high-volatility cryptocurrency market dynamics can potentially influence both unwilling and unsuspecting investors and the real economy alike. We present five key results. First, there exists a stock price premium based on the type of cryptocurrency announcement that companies have made, however this effect is short lived and disappears after a quarter, indicating a hype-and-dump kind of a share price behaviour. Secondly, there exists a substantial and sustained increase in both unconditional and conditional share price volatility in the period after cryptocurrency announcements, where fundamentally dividing such announcements into sub-groups denoted to be either strategic in use or indeed speculative, the latter group exhibits substantially more pronounced share price growth and volatility. Third, we find evidence that there exists both a significant and substantial changes in dynamic correlations between cryptocurrency markets and companies that have partaken in such speculative announcements, with particular emphasis on those companies that have announced their intentions to create a cryptocurrency and those who have taken the step to incorporate cryptocurrency terminology within a new company name. After they make their announcements, stock prices of these companies tend to display a significant coupling behaviour with cryptocurrency markets and also significant decoupling behaviour with their peers in the markets that they are traded. A fourth finding indicates that there exists a substantial change in the determination of price discovery and information flow between the announcement company and cryptocurrency markets. Finally, we have found another evidence of a decoupling of companies with domestic peers in the aftermath of speculative blockchain and cryptocurrency announcements to the extent that the company's share price absorbs substantially increased levels of information flow from cryp- 
tocurrency markets. This latter finding is somewhat concerning as in the majority of these speculative cases, the business practice of the announcement company has no connection with either blockchain or cryptocurrency development.

Our results indicate the potential presence of a number of ethical and regulatory issues with regards to the interactions of companies with blockchain and cryptocurrency development. These results broadly indicate that there exists a wide-ranging reward for companies that partake in such blockchain and cryptocurrency-related announcements. The moral hazard that is contained within such strategic selection is based on the very fact that such a company may not, in the short-to-medium term ever complete such a project, yet could appease corporate stakeholders though elevated share prices and corporate valuations. The probability that asymmetric information and illicit trading practices is also increased due to the substantial differentials between insider knowledge and the euphoria established in financial markets through the very association of the company and this new digital asset. Further, elevated share price volatility attracts risk-loving options and leveraged financial traders such as those using contracts for difference. The very nature of this informational distortion and the changing risk profiles of traders in the companies could be considered to be quite alarming for more risk adverse traders, however, due to the opaque nature of the examined announcements, the true financial health of these companies becomes somewhat masked as traders search for continued mechanism in which to profit from the growth of cryptocurrencies.

The continued escalation of such crypto-euphoria is confirmed in the changing dynamics of information flow and price discovery. Our results indicate that companies that have no interconnection with cryptocurrency markets begin to share informational correlations with these new high-risk products, with companies developing on announcements of a more speculative nature exposing their respective companies to substantial risk. Such risk is therefore passed to unwilling investors with little knowledge as to whether the company will or will not complete their selected blockchain or cryptocurrency developments. The very role of international regulatory agencies is to determine as to whether these corporate actions and announcements are illegal in nature. While considering that corporate development of these new products are vital to continued technological progress, one must very much consider that there is both an incentive and a reward for a corporate entity that would see fit to benefit from the current presence of crypto-exuberance. While necessary to determine each announcement's validity on a case by case basis, we very much advise that all cases where companies announce their intentions to create a company-related cryptocurrency, and all announcements relating to the changing of the company's identity to incorporate cryptocurrency 'buzzwords' be observed as an attempt to take advantage of artificial premiums and 
volatility unless a clear plan of production and release be provided. As with all financial bubbles that have occurred in the past, we must learn from such mistakes and reduce the channels through which such new financial products could ever influence international real economies. This should be of central importance, regardless as to whether blockchain and cryptocurrencies have a long-term place to coincide with traditional financial market assets.

\section{Bibliography}

Adhami, S., Giudici, G., Martinazzi, S., 2018. Why do businesses go crypto? An empirical analysis of initial coin offerings. Journal of Economics and Business 100, 64-75.

Antonakakis, N., Chatziantoniou, I., Gabauer, D., 2019. Cryptocurrency market contagion: Market uncertainty, market complexity, and dynamic portfolios. Journal of International Financial Markets, Institutions and Money 61, 37-51.

Bianchi, D., Dickerson, A., 2019. Trading volume in cryptocurrency markets. Available at SSRN, http://dx.doi.org/10.2139/ssrn.3239670.

Bouri, E., Gupta, R., Roubaud, D., 2019. Herding behaviour in cryptocurrencies. Finance Research Letters 29, 216-221.

Chaim, P., Laurini, M., 2018. Volatility and return jumps in Bitcoin. Economics Letters 173, 158163.

Cheah, E.-T., Fry, J., 2015. Speculative bubbles in Bitcoin markets? An empirical investigation into the fundamental value of Bitcoin. Economics Letters 130, 32-36.

Chen, M., Wu, Q., Yang, B., 2019. How valuable is fintech innovation? Review of Financial Studies $32,2062-2106$.

Corbet, S., Larkin, C., Lucey, B., Meegan, A., Yarovaya, L., 2020a. Cryptocurrency reaction to FOMC announcements: Evidence of heterogeneity based on blockchain stack position. Journal of Financial Stability 46, 100706.

Corbet, S., Larkin, C., Lucey, B., Yarovaya, L., 2020b. KODAKcoin: A blockchain revolution or exploiting a potential cryptocurrency bubble? Applied Economics Letters 27(7), 518-524.

Corbet, S., Lucey, B., Peat, M., Vigne, S., 2018a. Bitcoin futures - what use are they? Economics Letters $172,23-27$.

Corbet, S., Lucey, B., Urquhart, A., Yarovaya, L., 2019. Cryptocurrencies as a financial asset: A systematic analysis. International Review of Financial Analysis 62, 182-199.

Corbet, S., Lucey, B., Yarovaya, L., 2018b. Datestamping the Bitcoin and Ethereum bubbles. Finance Research Letters 26, 81-88. 
Corbet, S., Meegan, A., Larkin, C., Lucey, B., Yarovaya, L., 2018c. Exploring the dynamic relationships between cryptocurrencies and other financial assets. Economics Letters 165, 28-34.

Cretarola, A., Figà-Talamanca, G., 2019. Detecting bubbles in bitcoin price dynamics via market exuberance. Annals of Operations Research, 1-21.

Domingo, R.-S., Piñeiro-Chousa, J., López-Cabarcos, M. Á., 2020. What factors drive returns on initial coin offerings? Technological Forecasting and Social Change 153, 119915.

Dwyer, G., 2015. The economics of Bitcoin and similar private digital currencies. Journal of Financial Stability 17, 81-91.

Edwards, F. R., Hanley, K., Litan, R., Weil, R. L., 2019. Crypto assets require better regulation: Statement of the financial economists roundtable on crypto assets. Financial Analysts Journal $75,14-19$.

Engle, R., 2002. Dynamic conditional correlation: A simple class of multivariate generalized autoregressive conditional heteroskedasticity models. Journal of Business and Economic Statistics 20, 339-350.

Felix, T., von Eije, H., 2019. Underpricing in the cryptocurrency world: Evidence from initial coin offerings. Managerial Finance 45, 563-578.

Fisch, C., 2019. Initial coin offerings (ICOs) to finance new ventures. Journal of Business Venturing $34,1-22$.

Foley, S., Karlsen, J. R., Putnins, T. J., 2019. Sex, drugs, and Bitcoin: How much illegal activity is financed through cryptocurrencies? Review of Financial Studies 32, 1789-1853.

Fry, J., 2018. Booms, busts and heavy-tails: The story of Bitcoin and cryptocurrency markets? Economics Letters 171, 225-229.

Fry, J., Cheah, E. T., 2016. Negative bubbles and shocks in cryptocurrency markets. International Review of Financial Analysis 47, 343-352.

Gandal, N., Hamrick, J., Moore, T., Oberman, T., 2018. Price manipulation in the Bitcoin ecosystem. Journal of Monetary Economics 95, 86-96.

Goldstein, I., Jiang, W., Karolyi, A., 2019. To fintech and beyond. Review of Financial Studies 32, $1647-1661$.

Gonzalo, J., Granger, C., 1995. Estimation of common long-memory components in cointegrated systems. Journal of Business \& Economic Statistics 13, 27-35.

Griffins, J., Shams, A., 2018. Is Bitcoin really un-Tethered? Available at SSRN, http://dx.doi.org/10.2139/ssrn.3195066.

Guder, J., Kinateder, H., Wagner, N. F., 2019. Cryptocurrencies as financial bubbles: The case of Bitcoin. Finance Research Letters 31. 
Hasbrouck, J., 1995. One security, many markets: Determining the contributions to price discovery. Journal of Finance 50, 1175-1199.

Hauptfleisch, M., Putniņ̌̌, T. J., Lucey, B., 2016. Who sets the price of gold? London or New York. Journal of Futures Markets 36, 564-586.

Hayes, A., 2019. Bitcoin price and its marginal cost of production: Support for a fundamental value. Applied Economics Letters 26, 554-560.

Hendrickson, J., Luther, W., 2017. Banning Bitcoin. Journal of Economic Behavior and Organization 141, 188-195.

Holub, M., Johnson, J., 2019. The impact of the Bitcoin bubble of 2017 on Bitcoin's P2P market. Finance Research Letters 29, 357-362.

Jain, A., Jain, C., 2019. Blockchain hysteria: Adding 'blockchain' to company's name. Economics Letters 181, 178-181.

López-Cabarcos, M. Á., Pérez-Pico, A. M., Piñeiro-Chousa, J., Šević, A., 2019. Bitcoin volatility, stock market and investor sentiment. are they connected? Finance Research Letters, 101399.

Makarov, I., Schoar, A., 2020. Trading and arbitrage in cryptocurrency markets. Journal of Financial Economics 135, 293-319.

Nakamoto, S., 2008. Bitcoin: A peer-to-peer electronic cash system.

Panagiotidis, T., Stengos, T., Vravosinos, O., 2018. On the determinants of Bitcoin returns: A LASSO approach. Finance Research Letters 27, 235-240.

Panagiotidis, T., Stengos, T., Vravosinos, O., 2019. The effects of markets, uncertainty and search intensity on Bitcoin returns. International Review of Financial Analysis 63, 220-242.

Perez, C., Sokolova, K., Konate, M., 2020. Digital social capital and performance of initial coin offerings. Technological Forecasting and Social Change 152, 119888.

Putniņš, T. J., 2013. What do price discovery metrics really measure? Journal of Empirical Finance $23,68-83$.

Shen, D., Urquhart, A., Wang, P., 2019. Forecasting the volatility of Bitcoin: The importance of jumps and structural breaks. European Financial Management.

Van Vliet, B., 2018. An alternative model of Metcalfe's Law for valuing Bitcoin. Economics Letters $165,70-72$.

White, R., Marinakis, Y., Islam, N., Walsh, S., 2020. Is bitcoin a currency, a technology-based product, or something else? Technological Forecasting and Social Change 151, 119877.

Yan, B., Zivot, E., 2010. A structural analysis of price discovery measures. Journal of Financial Markets 13, 1-19. 
Zhang, S., Aerts, W., Lu, L., Pan, H., 2019. Readability of token whitepaper and ICO first-day return. Economics Letters 180, 58-61. 